University of Louisville

ThinkIR: The University of Louisville's Institutional Repository

8-2015

\title{
The effect of Protandim supplementation on oxidative damage and athletic performance.
}

Seteena Leigh Ueberschlag

University of Louisville

Follow this and additional works at: https://ir.library.louisville.edu/etd

Part of the Sports Sciences Commons

\section{Recommended Citation}

Ueberschlag, Seteena Leigh, "The effect of Protandim supplementation on oxidative damage and athletic performance." (2015). Electronic Theses and Dissertations. Paper 2209.

https://doi.org/10.18297/etd/2209

This Master's Thesis is brought to you for free and open access by ThinkIR: The University of Louisville's Institutional Repository. It has been accepted for inclusion in Electronic Theses and Dissertations by an authorized administrator of ThinkIR: The University of Louisville's Institutional Repository. This title appears here courtesy of the author, who has retained all other copyrights. For more information, please contact thinkir@louisville.edu. 
THE EFFECT OF PROTANDIM SUPPLEMENTATION ON OXIDATIVE DAMAGE AND ATHLETIC PERFORMANCE

$$
\text { By }
$$

Seteena Leigh Ueberschlag

B.A., Wilfrid Laurier University, 2010

B.Ed., University of Western Ontario, 2011

\author{
A Thesis \\ Submitted to the Faculty of the \\ in Partial Fulfillment of the Requirements \\ for the Degree of \\ Master of Science in Exercise Physiology \\ Department of Health and Sports Science \\ University of Louisville \\ Louisville, Kentucky
} College of Education and Human Development of the University of Louisville

August 2015 

THE EFFECT OF PROTANDIM SUPPLEMENTATION ON OXIDATIVE DAMAGE AND ATHLETIC PERFORMANCE

\section{By}

Seteena Leigh Ueberschlag

B.A., Wilfrid Laurier University, 2010

B.Ed., University of Western Ontario, 2011

A Thesis Approved on

-XQH25ா2015

By the Following Thesis Committee

Gerald Zavorsky, Ph.D. (Thesis Director)

Kathy Carter Ph.D., R.D.

Edward Weiss, Ph.D.

Rodney Folz, M.D., Ph.D. 


\section{ACKNOWLEDGEMENTS}

I would like to thank my thesis director, Dr. Gerald Zavorsky: you have helped me to grow as a professional researcher and scientist. Thank you for all the time and effort you have put into making this opportunity possible. I would like to thank my thesis committee for their time and effort in reviewing my work and providing me with excellent feedback. Thank you to all the participants who participated in the study. I appreciate your time and effort throughout the entire length of the study. Without you, this study would not have been possible. I would like to thank all the members of the research team: James Seay, Alexandra Roberts, Crissie De Spirito, and Jeremy Stith. I couldn't have asked for a more committed, and fun group of people to work with every day. Finally, I would like to thank LifeVantage Corporation, who funded this research study. 


\begin{abstract}
THE EFFECT OF PROTANDIM SUPPLEMENTATION ON OXIDATIVE DAMAGE AND ATHLETIC PERFORMANCE
\end{abstract}

\author{
Seteena L. Ueberschlag
}

June 25, 2015

A double-blind placebo-controlled trial determined the long term effects of Protandim ${ }^{\circledR}$ supplementation on 5-km running performance, as well as on acute and long-term oxidative damage assessed by serum lipid peroxides (Thiobarbituric acid-reacting substances: TBARS). Thirty-eight subjects were placed into one of two groups: an experimental (675 mg/day Protandim ${ }^{\circledR}$ ) or control group (675 mg/day corn starch). 5-km runs were performed at baseline and 88 (SD 4) days post-supplementation with samples taken immediately pre- and 10-min post 5-km run, as well as at rest $\sim 30$ and $\sim 60$ days during the supplementation period. There was $\sim 25 \%$ week-to-week coefficient of variation of TBARS at baseline (rested, fasted). The runs did not acutely increase mean TBARS, nor was there a change in 5-km time or in mean serum TBARS (at rest, fasted) in either group after supplementation. In conclusion, it is unlikely that Protandim ${ }^{\circledR}$ improves 5-km performance, or that it reduces serum TBARS at rest. 


\section{TABLE OF CONTENTS}

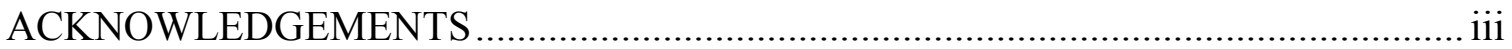

ABSTRACT

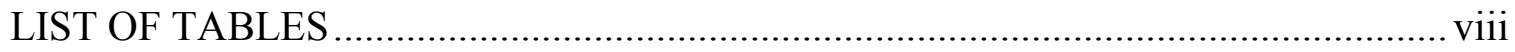

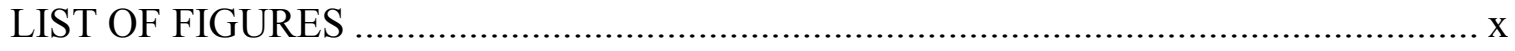

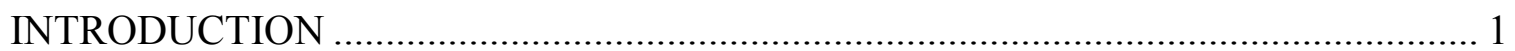

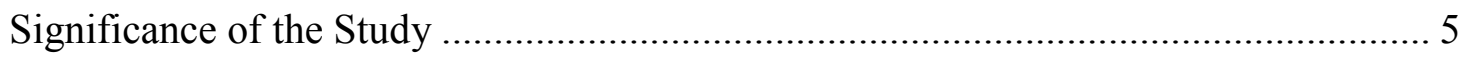

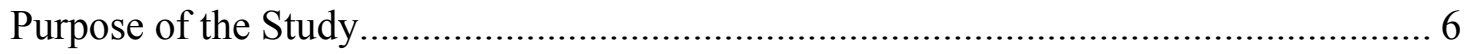

Research Questions \& Hypotheses........................................................................ 7

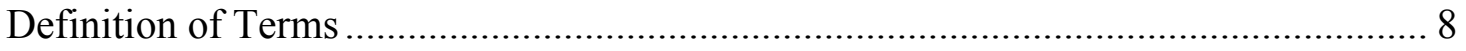

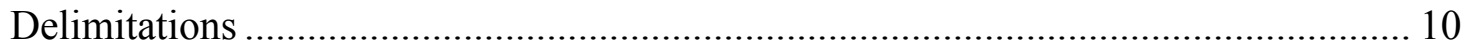

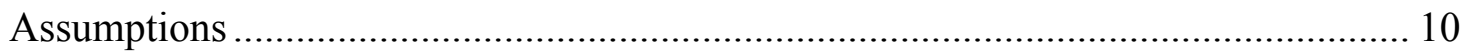

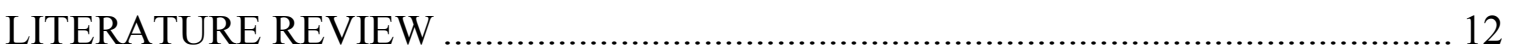

Background on Oxidative Stress Testing .................................................................. 12

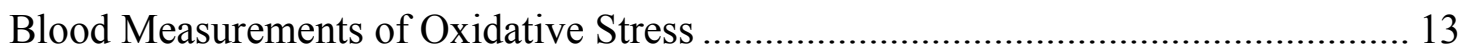

Earliest Research on Oxidative Stress and Exercise ................................................. 17

Exercise Frequency, Intensity, and Duration Effecting Free-Radical Production ....... 18

Chronic Training and its Effects on Oxidative Stress …………………………….... 21

Acute and Long Term Effects of Lipid Peroxidation, TAC, GPX, and SOD.............. 21

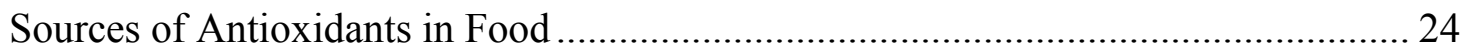

The Effects of Antioxidant Supplements on Health...................................................... 25

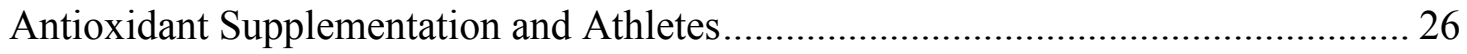

Sex Differences and Inter-Individual Differences........................................................ 28 
Resurgex and its Effects on Oxidative Stress................................................. 29

Protandim ${ }^{\circledR}$ Marketed by LifeVantage Corporation................................................... 29

Nrf2 Activation is the Future of Cellular Protection ............................................... 32

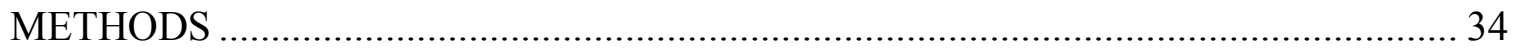

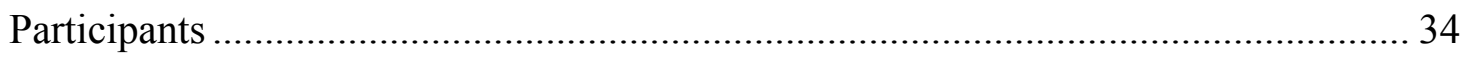

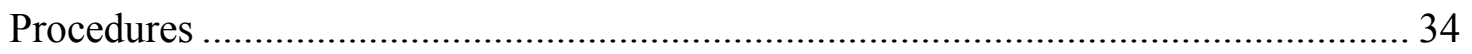

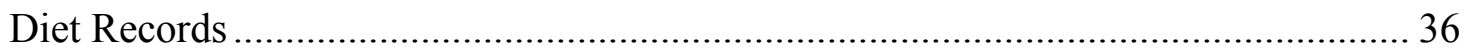

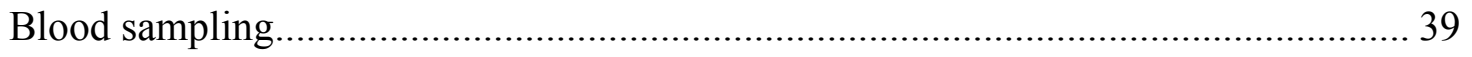

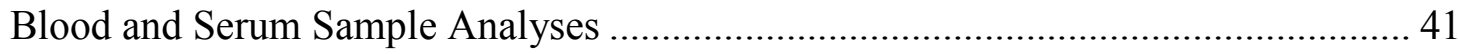

Thiobarbituric acid-reactive substances (TBARS): .......................................... 41

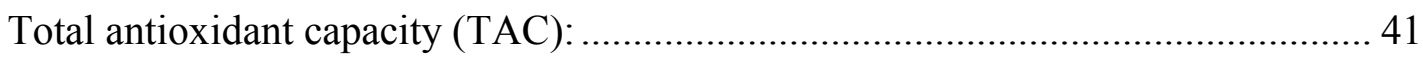

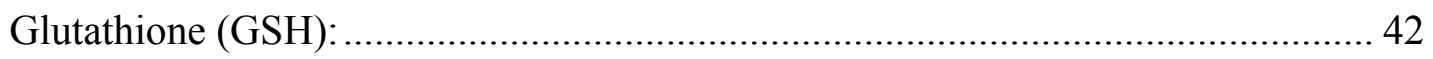

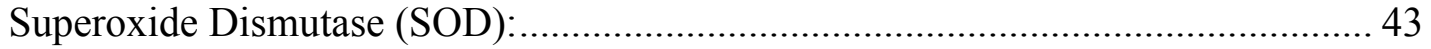

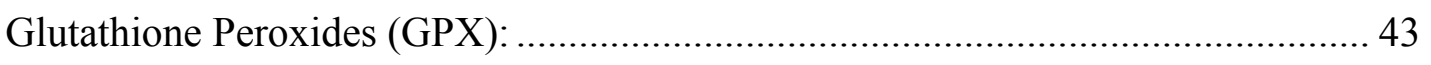

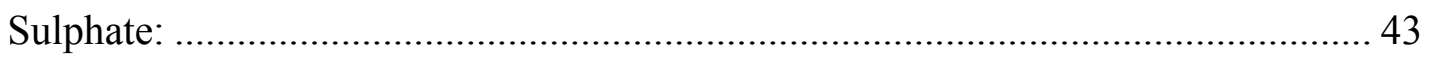

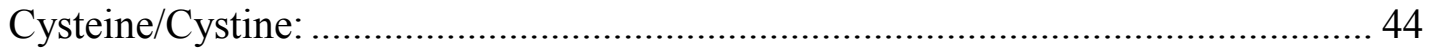

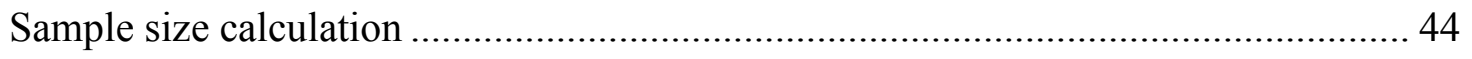

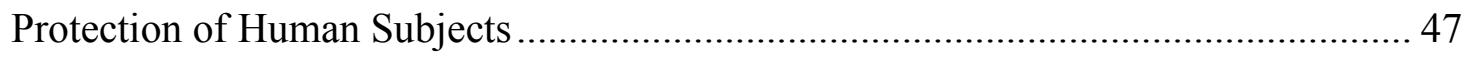

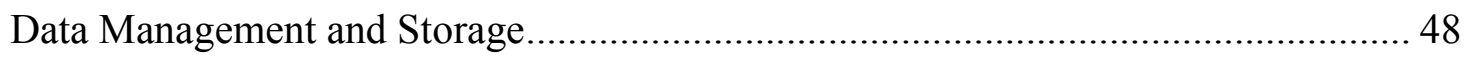

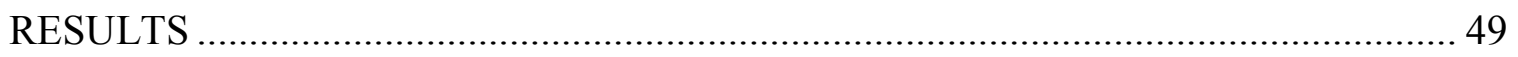

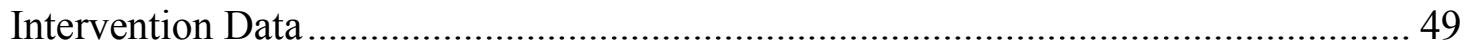

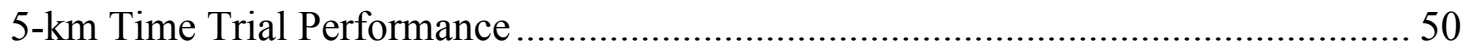

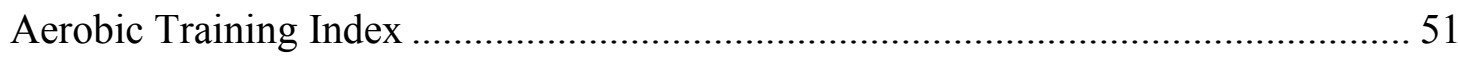

Environmental Conditions............................................................................. 51

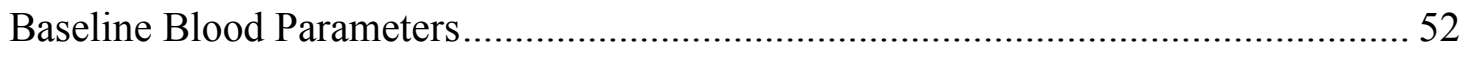

Chronic Effects of Supplementation on Blood Parameters Measured at Rest ............ 52

Acute Effects of Exercise on Blood Parameters .................................................... 53 


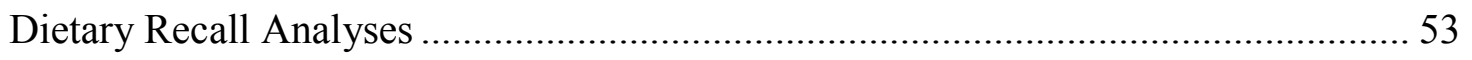

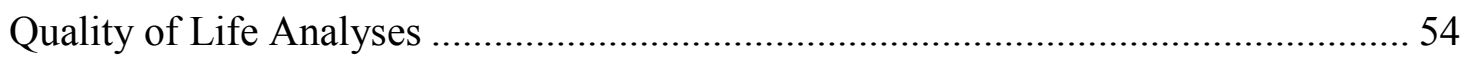

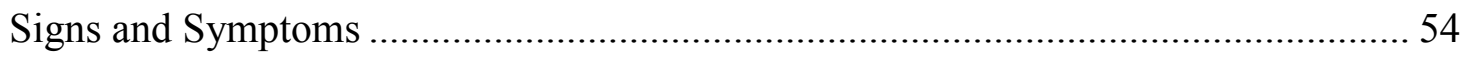

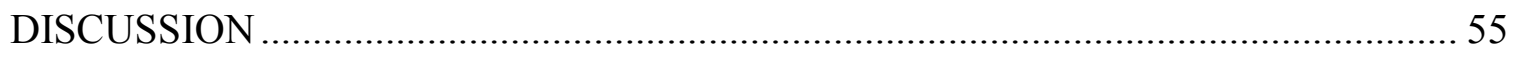

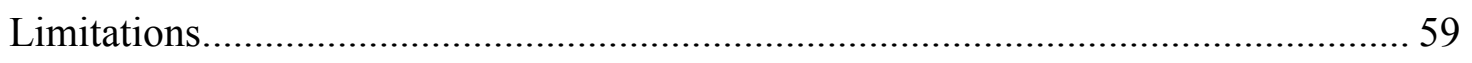

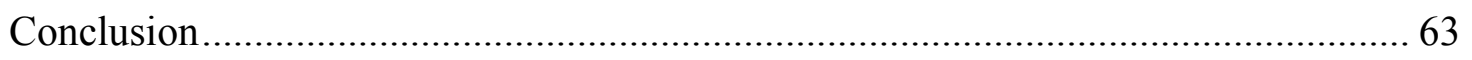

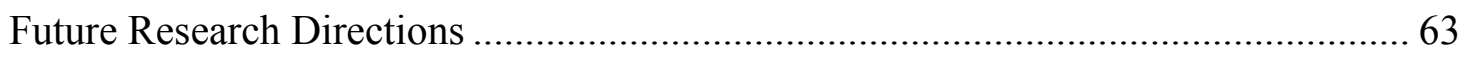

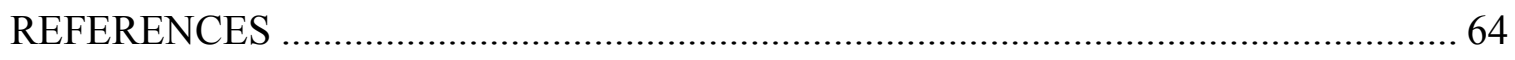

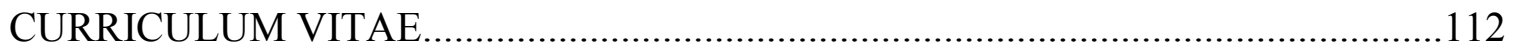




\section{LIST OF TABLES}

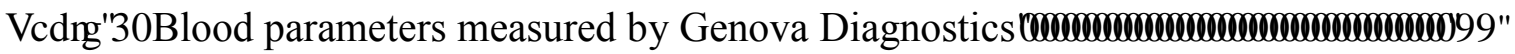
7DEGM $\square$ Baseline anthropometric characteristics, baseline 5-km time-trial results, and baseline fasting blood glucose results

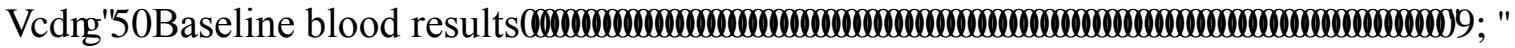
7DECOMШThe week to week coefficient of variation in the blood variables. All blood variables were measured by Genova Diagnostics $(\mathrm{n}=38) \mathrm{m}$ 7 DEOM $\square$ Genova Diagnostic's intra and inter-assay coefficient of variation for most parameters in the oxidative stress panel $7 \mathrm{DE} 9 \mathrm{D} \amalg$ The aerobic training index between groups. This is the total amount of physical activity in minutes over a two week period multiplied by the average rating of perceived exertion value

7DECOM पEnvironmental conditions for all three 5-km time trials held at the University of

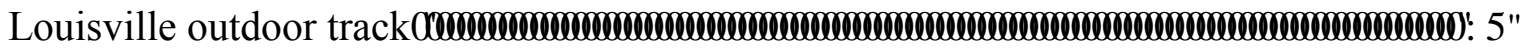

7DEGD Summary probabilities for all blood parameters at rest 7DEOHШThe number of individuals in each group that ate the same food $24 \mathrm{hrs}$ prior to the blood draw for each of the five blood draw days 7DECHपएPre and post exercise blood values from both baseline sessions and at 88 days post-supplementation 
7DEGT पसPre and post exercise blood values at both baseline sessions and at 88 days post-supplementation 7DECOM The total number of participants and events of a given sign / symptom over the supplementation period of 88 days 7DEOHपएThe stability of the responses for the WHOQOL-BREF Questionnaire over a

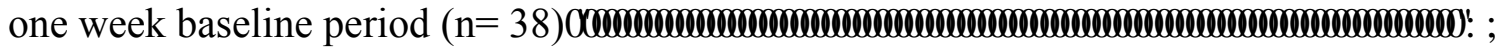




\section{LIST OF FIGURES}

) IJ XIHW आA meta-analysis of the effect of intense exercise on oxidative damage as assessed by lipid peroxides from serum blood samples

) IJ XIHW A meta-analysis of the effect of intense exercise on superoxide dismutase concentration from serum blood samples

) U XIHD A meta-analysis of the effect of intense exercise on glutathione peroxidase concentration from serum blood samples

) IJ XIHD A meta-analysis of the effect of intense exercise on total antioxidant capacity from serum blood samples

) IJ XIHDQA meta-analysis of the effect of long term chronic training on oxidative

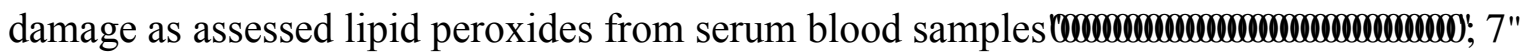

) IJ XIHDQ A meta-analysis of the effect of long term training on superoxide dismutase concentration from serum blood samples ) IJ XIHD A meta-analysis of the effect of long term training on glutathione peroxidase concentration from serum blood samples

) $\mathrm{U} X \mathrm{XHD} \triangle \mathrm{A}$ meta-analysis of the effect of long term training on total antioxidant capacity

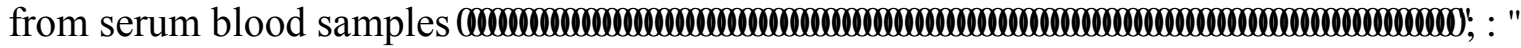

) IJ XIHD Normal subjects before supplementation with Protandim $\AA$ ए 


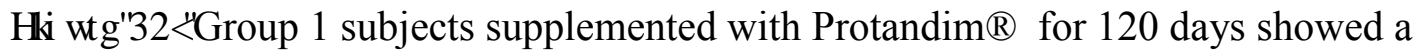
significant increase (*) in erythrocyte SODாس

) UJ XIH⿴囗तGroup 2 subjects supplemented with Protandim ${ }^{\circledR}$ at $338 \mathrm{mg} /$ day for 30 day

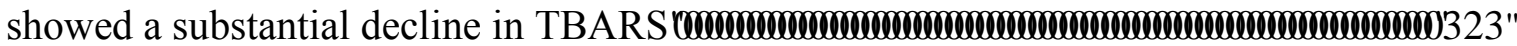

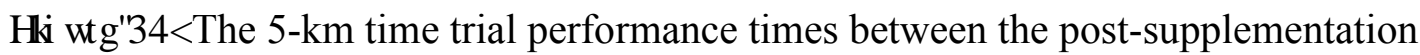
period and baseline (minutes)

) U XUHDपाFigure 13: Box-and-whisker plots of the change in 5-km time trial performance between post-supplementation period and baseline (post - pre) ) U XUHस पाThe long terms effects of supplementation on lipid peroxides and superoxide dismutase in the blood (rest, fasted state)யسயس

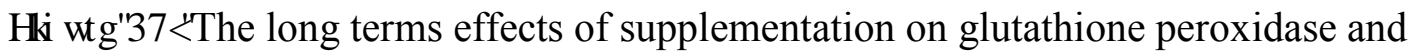

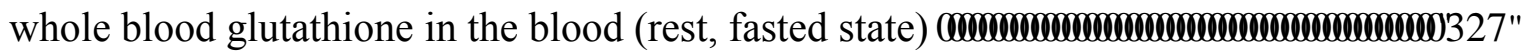
) U XIHD०एThe long terms effects of supplementation on total antioxidant capacity and sulphate levels in the blood (rest, fasted state) ) UJ XIHLOT The long terms effects of supplementation on cysteine and cystine levels in the blood (rest, fasted state) ) UXXHपि The long terms effects of supplementation the cysteine to cystine ratio and the cysteine to sulphate ratio in the blood (rest, fasted state)

) IJ XUHसपThe acute changes in lipid peroxides, superoxide dismutase, and glutathione peroxidase in the blood pre to 10 minutes post-exercise 
) IJ XUHDपाThe acute changes in whoel blood glutathione, total antioxidant capacity, and sulphate levles in the blood pre to 10 minutes post-exercisenسणाणm

) IJ XIHDOT The acute changes in cysteine, cystine, and the custeine to cystine ratio in the blood pre to 10 minutes post-exercise

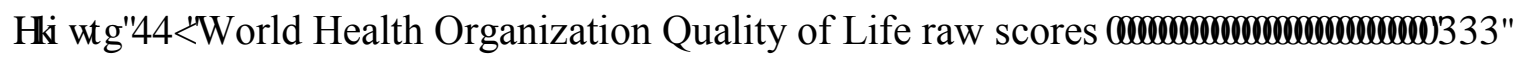




\section{INTRODUCTION}

For many years scientists have connected the process of aging with reactive oxygen molecules produced during a human's normal metabolism. Reactive oxygen molecules are often used interchangeably with "free radicals" or "reactive oxygen species (ROS)" and cause damage to cellular structures throughout the human body. Cellular structures that are most susceptible to cellular damage causing the cell to function improperly are cell membranes, DNA, the mitochondria (energy production), and immune function (neutrophilic phagocytosis) ${ }^{1}$. Oxidative stress occurs when the production of ROS outweighs the body's ability to remove them ${ }^{1}$. Therefore, the generation of reactive oxygen species causes oxidative stress ${ }^{1}$.

The human body produces these damaging ROS every day during normal living and breathing, but ROS are also in the environment in the form of car exhaust, air pollution, sunlight, cigarette smoking, alcohol consumption, a poor diet, as well as other sources ${ }^{1}$. As a result of free radicals being all around us in the environment, our bodies are constantly at risk of cellular damage unless the necessary precautions are made to protect ourselves.

Antioxidants are the bodies defense against free radical damage. Antioxidants have the ability to help protect every cell in our body from free radicals through reducing agents such as dietary antioxidants (such as Vitamin C, Vitamin E, and beta carotene), 
antioxidant enzymes, and nutritional supplements ${ }^{3}$. When free radicals are produced in the body, antioxidants donate their electrons to stabilize and counteract the free radicals damage $^{1}$. The body's main cellular antioxidant defenses are superoxide dismutase (SOD) and glutathione peroxides (GPX) ${ }^{2}$. SOD is the body's first line of enzymatic defense against intracellular free radical production through removal of one-electron dismutation of oxygen $\left(\mathrm{O}_{2}^{-}\right)$to hydrogen peroxide $\left(\mathrm{H}_{2} \mathrm{O}_{2}\right)^{3}$. Glutathione (GSH) acts as a substrate for GPX to remove hydrogen and organic peroxides (eg. lipid peroxides) within the body ${ }^{3}$. When glutathione levels are reduced in the blood it reflects the redox status of skeletal muscle and the heart ${ }^{4}$.

There is a growing amount of evidence that supports the involvement of oxidative stress in many pathological processes, including rheumatoid arthritis, arthritis, asthma, diabetes mellitus, cancer, atherosclerosis, macular degeneration, chronic fatigue syndrome, inflammatory bowel disease, environmental sensitivity, fibromyalgia, and neurodegenerative diseases such as Parkinson's and Alzheimer's ${ }^{1}$. Oxidative stress is not a disease entity, but rather a state in which the body's antioxidant defenses cannot adequately neutralize reactive oxygen species (ROS) $)^{1}$.

While the generation of reactive oxygen species (ROS) is a by-product of cellular respiration, ROS does increase with increasing intensity of exercise ${ }^{5}$. As well, physical overtraining can also increase oxidative stress ${ }^{5}$. According to a study by Margonis et al., three weeks of six days per week of high intensity resistance training increased TBARS by $56 \%$ while reducing GSH by $31 \%$, and total antioxidant capacity (TAC) by $20 \%{ }^{6}$. As a result of increasing oxidative stress levels, athletes can experience greater fatigue, muscle damage, and increased recovery time ${ }^{5}$. When an athlete experiences any of these 
symptoms they may not be able to perform to their fullest potential. However, individuals whom perform endurance training on a regular basis can increase enzymatic SOD and GPX by $25-35 \%$ within the muscle ${ }^{7}$, and $45 \%$ in blood $^{6}$. Endogenous antioxidants catalase (CAT), and glutathione (GSSH) can also be activated along with SOD and GPX by an acute bout of exercise at sufficient intensity ${ }^{1,8}$. The results of previous studies have demonstrated that the combined response of an antioxidant-rich diet plus antioxidant supplementation may provide a synergistic effect together . $^{5}$

As previously mentioned, nutritional supplementation with antioxidants has been recognized as a way to provide faster recovery, reduce injuries, improve performance, and further enhance overall well-being of athletes ${ }^{9}$. One study was conducted to determine if supplementation with Resurgex Plus would reduce oxidative stress and muscle damage in 24 college soccer players ${ }^{5}$. Resurgex Plus is made from $500 \mathrm{U}$ of an oral form of SOD and 1.5 grams of fruit polyphenols. Following twenty days of supplementation with Resurgex Plus twice per day, there were no significant improvements in performance compared to a placebo group ${ }^{5}$. Further results showed a one marker of oxidative stress, lipid hydroperoxide, decreased slightly post-exercise with Resurgex Plus supplementation (2.3 fold increase pre-workout before supplementation vs. 1.9 fold increase post-exercise with supplementation, $p=0.067)^{5}$. Another significant finding of the study was a decrease in muscle damage as seen by a smaller rise in creatine kinase $(\mathrm{p}=0.044)$ post-workout compared to pre-workout supplementation ${ }^{5}$.

In order to advance the scientific evidence supporting the beneficial value of antioxidants for athletes, further research needs to be done. A number of studies have evaluated the effects of antioxidant supplementation, such as Vitamin $\mathrm{C}$ and Vitamin $\mathrm{E}^{\text {9- }}$ 
${ }^{15}$. According to a study by Poljsak ${ }^{15}$, evidence suggests that supplementation of antioxidants no not provide adequate protection against oxidative stress, oxidative damage, or increased lifespan. Therefore, more research needs to be performed in the area of antioxidant supplementation.

Protandim ${ }^{\circledR}$ marketed by LifeVantage Corporation, is a nutritional supplement comprised of five phytochemicals components supposedly activates the Nuclear factor (erythroid-derived 2)-like 2, (called Nrf2) transcription factor pathway that is integral to several antioxidant enzymes, including $\gamma$-glutamyl cysteine synthase (an enzyme that catalyzes the committed step in glutathione synthesis) ${ }^{74}$. $\mathrm{Nrf} 2$ is a basic leucine zipper protein that regulates the expression of antioxidant proteins that protect against oxidative damage triggered by injury and inflammation. Protandim ${ }^{\circledR}$ may induce other endogenous antioxidant enzymes, such as SOD and catalase, while decreasing lipid peroxidation ${ }^{16}$.

In the past 10 years, there have been some studies published using Protandim ${ }^{\circledR 16,20-24,73}$ but only three were assessed in human subjects ${ }^{16,20,73}$. Two of those studies examined long-term oxidative damage assessed by serum lipid peroxides (Thiobarbituric acid-reacting substances: TBARS) and found a 20 to $40 \%$ decrease in plasma TBARS after 30 days of Protandim ${ }^{\circledR}$ supplementation ${ }^{16,73}$. However, the Nelson study was not randomized and not placebo controlled ${ }^{16}$. The third study, a doubleblinded, randomized, placebo-controlled trial published in 2012, examined the effect of Protandim ${ }^{\circledR}$ on pulmonary oxidative stress and alveolar permeability in 30 recovering alcoholics ${ }^{20}$. Protandim ${ }^{\circledR}$ was supplemented in 14 subjects at a dose of $1350 \mathrm{mg} /$ day; double the daily dose recommended by the manufacturer) or placebo (in 16 subjects) were administered for 7 days. Relative to placebo-treatment, Protandim ${ }^{\circledR}$ had no 
significant effects on alveolar epithelial permeability or on oxidative stress (TBARS), epithelial growth factor, fibroblast growth factor, interlukin $1 \beta$, and interlukin-10 levels in bronchoalveolar lavage fluid. Treatment with placebo, however, produced a significant reduction in plasma levels of TBARS by $\sim 28 \%{ }^{20}$. Thus, there is only $\sim 47$ subjects to date that has been given Protandim ${ }^{\circledR}$ in humans in scientific research studies.

As such, due to the limited research on Protandim ${ }^{\circledR}$ in humans, it is necessary to add to the scientific literature on this supplement. There are no studies evaluating the effects of Protandim ${ }^{\circledR}$ supplementation on endurance performance or subjective measures of quality of life according to the WHOQOL-BREF ${ }^{17}$. This study will address these issues.

\section{Significance of the Study}

A nutritional supplement is a product taken orally that contains a dietary ingredient intended to supplement the $\operatorname{diet}^{18}$. These include vitamins, minerals, herbs, or other botanicals, amino acids, and substances ${ }^{18}$. These include nutritional supplements that may help a recreational exerciser, elite athlete, or every day person improve their overall health and well-being ${ }^{18}$.

The results of this proposed study are important because it may provide an easy, practical, and scientifically proven antioxidant supplement regime for athletes to reduce their resting and post- 5-km oxidative stress levels as well and improve performance outcome. If the research hypothesis is correct and oxidative damage is reduced at rest and post 5-km race, athletes may have improved athletic performance during competitions. Also, as a result of the frequency, intensity, and time demanded for a varsity crosscountry or track athlete to train for their sport, it is very important for athletes to practice 
the best known nutritional practices based on scientific evidence in order to continually improve their performance (running time) and overall health and well-being.

Not only could this study examine the effect of Protandim ${ }^{\circledR}$ on running performance, but this study could also assess either the physical or mental components of quality of life according to the WHOQOL-BREF questionnaire ${ }^{17}$. Therefore, the results of this study are advantageous for athletes looking to improve their personal performance by decreasing oxidative stress level, while simultaneously improving quality of life.

The results of this study are important for sports practitioners so they can determine each athletes antioxidant needs to perform a specific sport. Protandim ${ }^{\circledR}$ supplementation may also impact the overall well-being of the athlete allowing for faster recovery, and a reduced number of injuries ${ }^{9}$. Finally, assessing blood markers of oxidative stress allows evaluation of one's reduction/oxidation ("redox") balance which can identify imbalances and prevent chronic illnesses ${ }^{19}$.

\section{Purpose of the Study}

The main objective of Protandim ${ }^{\circledR}$ supplementation is to reduce oxidative stress created in the body ${ }^{16}$. Since oxidative damage is connected to many diseases endpoints, determining the effectiveness of Protandim ${ }^{\circledR}$ at reducing oxidative stress produced following endurance performance may provide reliable and beneficial answers.

Currently there are no studies that have examined the effects of Protandim ${ }^{\circledR}$ supplementation on oxidative stress and endurance performance, although a similar study was conducted supplementing with a proprietary antioxidant and nutraceutical blend ${ }^{5}$. 
The purpose of the present study was to evaluate the effect of $\sim 90$ day Protandim ${ }^{\circledR}$ supplementation on 5-km running performance on acute and long term oxidative damage as assessed by serum lipid peroxides (Thiobarbituric acid-reacting substances: TBARS). Secondarily, another purpose of this study was to evaluate the effect of Protandim ${ }^{\circledR}$ supplementation on measures of quality of life. The experiment was a double-blind, placebo controlled study.

\section{Research Questions \& Hypotheses}

The study will address four specific research questions:

1. Does regular supplementation of $\operatorname{Protandim}^{\circledR}(675 \mathrm{mg}$ /day for 90 days $)$ reduce oxidative damage at rest as assessed by lipid peroxides (TBARS) in well-trained runners? Hypothesis: Based on the data by Nelson et al., oxidative damaged will be reduced by $40 \%(\text { effect size }=4.8)^{16}$.

2. Does regular supplementation of Protandim ${ }^{\circledR}$ in well-trained runners reduce the increase in oxidative damage post-race compared to pre-race as assessed by lipid peroxides (TBARS)? Hypothesis: Based on the data by Kyparos et al., we expect a $45 \%$ increase in TBARS post-exercise compared to pre-exercise (effect size of 3.6) ${ }^{25}$. However, we expect that those that are on $\operatorname{Protandim}^{\circledR}$ for 90 days will only have $31 \%$ increase in TBARS post-race (effect size $=2.5$ ) [based on changes in pre-post lipid peroxides from Arent et $a l^{5}{ }^{5}$

3. Does regular supplementation of Protandim ${ }^{\circledR}$ improve $5-\mathrm{km}$ running times in well-trained runners? Hypothesis: Protandim ${ }^{\circledR}$ will improve $5-\mathrm{km}$ running time by $0.5 \mathrm{~min}$ (SD 1$\min$ ). This is equivalent to an effect size of 0.5 . The placebo group will have no change in performance. 
4. Does regular supplementation of Protandim ${ }^{\circledR}$ improve any one of the four domains of quality of life according to the WHOQOL- BREF ${ }^{17}$. Hypothesis: There will be a statistical improvement in the quality of life post- Protandim ${ }^{\circledR}$ supplementation which a small effect size improvement of 0.33 .

\section{Definition of Terms}

For the purpose of this study, the following terms and their associated abbreviations are defined.

1. Antioxidant - any compound that protects biological systems against the potential harmful effect of processes or reactions that can cause excessive oxidation ${ }^{26}$.

2. Cysteine - is the rate-limiting amino acid for GSH, but also functions as an extracellular antioxidant and is a precursor for taurine, inorganic sulfate, acetylCoenzyme A, and protein synthesis. A water-soluble antioxidant ${ }^{27}$.

3. Cystine - is the oxidized disulfide form of cysteine (Cys) and is the predominant form of cysteine in the blood due to its greater relative stability. High cystine compared to cysteine, however, suggests a shifted redox balance and oxidative stress $^{27}$.

4. Cysteine/Cystine Ratio - is a reliable indicator of extracellular redox potential in the body. A low ratio can indicate a redox imbalance in the body, i.e., oxidative stress (noted in many chronic diseases) $)^{27}$.

5. Dietary Supplement - a product taken orally that contains a dietary ingredient intended to supplement the diet. These include vitamins, minerals, herbs, or other botanicals, amino acids, and substances ${ }^{18}$. 
6. Endurance - is defined as the time limit of a person's or animal's ability to maintain a specific power level during a running protocol ${ }^{11}$.

7. Free Radicals - any chemical species that has one or more unpaired electrons ${ }^{25}$.

8. Glutathione (GSH) - a tripeptide made up of Glutamine, Glycine, and Cysteine and is the body's most potent endogenous antioxidant. GSH has a central role in preventing oxidative stress, functioning as an intracellular antioxidant, as well as a detoxifying agent. Oxidative stress results when there is low GSH levels in the $\operatorname{body}^{27}$.

9. Lipid Peroxides - When prolonged or severe, oxidative stress eventually results in tissue damage and increased risk of disease, as indicated by an elevated lipid peroxides (reflecting oxidative damage to lipids in the body) ${ }^{27}$.

10. Overtraining Syndrome (OTS) - is characterized by declining performance despite an extended rest period, accompanied by physiological, biochemical, immunological, and psychological symptoms ${ }^{6}$.

11. Oxidative Stress - Oxidative stress results when pro-oxidants are insufficiently balanced by antioxidants, resulting in cellular damage. It is thus possible for antioxidant levels to be normal yet still inadequate in the face of excessive ROS $\operatorname{production}^{29}$.

12. Reactive Oxygen Species - is a general term for molecular oxygen-derived molecules that are reactive species or that are converted to reactive species. Reactive oxygen species causes oxidative stress ${ }^{1}$. 
13. Redox State (or Redox Balance) - The continuous interaction between reactive oxygen species and the cellular environment. Determines the level of oxidative stress, which has been linked to many diseases ${ }^{30}$.

14. Superoxide Dismutase (SOD) - Are endogenous antioxidant enzymes that protect against oxidative stress. SOD is critical for preventing the superoxide radical from generating other highly reactive species through its interactions with iron ${ }^{29}$.

15. Total Antioxidant Capacity (TAC) - reflects the collective power of reducing agents to neutralize free radicals for each individual ${ }^{29}$.

16. Sulphate - is produced from cysteine via sulfoxidation. Sulphate is a critical factor as part of Phase II detoxification reactions ${ }^{27}$.

\section{Delimitations}

The participants in the study were recruited from running clubs across the local community of Louisville. This group of participants was chosen based on the close proximity to University of Louisville for exercise testing. The average 5-km running times placed these runners as local or regional class runners, thus, extrapolating the results to a higher caliber athlete may be tenuous.

\section{Assumptions}

This study will use self-reporting for data collection. Participants will adhere to the supplement regime as directed ( 1 pill a day for 90 days). We also expect the runners to provide accurate information to the research team regarding their running logs, including the intensity, duration, and frequency of their running regime. Another assumption we must make is that athletes will provide a best effort during each of 5-km 
trials throughout the entire study. We must also assume the participants are not taking any other supplements throughout the course of the study. Furthermore, we are assuming that the runners will discontinue the use of any other supplement prior to the start of the study and not take any other supplement throughout the course of this study. Lastly, we assume the athletes are maintaining their fitness level throughout the duration of the study. 


\section{LITERATURE REVIEW}

\section{Background on Oxidative Stress Testing}

As previously stated, through normal human activity every day- detoxification of pollutants, immune defense, and energy production, free radicals are produced in the body. Continual free radical production can be damaging to the human body causing greater risk of disease and aging. However, free radical production can be controlled and counter-balanced by antioxidants present in our body and from supplementation. Therein lies the importance and benefits of oxidative stress testing.

Oxidative stress testing is used to assess equilibrium between oxidative damage and antioxidant reserve in the body. The first measure of oxidative stress testing addresses antioxidant reserve, which provides protection against free radical damage and is necessary for healthy functioning of neural, immune, endocrine, and detoxification systems in the body ${ }^{29}$. Our body's antioxidant reserve includes glutathione, total antioxidant capacity (TAC), cysteine, sulphate, cysteine/sulphate, cystine, and cysteine/cystine ratio ${ }^{29}$. The second measure of oxidative stress testing in the blood is enzyme protection ${ }^{29}$. The components of enzyme protection, superoxide dismutase (SOD) and glutathione peroxides (GPx), provide essential defense against oxidative damage $^{29}$. The last measure of oxidative stress testing is tissue damage. Tissue damage is measured by lipid peroxides in the blood and can determine the amount of imbalance 
between free radical production and antioxidants. However, the measured amount of lipid peroxides is far to general and lacks specificity of the location of the oxidative stress within the body. When lipid peroxides in the blood are high, oxidative damage occurs. Table 1 shows the reference ranges for each measure of protection, enzymes, and damage from blood samples ${ }^{29}$.

\section{Blood Measurements of Oxidative Stress}

\section{ANTIOXIDANT RESERVE}

The strongest most powerful endogenous antioxidant produced by the body is glutathione (GSH). Glutathione has many roles as an antioxidant such as detoxification of xenobiotics, which are found in pesticides and plastic, as well as prevention of many disorders and chronic diseases ${ }^{4}$. When glutathione levels are deficient, individuals are at a higher risk for heart disease, AIDS, stroke, diabetes, Parkinson's and Alzheimer's disease, cancer, and inflammatory bowel disease ${ }^{4}$. Glutathione is a tripeptide composed of amino acids cysteine, glutamic acid and glycine, which synergistically work to prevent oxidative stress $^{4}$.

When free radicals are produced in the body GSH synthesis is upregulated to reduce inflammation and protect the body from harmful damage. GSH concentrations are not unlimited and when stores in the blood and tissues become depleted they need to become replenished ${ }^{27}$. According to the Interpretive Guidelines by Genova Diagnostics ${ }^{27}$, low GSH is associated with reduced antioxidant capacity, reduced ability to detoxify environmental toxins and byproducts of metabolism, compromised gut lining, decreased immunity, reduced exercise endurance, and lastly, reduced SAMe synthesis and 
methylation. $S$-Adenosyl-L-methionine (SAMe) is synthesized from L-methionine and ATP in a 2-step reaction where the complete tripolyphosphate moiety is cleaved from ATP as SAMe is being formed ${ }^{27}$.

There are a number of treatment options to increase glutathione levels in the blood. These include: 1) consuming a diet rich in antioxidants (which will be discussed later), 2) supplementation (e.g. digestion support, GSH and/or its building blocks and cofactors, B2, B6, B12, and folic acid), 3) additional supportive nutrients (e.g. vitamins C \& E, plant-based antioxidants, B5, selenium, zinc, and bioflavonoids ${ }^{27}$.

Total Antioxidant Capacity (TAC) is defined as the total amount of all antioxidants in a person's blood ${ }^{27}$. TAC is the overall cumulative effect of all antioxidants to neutralize free radical damage and prevent oxidative stress to tissues ${ }^{27}$. Similar to GSH, low TAC has been observed in individuals with heart disease, metabolic syndrome, major depression, sepsis, fibromyalgia inflammatory bowel disease, cancer, sulfite excess, and hypertension ${ }^{27}$.

In order to neutralize ROS in the blood it is important to first identify the cause of oxidative stress such as from infection, inflammation, toxic metal exposure etc ${ }^{27}$. Once the cause of oxidative stress is known, treatment options include a diet rich in antioxidants, as well as a combination of fat-soluble and water-soluble antioxidants including vitamins $\mathrm{C}, \mathrm{E}$, and $\mathrm{A}, \mathrm{GSH}$ and precursors and cofactors, beta-carotene, Coenzyme Q10, and epigallocatechin gallate (ESCG- green tea extract) to name a few ${ }^{27}$. Increasing TAC is most effectively done when more than one treatment option is performed since TAC encompasses the whole antioxidant levels in the body ${ }^{27}$. TAC measurement is the best indicator of antioxidant levels in the blood and tissue ${ }^{27}$. 
A third antioxidant reserve measured in the blood is Cysteine. Cysteine is a semiessential amino acid and functions as a rate-limiting amino acid in GSH synthesis ${ }^{27}$. Cysteine also serves as a precursor for the amino acid taurine, inorganic sulfate (important for detoxification), acetyl-Coenzyme A, and protein synthesis ${ }^{27}$. When low levels of Cysteine are observed in the blood there is reduced antioxidant capacity as well as a reduced ability for the body to form $\mathrm{GSH}^{27}$. Individuals with low GSH are at a higher risk for oxidative stress and many chronic diseases ${ }^{27}$.

A fourth blood measurement of oxidative stress is the Cystine and the Cysteine/Cystine Ratio ${ }^{27}$. Cystine is the oxidized form of cysteine (Cys), and when levels of cystine are high, oxidative stress is present ${ }^{27}$. A low cysteine/cystine ratio is also associated with a redox balance in the direction of oxidative stress ${ }^{27}$. Low ratios are linked to aging, smoking, and chronic conditions such as atherosclerosis, amyotrophic lateral sclerosis (ALS), Parkinson's and Alzheimer's disease, diabetes, cancer, persistent atrial fibrillation, and cataract formation in the eyes ${ }^{27}$.

A fifth measurement of oxidative stress in the blood is the Sulfate and the Cysteine/Sulfate Ratio ${ }^{27}$. Sulfate is produced from Cysteine by means of sulfoxidation. Sulfates role in the body is detoxification ${ }^{27}$. Therefore, when individuals have a low cysteine/sulfate ratio and/or low sulfate in the blood, they are at a greater risk of leaky gut, environmental illness, food sensitivities, rheumatoid arthritis, motor neuron disease, Alzheimer's and Parkinson's disease, and gastrointestinal tract problems ${ }^{27}$. When high concentrations of sulfate are observed in the blood it can directly lower total antioxidant capacity (TAC) as well as increase lipid peroxides as a result of oxidative stress ${ }^{27}$. 


\section{ENZYME PROTECTION}

The human body classifies cellular antioxidant defenses into two categories: enzymatic and nonenzymatic antioxidants ${ }^{27}$. The main antioxidant enzymes that provide a vital defense against oxidative stress are superoxide dismutase (SOD), glutathione peroxides (GPX), and catalase (CAT) ${ }^{27}$. Both SOD and GPX are endogenous antioxidants, meaning they are produced by the body and therefore provide the greatest protection against oxidative stress ${ }^{4}$. Superoxide dismutase is the first line of enzyme defense against free radical production by removing one-electron dismutation of oxygen $\left(\mathrm{O}_{2}\right)$ to hydrogen peroxide $\left(\mathrm{H}_{2} \mathrm{O}_{2}\right)^{4}$. Glutathione peroxides catalyses the reduction of $\mathrm{H}_{2} \mathrm{O}_{2}$ and organic hydroperoxide to water and alcohol, respectively, using GSH as the electron donor ${ }^{4}$. Glutathione serves as a substrate for GPX to remove hydrogen and organic peroxides (e.g. Lipid peroxides) ${ }^{4}$. GSH is then oxidized to oxidized glutathione (GSSH) by donating a pair of hydrogen ions ${ }^{3}$. Reduced glutathione measured in the blood can adequately reflect the redox status (oxidative stress) of skeletal muscle and the heart ${ }^{4}$. Imbalances in SOD levels have been linked to Parkinson's and Alzheimer's disease, ALS, neurological diseases, Down's syndrome, impaired glucose tolerance, diabetes, dengue fever, and cataracts ${ }^{27}$. GPX is considered an irreplaceable antioxidant in the mitochondria of the cell because mitochondria do not contain catalase for protection against peroxides $^{27}$. Imbalances in GPX are linked with accelerated aging, as well as chronic disorders such as cardiovascular disease, cancer, diabetes, Alzheimer's disease, alcoholinduced oxidative stress, cholecystitis (inflammation of the gallbladder), and urticaria (a rash of round, red welts on the skin that itch intensely, sometimes with dangerous swelling, caused by an allergic reaction $)^{27}$. 


\section{$\underline{\text { DAMAGE }}$}

The final measurement included in oxidative stress testing is lipid peroxidation. The oxidation of lipids, also known as lipid peroxidation, is a marker of injury caused by free radical damage to polyunsaturated fatty acids (PUFAs), suggesting that production of ROS has been inadequately imbalanced by antioxidants ${ }^{27}$. In the face of excessive ROS it is possible for antioxidant levels to be normal, however still inadequate due to high levels of ROS production ${ }^{27}$. Lipid peroxidation in cell membranes can result in cellular dysfunction and is associated with increased risk of disease ${ }^{27}$. Normal lipid peroxide values demonstrate the ability of antioxidants to prevent oxidative stress, and therefore oxidative damage has not occurred ${ }^{27}$.

\section{Earliest Research on Oxidative Stress and Exercise}

The earliest research conducted in the area of oxidative stress and exercise was performed in the fifties and showed evidence of free radicals present in muscles with exercise $^{31}$. Further studies conducted in 1980 by Koren et al., ${ }^{32}$ showed that when limb muscles are stimulated to contract repeatedly, free radical content in the muscle tissue and blood were elevated. Following these findings, research was performed in 1982 by Davies et al., ${ }^{33}$ which demonstrated free radical production in skeletal muscle of rats after running until exhaustion. Another study performed 10 years later by Vina et al., showed that a single bout of exhaustive exercise causes oxidative stress but only when the exercise is exhaustive ${ }^{12}$. The findings of these three studies were just the beginning of research on oxidative stress and exercise. 


\section{Exercise Frequency, Intensity, and Duration Effecting Free-Radical Production}

The intensity at which an individual exercises does affect the amount of free radicals produced. Low-intensity exercise causes lower free radical production and typically does not exceed antioxidant capacity, therefore it does not result in oxidative stress $^{34}$. However, the higher the intensity of exercise an individual performs, the greater the free radical production and oxidative stress ${ }^{34}$.

When an individual performs moderate intensity physical activity there is mild tissue trauma which decreases during recovery ${ }^{6}$. When moderate physical activity is performed on a regular basis the human body is able to adapt to the stress from exercise and athletic performance improves ${ }^{6}$. When exercise volume, intensity, or frequency are increased too much all together or individually, the body is not able to recover quickly enough and tissue damage results ${ }^{6}$. If intense training continues for a prolonged period of time the individual will experience a decline in performance accompanied by biochemical, physiological, psychological, and immunological symptoms ${ }^{6}$. In exercise and sports, this is called Overtraining Syndrome. Overtraining syndrome has been reported to produce high levels of free radicals, causing oxidative damage ${ }^{6}$. According to a study by Margonis et al., there is a dose response relationship between training load and oxidative stress biomarkers, were exercise induced overtraining elicits a significant response of oxidative stress biomarkers ${ }^{6}$.

The effects of overtraining also have an impact on maximal strength performance. Overtraining causes prolonged muscular strength deterioration and is associated with ROS-induced muscle damage. Margonis et al., investigated responses to oxidative stress biomarkers to a resistance training protocol of progressively increased and decreased 
volume and intensity ${ }^{6}$. Twelve males (21 (SD 2) participated in the 12-week resistance training program consisting of five three-week periods of varying frequency, intensity and duration for each group, followed by a three week period of rest ${ }^{6}$. They showed that when a decline in maximal strength performance was observed, biomarkers of oxidative stress reduced glutathione/oxidized glutathione (GSH/GSSG) and urinary F2isoprostanes (F2-IsoP) increased ${ }^{6}$. The results of blood samples demonstrated that TBARS increased following overtraining by $\sim 56 \%{ }^{6}$. A second finding showed exerciseinduced oxidative stress, observed by lipid peroxide levels, may not reach peak levels immediately post-exercise and may has a delayed response ${ }^{6}$. This was proven in the present study when TBARS elevated (40-70\%), at 48 hours post-exercise in the strenuous exercise group ${ }^{6}$. Higher TBARS concentrations 48 hours post-exercise were likely caused by lipid peroxidation of low density lipoproteins (LDL) in the blood cause injury to muscle cell membranes ${ }^{6}$. Therefore, overtraining results in an increase in oxidative stress biomarkers that are proportional to the frequency, intensity, and duration of the training $\operatorname{protocol}^{6}$.

In the same study by Margonis et al., the antioxidant glutathione (GSH) decreased by $\sim 30 \%$ in the blood following overtraining only, and $\sim 20 \%$ following intense resistance exercise, but both returned to normal levels soon after $^{6}$. Lower training intensities and volumes did not have a significant effect on participants' glutathione levels and therefore adequate levels of GSH were present prior to exercise to counterbalance the small amount of free radicals produced ${ }^{6}$. Total antioxidant capacity (TAC) increased following light and intense training, but decreased following overtraining ${ }^{6}$. The increase in TAC levels can be explained by an elevation in uric acid ${ }^{6}$. Uric acid accounts for 
approximately one-third of TAC in the body and is elevated post-exercise to counterbalance free radical production ${ }^{6}$.

There have been numerous studies showing the effects of oxidative stress following extreme exercise (indicated by increases in plasma TBARS), but there has only been one study performed on rats that investigated endurance exercise overtraining ${ }^{35}$. However, the results of the study were not significant in showing endurance exercise overtraining causes an increase in oxidative stress, likely because the training protocol was not strenuous enough in nature ${ }^{35}$.

As previously stated, exercise duration does effect the amount of oxidative stress produced in the body. In a study by Revan et al., short duration high intensity exhaustive running of $\sim 4$ minutes in duration was performed by males approximately 24 years of $\operatorname{age}^{8}$. They examined lipid peroxidation, antioxidant status and muscle damage postexercise $^{8}$. The results of this study showed a non-significant decrease in GPX levels in the blood, which demonstrates that there is likely a relationship between exercise performed to exhaustion (intensity) and the duration of the exercise performed ${ }^{8}$.

Numerous studies have investigated the effects of short duration exhaustive exercise and endurance exercise on oxidative stress level but only one has compared the blood redox status at rest and post-exercise in two groups of rowers, a group that showed exercise-induced hypoxemia during rowing, and a group that did not ${ }^{25,28}$. The two groups of trained rowers showed no significant difference in baseline redox status, however both groups showed significant increases in oxidative stress levels post-2000-m row, observed by increases in serum TBARS, protein carbonyls, catalase activity and $\mathrm{TAC}^{25,28}$. Therefore, despite differences in oxygenation during exercise between the two groups, 
well-trained rowers showed similar and significant post-exercise increases in oxidative stress $^{25,28}$.

\section{Chronic Training and its Effects on Oxidative Stress}

There is a lack of research performed on humans regarding whether chronic exercise training produces less oxidative stress. Recent studies performed on mice have shown that ROS can exert favorable effects in the process of training adaptation ${ }^{36}$. With chronic training there is an up-regulation of endogenous antioxidant enzymes such as mitochondrial superoxide dismutase (MnSOD), glutathione peroxidase, and $\gamma$ glutamylcysteine synthetase (GCS) ${ }^{36}$. The up-regulation of these antioxidants results from the cumulative effects of repeated exercise bouts ${ }^{36}$. However, the exercise intensity must be sufficient enough to stimulate ROS and therefore cause an up-regulation of endogenous antioxidants ${ }^{36}$. Not only has chronic training in animals resulted in less

oxidative stress compared to untrained animals, but regular exercise has also shown to prevent chronic diseases and increase longevity ${ }^{11,36}$. In a similar study, when antioxidants were administered to rats before regular training, these training adaptations were diminished because the antioxidants interfered with muscle cell adaptation ${ }^{36}$. However, when exercise training was exhaustive in trained rats, results showed it was beneficial to consume an antioxidant supplement since the generation of ROS would overwhelm endogenous antioxidant defences ${ }^{36}$.

\section{Acute and Long Term Effects of Lipid Peroxidation, TAC, GPX, and SOD.}

Acute exercise training can promote oxidative stress within the blood. One of the most widely used measurements of oxidative stress is plasma thiobarbituric acid-reactive 
substances (TBARS) ${ }^{25}$. TBARS is a strong marker of lipid peroxidation that reflects oxidative damage to polyunsaturated fatty acids within the cell membranes of our DNA ${ }^{25}$. At rest and during exercise, serum TBARS elicits a moderate to strong correlation with lipid peroxide values within the heart muscle ( $\mathrm{r}=0.71$ and $\mathrm{r}=0.99$ respectively), and a strong and moderate correlation $(r=1.0$ and $r=0.68)$ at rest and during exercise with the liver ${ }^{25}$. In the review of literature on the acute effects of intense exercise on oxidative damage, as represented by lipid peroxidiation obtained from serum blood samples, there was a mean increase in oxidative damage with an standardized mean difference (or effect size $)+1.6$ using a random effects model $\left(\mathrm{n}=282\right.$ subjects, 22 studies, Figure $\left.1^{5,8,25,38-56}\right)$. The preponderance of data suggests that acute intense exercise increases serum lipid peroxide from pre- to post exercise. Therefore, it can be stated that an acute bout of strenuous exercise bout can promote oxidative stress within the blood ${ }^{35}$.

In the review of literature on the acute effects of intense exercise on superoxide dismutase concentration from serum blood samples, there was a mean increase in the concentration of this antioxidant enzyme in the blood with an standardized mean difference (or effect size) +1.2 using a random effects model $(\mathrm{n}=85$ subjects, 8 studies, Figure $2^{40,42,45,48,50,51,54,55}$ ). The prevalence of data suggests that acute intense exercise increases serum superoxide dismutase from pre- to post exercise.

Based on the findings of 11 studies investigating the acute effects of intense exercise on glutathione peroxidase concentration from serum blood samples, there was a mean increase in concentration of this antioxidant enzyme in the blood with a standardized mean difference (or effect size) +0.8 using a random effects model $(n=167$ 
subjects, Figure $3^{8,19,40-42,45,49,50,52,54,55}$ ). According to these findings, acute intense exercise increases serum glutathione peroxidase from pre- to post exercise.

Several studies have analyzed the acute effects of intense exercise on total antioxidant capacity (TAC) concentrations from serum blood samples. Based on the results of 9 studies, there was a mean increase in this parameter showing a standardized mean difference (or effect size) +1.2 using a random effects model $(\mathrm{n}=143$ subjects, Figure $4^{13,19,25,28,38,39,45,48,49,52}$ ). Data taken from Kyparos et al. ${ }^{25,28}$ seemed to be the same data published in both articles, therefore nine studies were used in the meta-analysis. The data suggests that acute intense exercise increases serum total antioxidant capacity from pre- to post exercise.

Based on a review of literature performed looking at the long term effects of chronic training on oxidative damage, as represented by lipid peroxides obtained from serum blood samples in a rested state after a period of long term training, there was no statistical effect of long term training on serum lipid peroxide using a random effects model ( $n=61$ subjects, 5 studies, Figure $\left.5^{43,49,52,55,57}\right)$. The data from these studies suggests that long term chronic training has no effect on serum lipid peroxides taken at rest after long term training.

A literature review was performed to determine the long term effects of chronic training on superoxide dismutase, as obtained from serum blood samples in a rested state after a period of long term training. There was no statistical effect of long term training on serum superoxide dismutase values using a random effects model $(\mathrm{n}=26$ subjects, 2 studies, Figure $6^{55,58}$ ). Based on these two studies, data suggests that long term chronic 
training has no effect on serum superoxide dismutase taken at rest after long term training.

Based on four studies that investigated the long term effects of chronic training on glutathione peroxidase, as obtained from serum blood samples in a rested state after a period of long term training, there was no effect of long term training on serum glutathione peroxides values using a random effects model $(\mathrm{n}=53$ subjects, Figure 7 ${ }^{49,52,55,58}$ ). Based on these results, the data suggests that long term chronic training has no effect on serum glutathione peroxides taken at rest after long term training.

A review of literature was performed on the long term effects of chronic training on total antioxidant capacity, as obtained from serum blood samples in a rested state after a period of long term training. There was no effect of long term training on serum total antioxidant values using a random effects model ( $\mathrm{n}=42$ subjects, 4 studies, Figure 8 $43,49,52,57)$. The data suggests that long term chronic training has no effect on serum total antioxidant capacity taken at rest after long term training.

\section{Sources of Antioxidants in Food}

At the present time, there is not a recommended daily amount of antioxidants an individual should consume on a daily basis ${ }^{59}$. The amount of antioxidants each person should have will be different depending on activity levels and competition goals ${ }^{59}$. A diet high in antioxidants can fend off exercise-induced oxidative stress and promote training adaptations ${ }^{9}$.

Reducing exercise-induced oxidative stress takes dietary planning. High amounts of antioxidants can be found in fruits and vegetables ${ }^{9}$. The brighter the fruit or vegetable is, the higher its antioxidant content ${ }^{9}$. In general, each color group of fruit or vegetable 
represents a class of antioxidants ${ }^{9}$. It is recommended that individuals consume a few servings from each color group every day for optimal health ${ }^{9}$.

Research has shown that the body's ability to produce its own internal endogenous antioxidant enzymes (SOD, GPX, and catalase) is more effective in fighting free radicals than consuming an antioxidant supplement ${ }^{11}$. In a study by Jacob et al.,${ }^{60}$ normal healthy men (both smokers and non-smokers) with low intakes of fruits and vegetables consumed a moderate supplement of vitamins E, C, and folic acid to reduce oxidative stress. The results of the study showed no significant change in normal healthy males oxidative stress levels with supplementation of vitamins E, C, and folic acid ${ }^{60}$. A similar study performed by Van den Berg et al. ${ }^{61}$ and Moller et al. ${ }^{62}$ showed that supplementation with a daily intake of 600 grams of fruits and vegetables or supplementation with a concentrate of fruits and vegetables results in no significant effects on markers of oxidative stress. Therefore, there appears to be no improvement in reducing oxidative stress through antioxidant supplementation ${ }^{16}$.

\section{The Effects of Antioxidant Supplements on Health}

Most research conducted using nutritional antioxidants are vitamins $\mathrm{E}$ and $\mathrm{C}^{63}$. The optimal antioxidant intake is one that minimizes the incidences of both deficiency and toxicity 9 . For example, when doses of vitamin $\mathrm{E}$ are excessively high, it may interfere with vitamin $\mathrm{K}$ metabolism as well as platelet function ${ }^{64}$. Other antioxidants such as selenium, vitamin $\mathrm{C}$, and vitamin $\mathrm{E}$ in high does can act as pro-oxidants in the body. Excessive high doses of zinc has also been associated with depressed immune functioning ${ }^{64}$. 
The results of these studies lead us to believe that high-dose antioxidant supplementation may disrupt our body's natural antioxidant defense against ROS. Since approximately $70 \%$ of the U.S. population uses isolate high-dose antioxidant supplements at least occasionally and $40 \%$ uses them on a regular basis, individuals may be causing more harm than good to their body every day ${ }^{11}$.

Currently, there is debate as to whether athletes should consume high doses of antioxidants to help reduce the increased production of ROS. However, research as early as 1971 reported that vitamin E supplementation (400 IU daily for 6 weeks) had no benefits, but did have result in unfavorable effects on the adolescent swimmers endurance performance ${ }^{65}$. More recently, a study was performed to determine the effects of vitamin C supplementation on training-induced increases in aerobic capacity and endurance, and on skeletal muscle mitochondrial biogenesis in rats and humans ${ }^{11}$. The results of the study showed vitamin C supplementation significantly reduced endurance capacity in rats, and did not improve aerobic capacity in both humans and rats ${ }^{11}$. Vitamin $\mathrm{C}$ supplementation prevented the activation of antioxidant enzymes in skeletal muscle when exercise was performed ${ }^{11}$. Vitamin C supplementation also hindered endurance swimmers' mitochondria biogenesis in skeletal muscle, which is directly related to endurance capacity ${ }^{11}$. Thus, since endurance capacity may be negatively affected by vitamin $\mathrm{C}$ and $\mathrm{E}$ supplementation, athletes should not consume high-dose vitamin $\mathrm{C}$ and E supplements since it could hamper their performance ${ }^{11}$.

\section{Antioxidant Supplementation and Athletes}

Athletes are normally the healthiest and fittest individuals, yet ironically athletes are among the highest consumers of supplements on the market today ${ }^{59}$. Athletes are 
generally those with 1) the healthiest diet that is high in fruits and vegetables, 2) nonsmokers, and 3) have a regular, structured exercise program ${ }^{59}$. Through regular training on a daily basis and a progressive training load, an individual's antioxidant reserve adapts and is able to produce enough antioxidant enzymes to rid the blood and muscle tissue of ROS more rapidly ${ }^{41,59}$. However, the speed at which each individual's endogenous antioxidant reserve adapts to a training load differs ${ }^{59}$. The adaptive response is the function of individual factors such as the type of exercise performed, the age of the individual, the training period and level, environmental conditions, and lastly interindividual differences ${ }^{59}$.

Athletes are always seeking out ways to improve their performance and the best method may require improving their daily nutrition and removing foods and drinks which cause ROS (e.g. alcohol) ${ }^{59}$. A healthy diet can play a protective role in reducing ROS produced throughout the day and during exercise when ROS levels are higher ${ }^{59}$. The adequate intakes of antioxidant micronutrients for athletes is unknown because it has been poorly investigated in the past ${ }^{59}$.

Traditionally, antioxidant supplements have been prescribed to athletes undergoing intensified training protocols to aid in the maintenance and balance of oxidative, inflammatory, and neuro-endocrinological systems ${ }^{2}$. However, the excessive nature in which some individuals' intake antioxidant supplements may suppress redox signaling processes and reduce the benefits of regular training within the cell ${ }^{2}$. Nevertheless, at the present time there are findings reporting the potential of antioxidant supplements to interfere with the body's ability to adapt to exercise, causing reduced performance ${ }^{2}$. 
Future research should focus on the amount of antioxidant supplementation athletes require to improve athletic performance without interfering with cellular signaling processes ${ }^{2,59}$.

\section{Sex Differences and Inter-Individual Differences}

Research has shown that gender is a determinant of aging and an individuals' life span, however little is known about free-radical homeostasis differences between males and females ${ }^{66}$. Many factors contribute to the aging process, but it is known that free radicals play a key important role ${ }^{66}$. Since it has been demonstrated that females have a longer life span than males, it is believed that females live longer as a result of lower oxidative stress levels ${ }^{66}$. Further research has reported gender differences influence the adaptation to changes in antioxidant capacity ${ }^{66}$. Studies has shown that males and females have different ROS production following exercise ${ }^{66}$.

According to a study by Mullins et al., there were no significant differences in changes in protein carbonyls (PC), GPX, and TAC between females and males following a maximal treadmill exercise test to exhaustion ${ }^{19}$. However, males were found to have a higher GPX pre-exercise compared to females, as well as higher post-exercise TAC and GPX values compared to females following a maximal treadmill exercise test ${ }^{19}$. Although there were no significant changes in PC, GPX, and TAC levels between males and females, it is believed there is a large inter-individual difference in exercise-induced changes in oxidative stress and antioxidant biomarkers, suggesting there may be responders and non-responders to exercise induced oxidative stress ${ }^{19}$. 


\section{Resurgex and its Effects on Oxidative Stress}

Nutritional supplementation with antioxidants have been discussed as a way to further enhance overall well-being for athletes, faster recovery, minimization of injury time, and overall improved performance ${ }^{9}$. One study used Resurgex Plus (which includes $500 \mathrm{U}$ of an oral form of SOD and 1.5 grams of fruit polyphenols) in 24 fit male college division 1 soccer players to determine if supplementation decreased muscle damage and reduced oxidative stress ${ }^{5}$. The experimental group consumed Resurgex supplements $2 \mathrm{x}$ per day for 20 days and results showed no improvement in performance compared to the placebo group 5 . However, with Resurgex supplementation, lipid hydroperoxide seemed to be blunted post-exercise compared to pre-exercise (2.3 fold increase in lipid hydroperoxide before supplementation, to 1.9 fold increase post-supplementation, $p=$ $0.067)^{5}$. A second finding of the study was a lower resting CK (creatine kinase) compared with the control group ${ }^{5}$. The rise in creatine kinase (a marker of muscle damage), post-workout compared to pre-workout was smaller with the supplementation ${ }^{5}$.

\section{Protandim ${ }^{\circledR}$ Marketed by LifeVantage Corporation}

A current nutritional antioxidant supplement on the market is Protandim ${ }^{\circledR}$ marketed by LifeVantage Corporation. Protandim ${ }^{\circledR}$ is comprised phytochemicals, specifically five botanical sources $(675 \mathrm{mg}$ /day containing $225 \mathrm{mg}$ of milk thistle, 150 $\mathrm{mg}$ of bacopa extract, $150 \mathrm{mg}$ dose of ashwagandha root, $75 \mathrm{mg}$ of turmeric, and $75 \mathrm{mg}$ green tea $)^{16}$. These phytochemicals are thought to help the body to produce its own antioxidant enzymes and lower oxidative damage in blood/tissues. Protandim ${ }^{\circledR}$

supplementation has shown to reduce lipid peroxidation in the blood in humans ${ }^{16,73}$. 
In a study by Nelson et al., subjects were assigned to one of two groups ${ }^{16}$. Twenty subjects were assigned to Group 1 and received the full supplement of Protandim ${ }^{\circledR}$ (675 $\mathrm{mg}$ ) in a single daily capsule for 30 days $^{16}$. Twelve subjects from Group 1 continued supplementation for a total of 120 days. Group 1 had blood sampling taken at 0,30 days, and 120 days $^{16}$. Group 2 consisted of four subjects who received $338 \mathrm{mg} /$ day of Protandim ${ }^{\circledR}$ in a single capsule for 30 days $^{16}$. Blood sampling was taken at 0,5 days, 12 days, and 30 days. Oxidative stress was measured by serum blood analysis of TBARS ${ }^{16}$.

Figure 9 shows results of the study ${ }^{16}$. Figure 9 (A) shows an age-dependent increase in TBARS in normal subjects before supplementation with Protandim ${ }^{\circledR}$. However, supplementation of Protandim ${ }^{\circledR}$ for 30 days caused the age-related increase in TBARS to disappear ${ }^{16}$. When subjects were separated by gender there were no significant differences in plasma TBARS [Figure 9 (B)]. In Figure 9 (C), subjects who self-reported supplementation with vitamin $\mathrm{C}$ and $\mathrm{E}$ had significantly higher plasma TBARS as well as greater age relatedness, compared to subjects who reported taking no vitamin supplements ${ }^{16}$. Lastly, Figure 9 (D) shows TBARS levels dropped an average of $40 \%$ (n $=20 ; \mathrm{p}<0.0001)$ following 30 days supplementation of Protandim ${ }^{\circledR}$.

Figure 10 shows the results of subjects supplemented with Protandim ${ }^{\circledR}$ for 120 days on SOD activity ${ }^{16}$. After 30 days of supplementation, erythrocyte SOD increased by $8 \%$ compared to baseline, and increased by $30 \%$ compared to baseline after 120 days ${ }^{16}$. Since erythrocytes have a circulating lifespan of 120 days, during the 120 days of the study the red blood cells would have been replaced by maturing reticulocytes from the bone marrow ${ }^{16}$. Therefore, it would be expected that after 120 days of supplementation, 
$100 \%$ of erythrocytes would have turned over, reflecting new steady state levels of $\mathrm{SOD}^{16}$.

Figure 11 shows the results of Group 2 subjects who consumed half a pill per day (338 mg/day) of Protandim ${ }^{\circledR}$ and its effects on plasma TBARS ${ }^{16}$. There appears to be a rapid initial decrease in plasma TBARS levels occurring by 5 to 12 days post supplementation ${ }^{16}$. Although no significant difference was not seen, these results also showed that a full dose of Protandim ${ }^{\circledR}$ supplementation $(675 \mathrm{mg} /$ day) is more effective at lowering TBARS to an average of $1.10(0.05) \mu \mathrm{M}(\mathrm{n}=20)$ versus of $1.29(0.14) \mu \mathrm{M}(\mathrm{n}=$ $4)^{16}$.

Nelson et al., also concluded from the study that the age-dependent increase in oxidative stress observed prior to supplementation was almost completely abolished when subjects consumed the full dose of Protandim ${ }^{\circledR}(675 \mathrm{mg} / \text { day })^{16}$. The overall reduction in plasma TBARS was $40 \%$ with Protandim ${ }^{\circledR}$ supplementation ${ }^{16}$. In conclusion, all subjects benefited from Protandim ${ }^{\circledR}$ supplementation by experiencing reduced oxidative stress levels observed by TBARS ${ }^{16}$. Individual differences were observed between subjects with low initial levels of lipid peroxidation and those with higher initial levels, where lower initial levels saw only modest declines in TBARS ${ }^{16}$.

However, the Nelson study was not a randomized, placebo-controlled study, which would limit the study's findings. In 2012, a double-blinded, randomized, placebocontrolled trial examined the effect of Protandim ${ }^{\circledR}$ on pulmonary oxidative stress and alveolar permeability in 30 recovering alcoholics ${ }^{20}$. Protandim ${ }^{\circledR}$ was supplemented in 14 subjects at a dose of $1350 \mathrm{mg} /$ day; double the daily dose recommended by the manufacturer) or placebo (in 16 subjects) were administered for 7 days. Relative to 
placebo-treatment, Protandim ${ }^{\circledR}$ had no significant effects on alveolar epithelial permeability or on oxidative stress (TBARS), epithelial growth factor, fibroblast growth factor, interlukin $1 \beta$, and interlukin-10 levels in bronchoalveolar lavage fluid. Treatment with placebo, however, produced a significant reduction in plasma levels of TBARS by $\sim 28 \%{ }^{20}$.

In 2014, an abstract was published in the FASEB journal examining the effects of 30 days of $675 \mathrm{mg} /$ day of Protandim ${ }^{\circledR}$ on serum lipid peroxidation in 13 overweight and/or obese subjects ${ }^{73}$. Ashwagandha is a banned medicinal ingredient in some countries, so the phytochemical piperine was substituted for Ashwagandha in this study. Serum TBARS decreased from 6.3 (3.3) to $4.9(1.7) \mathrm{nmol} / \mathrm{mL}(p<0.05)$, or $\sim 28 \%$ in the Protandim ${ }^{\circledR}$ (piperine) group. The placebo group, on the other hand, showed no change in serum TBARS post-supplementation.

Thus, based on these three human studies to date ( $\sim 47$ subjects), there is still debate as to whether Protandim ${ }^{\circledR}$ actually reduces oxidative damage as reflected by serum TBARS.

\section{Nrf2 Activation is the Future of Cellular Protection}

Nrf2 is a protein that regulates the body's antioxidant response to oxidative stress $^{67,68}$. Nrf2 has been called the 'thermostat' within our cells because it can determine the level of oxidative stress and initiate an antioxidant protective response to combat the stress $^{67,68}$. Nrf2 activation enables our cells to use their own antioxidant reserve from naturally-occurring and plant-derived activators, such as sulforaphane from broccoli and curcumin from turmeric ${ }^{67,68}$. Some Nrf2 activators are synthetic compounds and thus must be developed by pharmaceutical treatments ${ }^{67,68}$. New research findings are revealing 
that the human body's own internal network of antioxidant enzymes is approximately one million times more protective against oxidative stress versus consumption of antioxidant supplements on the market, such as vitamins $C$ and $E^{67,68}$. Therefore, the future of cellular protection may lie in Nrf2 activation.

The ingredients in Protandim ${ }^{\circledR}$ by LifeVantage provide a natural option to activate Nrf2 within the cells. As previously stated, Protandim ${ }^{\circledR}$ is comprised of five botanical sources: bacopa monniera, silybum marianum (milk thistle), withania somnifera (ashwagandha), camellia sinensis (green tea), and curcuma longa (turmeric), which have been shown to change the gene expression in hundreds of genes associated with heart, brain, and colon health ${ }^{16}$. Therefore, these research findings suggest that our cells have the genetic resources and capability of maintaining oxidative balance and slowing the aging process if Nrf2 can be adequately activated ${ }^{16}$.

In order to make conclusions about the effectiveness of Protandim ${ }^{\circledR}$ to reduce oxidative stress and improve endurance performance, extensive research needs to be conducted. There are currently no studies to date that have measured oxidative stress and endurance performance with Protandim ${ }^{\circledR}$ supplementation, although a similar study has been done using another supplement ${ }^{5}$. 


\section{METHODS}

\section{Participants}

A total of 40 community runners between the ages of 18 and 55 years were sought to participate in this study. Runners were recruited from running clubs across the local community. Local residents of the Louisville area were targeted due to availability and close proximity for exercise testing in the study. The runners had to be considered "local class" or faster for 5-km time, based on USA Track-and-Field age and sex graded performance categories ${ }^{78}$. The age- graded score is the ratio of the approximate worldrecord time for that age and sex divided by the runner's actual time. "Local class" classified as an age and sex-graded score of $60 \%$ to $69 \%$, "regional class" is classified as an age and sex-graded score of 70.0 to $79.9 \%$, "national class" is classified as an age and sex-graded score of 80.0 to $89.9 \%$, and "world class" is classified as an age and sexgraded score of 90 to $100 \%$ of approximate world record time.

\section{Procedures}

This study was a double-blind, randomized, placebo controlled trial where participants were placed into one of two groups randomly by blocks of two, controlling for sex and running time (clinicaltrials.gov identifier: NCT02172625). The experimental group was taking the supplement Protandim ${ }^{\circledR}$ for the entire duration of the study, whereas 
the control group was taking a placebo (corn starch and food coloring). To control threats to internal validity the study was a double-blind setup, the subjects' were selected through randomly assigned blocks of two, and there was a placebo group. Each subject underwent six testing sessions, with five different days of blood draws.

\section{$\underline{\text { Session } 1 \text { (Initial Screening Day) }}$}

Every subject was provided with an informed consent document explaining their responsibilities and risks by participating in this study. Subjects were also instructed to complete a physical activity readiness questionnaire (PARQ) to clear them for physical activity $^{69}$. Each participant was asked to list all the nutritional supplements they were taking, including multivitamins.

Subjects were asked to refrain from taking any multivitamins or nutritional supplements for the duration of the study due to the previous evidence that Vitamin E and C supplementation affects plasma TBARS ${ }^{16}$. A training diary was given to each participant to fill out for the entire duration of the study. Participants were asked to use the diary to record their intensity, training duration, and mileage per week of running. Lastly, each participant was given five quality of life questionnaires (WHOQOL- BREF) to fill out at home for the duration of the study ${ }^{17}$. The quality of life assessments are easily administered and do not require much time to complete. The assessment is scored in four domains: Domain 1: Physical health, Domain 2: Psychological, Domain 3: Social relations, and Domain 4: Environment ${ }^{17}$. The WHOQOL-BREF has a good to excellent psychometric properties of reliability and performs well on tests of construct validity 
(The Health and QOL R ${ }^{2}$ was 0.52 overall, with Physical $=0.32$, Psychological $=0.26$, Social $=0.10$, and Environment $=0.17)^{17}$.

\section{Diet Records}

To examine whether dietary changes influences lipid peroxidation and antioxidant status outcomes, subjects were given instructions to record what they eat during the $24 \mathrm{hr}$

prior to each session. Subjects were taught how to complete the diet recall and determine food serving and sizes. Participants were asked by a member of the research team to eat the same thing and do same activity before the five pre-determined follow up sessions.

\section{$\underline{\text { Session } 2 \text { (Baseline, About } 15 \text { days after Session 1) }}$}

Subjects were fasted in the morning when they arrived at University of Louisville for their pre-exercise blood sampling. Each subject brought their 24-hr dietary recall to the session, as well as their WHOQOL- BREF form ${ }^{17}$. Approximately three teaspoons of blood was withdrawn 30 minutes prior to exercise for analysis of several blood parameters (Table 1).

Following blood samples being taken, participants partook in the first of two baseline 5-km time trials at the University of Louisville outdoor track. Time trials have greater logical validity compared to time-to-exhaustion tests, which is the reason timetrials were selected as the performance measure ${ }^{70}$.

Approximately 10-minutes post-exercise, another three teaspoons of blood was taken from each subject. Only after their post-exercise blood draw were subjects able to eat.

Participants were divided into one of two groups based on their first 5-km time 
trial results. The participants were randomly assigned in blocks of two so that number of males and females per group would be similar and the average 5-km performance time per group would be similar. Based on the first baseline 5-km results, all the women and men were ranked from fastest to slowest based on their $5-\mathrm{km}$ performance from this session. Women were ranked amongst themselves, and then the men were ranked amongst themselves. The first two ranked women were grouped together and then a coin was flipped. If the coin came up heads, the first ranked woman of the pair was placed in Group 1, if the coin came up tails, the second ranked woman in that pair would be placed in Group 1. This would then continue for the next two fastest women, and so on. The men were then randomly assigned into one of two groups the same way, in groups of two, with the first two ranked males placed together, and randomized by a coin toss, and then the next two ranked males were placed together, and then randomized by a coin toss, and so on.

\section{Session 3 (About 7 days after Session 2)}

Subjects were fasted in the morning when they arrived at University of Louisville for their pre-exercise blood sampling. A member of the research team collected each participants' post- 24-hr food diary and their WHOQOL- BREF forms ${ }^{17}$. Approximately three teaspoons of blood was withdrawn 30 minutes prior to exercise for analysis of several blood parameters (Table 1). Following participants blood being drawn, each subject was required to partake in another baseline $5-\mathrm{km}$ time trial at the University of Louisville track. 
At approximately 10-minutes post-exercise, another three teaspoons of blood was taken from each subject. Only after their post-exercise blood draw were subjects able to eat.

Then, depending on the group, subjects were given either a $\sim 90$ day supply of Protandim ${ }^{\circledR}$ pills (US Protandim ${ }^{\circledR}$ Lot\# X14-0901) or $\sim 90$ supply of placebo pills (corn starch and food coloring). Since the study was double-blinded, neither the researchers nor the subjects knew which pills they were ingesting. Subjects were instructed to ingest one pill per day, ideally with breakfast (675 mg per day, for $\sim 90$ days). The subjects were also given a signs/symptoms form, where they were asked to report any signs/symptoms they had during the supplementation period, such as diarrhea, stomach aches, nausea etc...

\section{Session 4 ( $\sim 30$ days post-supplementation)}

At session four, participants arrived fasted in the morning at the University of Louisville for their pre-exercise blood sampling. Each subject brought their 24-hr dietary recall with them and their WHOQOL- BREF forms ${ }^{17}$. The forms were collected by a member of the research team. Participants had approximately three teaspoons of blood drawn. There was no 5-km running race performed at this session.

\section{$\underline{\text { Session } 5 \text { ( } ~ 60 \text { days post-supplementation) }}$}

At session five, participants arrived fasted in the morning at the University of Louisville for their pre-exercise blood sampling. Each subject brought their 24-hr dietary recall with them and their WHOQOL- BREF forms ${ }^{17}$. The forms were collected by a 
member of the research team. Participants had approximately three teaspoons of blood drawn. There was no 5-km running race performed at this session.

\section{Session 6 ( $\sim 90$ days post-supplementation)}

At session six, participants arrived fasted in the morning at the University of Louisville for their pre-exercise blood sampling. They each brought their 24-hr dietary recall with them and their WHOQOL- BREF forms ${ }^{17}$, and their running logs. The forms were collected by a member of the research team. Participants also brought with them any unused pills for proper documentation. Participants had approximately three teaspoons of blood drawn 30 minutes prior to exercise. Following participants' blood being drawn, each subject was required to partake in a $5-\mathrm{km}$ time trial at the University of Louisville track.

At approximately 10-minutes post-exercise, another three teaspoons of blood was withdrawn from each subject. Only after their post-exercise blood draw were subjects able to eat.

\section{Blood sampling}

Blood sampling was completed using a traditional venipuncture method with a mix of 21 and 23 gauge needles. Both straight and "Butterfly" needles were used to accommodate the comfort of test subjects. Blood was collected in vacuum-sealed tubes designed to contain and preserve specimens in a manner appropriate with their respective analysis. The tubes used were two ten-millimeter tubes designed to promote clotting and formation of a platelet barrier that permanently separates the serum from the cellular elements and clotting factors of whole blood, and one six-millimeter tube treated with 
Potassium Ethylenediaminetetraacetic acid (EDTA). This not only preserves the cellular element of the whole blood, but allows the coagulation factors to remain suspended in the plasma. EDTA prevents coagulation in the blood via a removal of ionized calcium from the blood, which acts as a co-factor in the coagulation cascade. The presence of potassium in the preservative and the absence of calcium has physiological effects on enzymatic activity within the blood, thus both samples were necessary for analysis for a clear view of the oxidative activity within the subjects ${ }^{4}$.

Once drawn, specimens were separated and the EDTA tubes were put into immediate refrigeration, whereas the larger gel tubes were allowed to clot for fifteen minutes, then centrifuged at 3000 RPM (Champion F-33 Series Centrifuge, Ample Scientific, Norcross, GA) for fifteen minutes. The pre-centrifugation clotting is necessary to prevent fibrin, a co-factor of coagulation, from forming a gel matrix in the serum, rendering it unsuitable for analysis. Hemolysis always being a factor in venipuncture analysis was mitigated by ensuring proper vein selection before the procedure begins, central placement of the needle within the vein during the procedure, and gentle rocking of the specimens after the venipuncture to ensure uniform contact with the walls of the tube $\mathrm{s}^{4}$

After centrifugation, the serum samples were frozen at $-20^{\circ} \mathrm{C}$ for at least 4 hours and then shipped overnight to Geneva Diagnostics for analyses. Genova Diagnostics is a global, fully accredited clinical laboratory, located in Ashville, North Carolina [Licensed by Clinical Laboratory Improvement Amendments (CLIA) Certification number \#34D0655571]. 


\section{Blood and Serum Sample Analyses}

Thiobarbituric acid-reactive substances (TBARS): This is a direct marker of oxidative damage to polyunsaturated fatty acids within cell membranes, otherwise known as lipid peroxidation. Serum TBARS have been shown to be correlated with oxidative damage to certain tissues, namely heart and liver tissue at rest $(r=0.71$ to 1.0$)$ and exercise $(r=0.68$ to 0.99$)^{4}$. The lipid peroxide assay is designed to measure the lipid peroxidation products in serum. After acid hydrolysis the lipid peroxidation products are reacted with thiobarbituric acid resulting in a spectrophotometrically active product. Malondialdehyde (MDA) is used as the standard for determination of levels of lipid peroxidation products. The specimen type for this assay is serum obtained from a clot activated serum separator tube. A TBARS assay kit (Cayman Chemical, U.S.), which allows a rapid photometric detection of the thiobarbituric acid malondialdehyde (TBAMDA) adduct at $532 \mathrm{~nm}$, was used. Samples were read by a microplate reader spectrophotometer (Infinite M200, Tecam, Austria). A linear calibration curve was computed from pure MDA-containing reactions ${ }^{4}$.

Total antioxidant capacity (TAC): Plasma TAC, assesses an individual's blood specimen to inhibit an oxidation reaction. This test reveals the combination of all antioxidants blood to neutralize free radicals. Plasma TAC was determined from serum using a proprietary methodology (Genova Diagnostics, Asheville, NC). The basis for this assay is that it measures the antioxidant capacity of a serum sample via the ability of the antioxidants within the sample to neutralize a spectrophotometrically active compound that is optically active when oxidized. The decrease in color intensity of the compound 
when compared to the standard, Trolox, under the same reaction conditions is equivalent to the serum antioxidant capacity of the serum sample. The specimen type for this assay is serum obtained from a clot activated serum separator tube. It was measured by an enzymatic reaction assay kit (Cayman Chemical, U.S.) using a microplate reader spectrophotometer (Infinite M200, Tecam, Austria). This enzymatic reaction assay is based on the ability of antioxidants in the plasma to inhibit the oxidation of 2, 2'-azinobis (3-ethylbenzithiazoline) sulfonic acid (ABTS, Sigma) to the radical cation ABTS+ by a peroxides. The amount of the produced ABTS+ has been assessed by measuring the absorbance signals at $705 \mathrm{~nm}$. The antioxidants concentration is proportional to the suppression of the absorbance signal. TAC was evaluated by a trolox (6-hydroxy-2,5,7,8tetramethylchroman-2-carboxylicacid, Aldrich) standard curve, and was expressed as trolox-equivalent antioxidant capacity concentration $(\mathrm{mM})^{4}$.

Glutathione (GSH): Blood Glutathione, the most potent endogenous antioxidant, is correlated well with muscle and heart tissue at rest $(r=0.93$ to 1.0$)$ and at exercise $(r=$ 0.66 to 1.0$)^{4}$. GSH was determined from whole blood using a proprietary methodology (Genova Diagnostics, Asheville, NC) and is designed to measure the level of glutathione in whole blood. The basis for this assay is a follows: The samples is first completely lysed and proteins are precipitated. The supernatant is then reduced and combined with a spectrophotometrically reactive compound which generates a detectable absorption peak. When compared to known concentrations of GSH under the same reaction conditions a determination of GSH levels in blood is determined. The colorimetric assay is performed using the Abbott Diagnostics Architect System. The specimen type for this assay is EDTA preserved whole blood ${ }^{4}$. 
Superoxide Dismutase (SOD): Superoxide Dismutase (both cystolic and mitochondrial SOD), is another protective anti-oxidant enzyme that was measured by a colorimetric assay. Superoxide Dismutase assay is designed to measure the activity of the SOD enzyme in red blood cell lysates. The SOD activity is determined spectrophotometrically based on the ability of the superoxide dismutase compound to reduce reactive oxygen species in an enzymatic reaction necessary for the production of an optically active compound. The result is expressed as units of SOD relative to the gram amount of hemoglobin in the sample. The colorimetric assay is performed using the Abbott Diagnostics Architect System. The specimen type for this assay is EDTA preserved whole blood ${ }^{4}$.

Glutathione Peroxidase (GPX): This was determined from whole blood using a proprietary methodology (Genova Diagnostics, Asheville, NC). The Glutathione Peroxidase (GPX) assay is designed to measure the level of glutathione in red blood cell lysates. The level of GPX in the sample is determined spectrophotometrically based on the ability of the compound to catalyze a reduction reaction in the presence of glutathione. The change in the absorption level of the substrate is then utilized to determine the level of GPX present in the sample. The result is expressed as units of GPX relative to the gram amount of hemoglobin in the sample. The colorimetric assay is performed using the Abbott Diagnostics Architect System. The specimen type for this assay is EDTA preserved whole blood ${ }^{4}$.

Sulphate: Sulphate was determined from whole blood using a proprietary methodology (Genova Diagnostics, Asheville, NC). The basis of this assay is as follows: Sulfate was measured via a Turbidimetric Assay Kit. This assay is designed for determination of 
sulphate levels in serum utilizing the chemical property of sulfate ions to cause the formation of precipitates that can be measured by absorbance of light. The use of a sulphate standard curve under the same reaction conditions facilitates the ability to determine the level of sulphate in the serum sample. The assay is performed using the Abbott Diagnostics Architect System. The specimen type for this assay is serum obtained from a clot activated serum separator tube ${ }^{4}$.

Cysteine/Cystine: The assay designed for the measurement of serum cysteine is an adaptation of the Gaitonde procedure developed for the detection of amino acids which utilizes the colorimetric reaction of amino acids with ninhydrin. The specimen type for this colorimetric assay is serum obtained from a clot activated serum separator tube $\mathrm{A}^{4} \mathrm{~A}$ lower cysteine to cystine ratio demonstrates a shift towards increased oxidative stress ${ }^{4}$.

Throughout the study, information was gathered through self-report at sessions two through six ensure adherence to the program, as well as the three planned exercise tests. Participants were responsible for bringing their weekly training log with intensity, training duration and mileage per week of their runs as well as a food record of what they ate during the 24 hour period prior to the test day (Session 2). Participants were asked to eat the same thing and do the same activity before the follow up tests at 7 days and 90 days post supplementation.

\section{Sample size calculation}

The independent variable in this study was the two different supplementation groups. The main dependent variables measured were 5-km finishing time, TBARS, SOD, GPX, TAC, and the four domains of the WHOQOL- BREF questionnaire ${ }^{17}$. Based 
on a $5-\mathrm{km}$ time improvement of $2.5 \%$ or about 30 seconds $(\mathrm{SD}=1$ minute) with Protandim ${ }^{\circledR}$, and no improvement in the placebo group, about 34 runners in total were needed (Effect size $f=0.25$, statistical power $=80 \%$, alpha error probability $=5 \%$, two measurements per group, correlation amongst repeated measures $=0.50$, F-test Family, ANOVA repeated measures, within-between interaction, $G^{*}$ Power 3.1.2, Universität Kiel, Germany). Accounting for a $\sim 20 \%$ attrition rate ( 8 subjects), a total of 40 subjects was recruited (20 per group).

\section{Statistical Analyses}

A $2 \times 4$ repeated measures analysis of variance (ANOVA) was chosen to compare long term, chronic changes in blood parameters (rested, fasted state) over the duration of the study (2 groups; 4 time-points: average baseline, 30, 60, 90 days postsupplementation). A $2 \times 3$ repeated measures ANOVA compare the acute changes in blood parameters between pre and immediately post exercise (2 groups; 3 time-points: baseline 1, baseline 2, 90 days post-supplementation). A repeated measures design also provided the experimenter the opportunity to control for individual differences among participants. To adjust for multiple comparisons post-hoc, a Bonferroni correction was used.

To compare groups, baseline subject characteristics (including anthropometric data, environmental conditions, and resting, fasted, blood variables) were performed using independent $t$-tests. If any of the variables were not normally distributed (as verified by a Shapiro-Wilk test), then a Mann-Whitney $t$-test was used to compared groups. 
It is also important to determine the inter-session variability over time so that one can distinguish between the inherent variability of the test, from small, real physiological change caused by an interventional study. To compare the variability in baseline $5-\mathrm{km}$ time-trials from week-to-week, the coefficient of variation (C.V.) was calculated for each subject and averaged $[(\mathrm{SD} \div$ mean $) \cdot 100]$. To calculate the reproducibility in $5-\mathrm{km}$ times, the following was done: Reproducibility was calculated by obtaining the square root of the mean square error obtained from a repeated measures analysis of variance obtained from the two $5-\mathrm{km}$ baseline time trials that were performed a one week period. Both groups were placed together in this analyses because neither group as of that point was under the influence of the supplement. The square root of the mean square error obtained from the repeated measures ANOVA was reported as the common week-to-week within subject standard deviation $\left(\mathrm{SD}_{\mathrm{w}}\right)^{74}$. Reproducibility was defined as $2.77 \cdot \mathrm{SD}_{\mathrm{w}}{ }^{74}$. That is, the difference between the 5-km times on different weeks for the same subject is expected to be less than 2.77 times the within-subject standard deviation for $95 \%$ of pairs of observations ${ }^{74}$. Since the calculation of reproducibility may be considered too stringent, the smallest measureable change was reported as half of the reproducibility ${ }^{75}$. Any $5-\mathrm{km}$ time that was above or below the smallest measureable change was considered a meaningful change. As well, the C.V. and reproducibility was calculated for each domain of the WHOQOL- BREF. Furthermore, the baseline C.V. was calculated for all blood parameters.

The baseline $5-\mathrm{km}$ time was reported as the as the fastest of the two baseline $5-\mathrm{km}$ time trials. A Fisher's exact test determined whether there was a difference between the two groups in the number of subjects that improved by more than the smallest meaningful 
change in 5-km time post-supplementation. A Fisher's exact test was also used to compare groups for the signs and symptoms reported during the supplementation period.

In order to control for differences in the exercise training regimes between the two groups, an aerobic training index was calculated at baseline, and then again postsupplementation. The aerobic training index was calculated as the total number of minutes of aerobic physical activity over the previous 14 days multiplied by the average rating of perceived exertion score over the previous 14 days $(6=$ no exertion, $20=$ maximal exertion. A Kruskal-Wallis one-way analysis of variance was used to compare the training index between groups pre and post supplementation.

A Kruskal-Wallis one-way analysis of variance was also used to compare each domain of the WHOQOL- BREF between groups during the supplementation period.

Statistical significance was set at 0.05 . Statistical analyses was performed using IBM SPSS for Windows version 21.0, released in 2012 (IBM Corporation, Armonk, NY).

\section{Protection of Human Subjects}

Prior to group assignments, subjects were notified of the benefits and risks associated with the study through informed consent. The protocol for the study was discussed in detail to ensure everyone was aware of the expectations involved, and they were informed of their rights as participants in the study. After providing this information, an informed consent form were given to the participants to sign. This study was reviewed and approved by Institutional Review Board (IRB) (Approval Number 14.0614). 


\section{Data Management and Storage}

All documents and data collected was stored in a locked cabinet in a locked lab (Dr. Zavorsky's Lab in room 17A, Crawford Gym). This lab was locked at all times with access granted only to the faculty advisor and three student researchers. Personal information and data that was on a computer was stored on a locked computer with a password needed to gain access. 


\section{RESULTS}

\section{Intervention Data}

Forty subjects, 20 to 46 years of age were recruited to participate in this clinical trial. These subjects were recruited through word of mouth, and through the local running stores. One subject did not make the time-trial standard so she was eliminated from the study, and the other subject did not continue on with the study after the informal information session. Thus, 38 subjects were retained. The anthropometric characteristics, baseline 5-km times, and fasting blood glucose concentration were not different between groups (Table 2).

In the end, one female subject withdrew from the study two weeks after the beginning of supplementation due to complaints that the supplement caused her to be depressed. It was later determined that she was in the Protandim ${ }^{\circledR}$ group. In addition, another female subject dropped out just before the final 5-km time trial because she was pregnant. A male subject also did not complete the final 5-km time trial because he was in a car accident a week earlier. However, he did have his fasted pre-exercise blood drawn at $\sim 88$ days supplementation. Thus, there is some missing data from these 38 subjects due to these unforeseen circumstances. 
Venous blood samples were obtained at baseline (there were two baseline sessions one week apart from each other), and at 30 (SD 2), 57 (2), and 88 (4) days postsupplementation. The subjects returned their pill bottles and the combined average number of pills not taken by both groups was 3 (4), with a range of 0 to 19 pills missed.

\section{5-km Time Trial Performance}

These 38 subjects were randomized into the experimental and control groups by random blocks of two according to gender and 5-km time trial performance. In the end, equal number of males and females were in the Protandim ${ }^{\circledR}$ group and the Placebo group, and both groups had similar 5-km times of 20.3 (2.1) minutes (Table 2). The mean rating of perceived exertion (RPE) for the baseline 5-km time trials was 17.5 (1.7) out of $20(6=$ no exertion, $20=$ maximal exertion $)$. This mean value is qualitatively labeled between "very hard" and "very very hard" for the effort of the 5-km runs. The data presented in Table 2 is the best performance of both baseline time trials. The mean coefficient of variation between both baseline $5-\mathrm{km}$ time trials was $1.1 \%$ and the correlation between both these $5-\mathrm{km}$ time trials was $0.99,(p<0.01)$. There was no difference in mean 5-km time trial performance between both baseline sessions. After removal of outliers, the reproducibility was 23 seconds, and the smallest meaningful change was 12 seconds (half of the reproducibility). Supplementation did not change 5$\mathrm{km}$ time trial performance in either group (Figure 12-13, $p=0.91$, Group x Time interaction effect, $p=0.84)$. There were eight out of 16 subjects that improved by $\geq 12$ seconds in the Protandim ${ }^{\circledR}$ group, while nine out of 19 subjects improved by $\geq 12$ seconds 
in the placebo group. Thus, the proportion of subjects that improved by the smallest measureable change of at least 12 seconds were similar between groups $(p>0.05)$.

\section{Aerobic Training Index}

In order to control for changes in training volume that could affect 5-km time trial performance, an aerobic training index was calculated at baseline and $\sim 90$ days postsupplementation. The baseline aerobic training index was the summed total number of minutes of running/physical activity for the 14 days prior to the distribution of the supplement multiplied by the average rating of perceived exertion for those 14 days $(6=$ no exertion, $20=$ maximal exertion). The aerobic training index at the $\sim 88$ days post supplementation period was the summed total number of minutes of running/physical activity for the 14 days prior to the end of the study multiplied by the average rating of perceived exertion for those 14 days $(6=$ no exertion, $20=$ maximal exertion $)$. While there was a significant correlation between the aerobic training index between baseline and post-supplementation (Spearman's rho $=0.66, p<0.01$ ), the changes in the aerobic training index in that period was not different between groups $(t=-1.63, p=0.11$, Table $6)$.

\section{Environmental Conditions}

The environmental conditions for all three 5-km time trials are presented in Table 7. There was no statistically significant differences in either temperature, dew point, or humidity measured between groups within any of the three sessions. However, there was some adjustment for the final $5-\mathrm{km}$ times for seven subjects. Those subjects experienced 
unseasonably hot and humid conditions (Temperature $=71^{\circ} \mathrm{F}$, Humidity $=71 \%$, Dew point $=61^{\circ} \mathrm{F}$. According to the following source which adjusts for temperature and dew point $^{79}$, the final times were adjusted down by $2 \%$ for only those seven subjects in that final session only.

\section{Baseline Blood Parameters}

The baseline blood parameters that is listed in the oxidative stress panel provided by Genova diagnostics are presented in Table 3. These data presented are the average baseline values measured twice over a period of one week. The mean values for both groups are within the reference ranges provided by Genova Diagnostics (Table 3). There was no difference in any parameter between groups at baseline (rested, fasted, Table 3, Table 8).

The week-to-week coefficient of variation for every blood parameter is presented in Table 4. As can be seen, the coefficient of variation ranged from as low as 5\% (for fasting blood glucose) to $26 \%$ (lipid peroxides, TBARS). This is similar to the acceptable laboratory coefficient of variation for replicates from the same sample, assayed at a different time-points (Table 5).

\section{Chronic Effects of Supplementation on Blood Parameters Measured at Rest}

Supplementation did not change blood parameters measured at rest (Table 8, Figures 14-18). However, there were mean differences in glutathione (GSH), total antioxidant capacity (TAC), cystine, sulphate, cysteine to sulphate ratio, superoxide 
dismutase (SOD), and glutathione peroxidase (GPX) measured across the four timepoints (all $p<0.05$, Table 8 , Figures 14 to 18 ).

\section{Acute Effects of Exercise on Blood Parameters}

The 5-km time trials did not affect any blood parameter in the oxidative stress panel (Figures 19 to 21). However, blood glucose increased by +70 (29) $\mathrm{mg} / \mathrm{dL}$ from preto 10 -minutes post-exercise (Table $10, p<0.01$ ). Supplementation did not affect these changes.

However, in a subset of subjects, the mean increase in TBARS in 21 individuals that were "responders to oxidative stress" when both baseline 5-km races were averaged, was $+1.6(\mathrm{SD} 1.4) \mu \mathrm{mol} / \mathrm{L}$ [minimum increase $=0.1$, maximum increase $=4.3 \mu \mathrm{mol} / \mathrm{L}]$. This represents 11 subjects out of 19 subjects $(\sim 58 \%)$ in the placebo group, and 10 subjects out of 19 subjects ( $\sim 53 \%)$ of the subjects in Protandim ${ }^{\circledR}$ group. After 88 days of supplementation, five out of nine responders in the Protandim ${ }^{\circledR}$ group ( $63 \%)$ experienced a reduction in serum TBARS post-race, while eight out of 11 responders in the placebo group $(\sim 73 \%)$ experienced a reduction in serum TBARS postrace (Fisher's exact test, $p=0.64$ ). Thus, Protandim ${ }^{\circledR}$ was ineffective in reducing postexercise serum TBARS in responders compared to placebo.

\section{Dietary Recall Analyses}

The number of individuals in each group that ate the same food 24 hours prior to the blood draw for each of the five blood draw days are shown in Table 9. Thirteen subjects in the Protandim ${ }^{\circledR}$ group ate mostly or completely the same food prior to each 
session compared to 5 subjects in the placebo group. This was significantly different $(p<$ 0.01, Fisher's exact test).

\section{Quality of Life Analyses}

Figure 22 displays the World Health Organization Quality of Life raw scores. There was no significant difference between groups in Physical Health, Social Relationships, and Psychological Health throughout the 88 days of supplementation. Only at 88 days post-supplementation did the Placebo group have higher environmental scores compared to the Protandim ${ }^{\circledR}$ group ( $p=0.047$, Figure 22). Table 13 shows the stability of responses for the WHOQOL-BREF over a one week period. The week-toweek coefficient of variation was 4 to $7 \%$ for all domains (Table 13).

\section{Signs and Symptoms}

Table 12 shows the total number of events of a given sign/symptom over the 88

day supplementation period. The total number of sign/symptoms in the Protandim ${ }^{\circledR}$ group over 88 days was 233 episodes (51\%), compared to 220 episodes (49\%) in the placebo group. The number of subjects that experienced at least one event was similar between groups $(p>0.05$, Fishers exact test). 


\section{DISCUSSION}

The purpose of this study was four-fold: First we wished to assess whether regular supplementation of Protandim ${ }^{\circledR}$ (675 mg/day for 90 days) reduces oxidative damage in the blood at rest as assessed by lipid peroxides (TBARS) in runners. The 88 (4) day supplementation period did not change serum peroxides levels in either group. Second, we wanted to determine whether regular supplementation of Protandim ${ }^{\circledR}$ in runners reduces the increase in oxidative damage post-race compared to pre-race as assessed by lipid peroxides. Since acute exercise did not change mean serum lipid peroxides levels, we were not able to assess whether supplementation had any effect on this change. However, in a group of responders of oxidative stress caused by $5-\mathrm{km}$ time trials, Protandim ${ }^{\circledR}$ did not mitigate the increase. Third, we wanted to know whether regular supplementation of Protandim ${ }^{\circledR}$ improved 5-km running times. The supplement did not improve running performance, but it did not worsen performance either. Lastly, we wished to determine whether regular supplementation of Protandim ${ }^{\circledR}$ improved any one of the four domains of quality of life according to the WHOQOL- BREF ${ }^{17}$. The week-to-week coefficient of variation in quality of life scores for both baseline sessions was small ( $4 \%$ to $\sim 7 \%$, depending on which domain was observed), yet after 88 (4) days of supplementation, Protandim ${ }^{\circledR}$ did not improve, nor worsen, quality of life ${ }^{17}$. 
Quality of life is a subjective measure of health and well-being frequently used by those in the health fields to assess an individual's satisfaction with various domains of their lives ${ }^{17}$. The full quality of life measure from the World Health Organization (WHOQOL-100) consists of 100 items throughout six domains, and has been shown to be highly reliable ${ }^{17}$. The brief version (WHOQOL-BREF) has been developed to decrease the burden on subjects completing it to allow for more accurate results in some clinical trials ${ }^{17}$. The domains covered in the WHOQOL-BREF are Physical Health, Social Relationships, Psychological Health and Environmental ${ }^{17}$. Bergner noted that during clinical trials, recording and examining quality of life is imperative in order to understand and quantify all potential side-effects or benefits ${ }^{77}$.

As mentioned previously, Protandim ${ }^{\circledR}$ marketed by LifeVantage Corporation is a nutritional supplement comprised of five phytochemicals components supposedly activates the Nuclear factor (erythroid-derived 2)-like 2, (called Nrf2) transcription factor pathway that is integral to several antioxidant enzymes, including $\gamma$-glutamyl cysteine synthase (an enzyme that catalyzes the committed step in glutathione synthesis) ${ }^{74}$. Nrf2 is a basic leucine zipper protein that regulates the expression of antioxidant proteins that protect against oxidative damage triggered by injury and inflammation. Protandim ${ }^{\circledR}$ may induce other endogenous antioxidant enzymes, such as SOD and catalase, while decreasing lipid peroxidation ${ }^{16}$.

There are many studies published using Protandim ${ }^{\circledR 16,20-24,73}$ but only three studies were assessed in human subjects ${ }^{16,20,73}$. Two of those studies examined long-term oxidative damage assessed by serum lipid peroxides (Thiobarbituric acid-reacting substances: TBARS) and found a $\sim 20$ to $\sim 40 \%$ decrease in plasma TBARS after 30 days 
of Protandim ${ }^{\circledR}$ supplementation ${ }^{16,73}$. However, one of these studies was not randomized and not placebo controlled ${ }^{16}$. The third study, a double-blinded, randomized, placebocontrolled trial published in 2012, examined the effect of Protandim ${ }^{\circledR}$ on pulmonary oxidative stress and alveolar permeability in 30 recovering alcoholics ${ }^{20}$. Protandim ${ }^{\circledR}$ was supplemented in 14 subjects at a dose of $1350 \mathrm{mg} /$ day; double the daily dose recommended by the manufacturer) or placebo (in 16 subjects) were administered for 7 days. Relative to placebo-treatment, Protandim ${ }^{\circledR}$ had no significant effects on alveolar epithelial permeability or on oxidative stress (TBARS), epithelial growth factor, fibroblast growth factor, interlukin $1 \beta$, and interlukin-10 levels in bronchoalveolar lavage fluid. Treatment with placebo, however, produced a significant reduction in plasma levels of TBARS by $\sim 28 \%{ }^{20}$. Furthermore, an abstract was published in 2014 in the FASEB journal examining the effects of 30 days of $675 \mathrm{mg} /$ day of Protandim ${ }^{\circledR}$ on serum lipid peroxidation in 13 overweight and/or obese subjects ${ }^{73}$. Ashwagandha is a banned medicinal ingredient in some countries, so the phytochemical piperine was substituted for Ashwagandha in this study. Serum TBARS decreased by $\sim 28 \%$ in the Protandim ${ }^{\circledR}$ (piperine) group. The placebo group, on the other hand, showed no change in serum TBARS post-supplementation. Thus, to date, there were only $\sim 47$ subjects given Protandim ${ }^{\circledR}$ in humans in scientific research studies.

In this study, 19 subjects were given Protandim ${ }^{\circledR}$ for $\sim 88$ days. Serum TBARs were within normal range before the three exercise sessions. Supplementation with Protandim ${ }^{\circledR}$ did not increase serum TBARs at rest (Table 10, Figure 14). Furthermore, acute, strenuous exercise has been shown to increase serum lipid peroxides in humans (Figure 1). As a whole, there was no increase in serum lipid peroxides caused by 
strenuous exercise (Table 10, Figure 19). However, the 5-km races did raise serum lipid peroxides in $21(\sim 55 \%)$ of the subjects, but 88 days of Protandim ${ }^{\circledR}$ supplementation did not attenuate the increase in these subjects compared to the placebo.

The changes in SOD over the supplementation period was not different between groups (Table 10, Figure 14). In a different cohort of subjects ranging from 20 to 80 years of age, SOD has been shown to increase by $\sim 20 \%$ after the same period supplementation (Figure 10), however our runners did not experience a similar increase in SOD while taking Protandim ${ }^{\circledR}$ compared to placebo. After $\sim 30$ and $\sim 88$ days post-supplementation, the increase in SOD was $\sim 25 \%$ and $\sim 66 \%$, respectively, compared to baseline (Table 10, Figure 14), however, this increase was experienced by both groups.

Blood glucose levels taken at rest from baseline to $\sim 88$ days supplementation increased post-exercise in both groups. The average increase post-exercise in blood glucose levels between the two baseline sessions +70 (29) $\mathrm{mg} / \mathrm{dL}(\mathrm{n}=38)$, which is similar to the increase in blood glucose levels experienced $\sim 88$ days post supplementation, with an increase of $+72(41) \mathrm{mg} / \mathrm{dL}(\mathrm{n}=35)($ Table 10). The pre and post exercise glutathione (GSH) values at both baseline sessions decreased by -11 (84) $\mu \mathrm{mol} / \mathrm{L}(\mathrm{n}=38)$, compared to $\sim 88$ days post-supplementation which experienced an increase in GSH of $+43(229) \mu \mathrm{mol} / \mathrm{L}(\mathrm{n}=35)$ (Table 10).

The results of the pre- to post exercise changes in TAC, from baseline to $\sim 88$ days supplementation demonstrated no statistical difference. The average of both baseline weeks had an increase in TAC post exercise of $+0.11(0.05) \mathrm{mmol} / \mathrm{L}(\mathrm{n}=38)$, which is the same as the increase observed at $\sim 88$ days supplementation, $+0.11(0.04) \mathrm{mmol} / \mathrm{L}(\mathrm{n}=35)$ (Table 10). 


\section{Limitations}

There were several limitations of this study. First, the standard deviation in 5-km running times was 2.1 minutes (128 seconds) in this cohort. Thus, to show any small improvement in performance from supplement use given the large standard deviation would require many more participants. However, the effect size in the improvement in performance was small $(<0.2)$, so that it is unlikely that any meaningful change would ever be found with supplementation of Protandim ${ }^{\circledR}$.

Second, the week-to-week variability in oxidative damage as expressed by serum lipid peroxides (resting values, fasted) was $\sim 26 \%$. This is a large variability and includes both biological variability and variability of the assay. According to Mullins and colleagues, the between subject-variability in oxidative stress biomarkers is large, suggesting that there may be responders and non-responders to oxidative stress postexercise $^{19}$. The between-individual coefficients of variation were: plasma F2-isoprostanes (Isop) (152\%), PC (240\%), GPX (130\%) and TAC $(243 \%)^{19}$. In the current study, there were 21 individuals ( $\sim 55 \%$ of the total sample) that experienced increases in oxidative stress from the 5-km race (when averaged over both baseline 5-km sessions). Those subjects that has an increase in TBARS post-race could mean that these particular subjects were unable to regulate redox homeostasis (ie. responders) ${ }^{19}$. The mean increase in TBARS in those 21 individuals that were "responders to oxidative stress" when both baseline 5-km races were averaged, was +1.6 (SD 1.4) $\mu \mathrm{mol} / \mathrm{L}$. As mentioned previously, this represents 11 subjects $(\sim 58 \%)$ in the placebo group, and 10 subjects $(\sim 53 \%)$ of the subjects in Protandim ${ }^{\circledR}$ group. Thus, approximately the same proportion of subjects in 
each group did not show increases in serum peroxides levels triggered by the 5-km race. In a post-hoc analyses, we examined whether those responders had a lower increase in TBARS post-race after the 88 day supplementation period. In the Protandim ${ }^{\circledR}$ group, 5 out of 8 subjects $(\sim 63 \%)$ showed lower increases in serum TBARS concentration postrace, while 8 out of 11 subjects ( $73 \%$ ) in the placebo group showed lower serum TBARS concentration post-race after the 88 day supplementation period. Thus, 88 days of Protandim ${ }^{\circledR}$ supplementation was not able to mitigate the increase in oxidative stress post-race in those responders of oxidative stress.

Third, serum lipid peroxides may have been measured too early post-exercise to show any meaningful increases in oxidative damage. The results of a study conducted by Michailidis et al., demonstrated that there is a range of ideal blood sampling time points after exhaustive aerobic exercise used to assess blood markers of oxidative stress at peak levels ${ }^{39}$. Following the cessation of exercise, each biomarker assessed in the blood can take up to a couple of hours to reach its peak oxidative stress level ${ }^{39}$. For example, the time to highest concentration post exercise for TBARS is $1.2(0.6)$ hours $(95 \% \mathrm{CI}=0.8$ to 1.6 hours post-exercise), and $2.2(0.9)$ hours $(95 \% \mathrm{CI}=1.6$ to 2.8 hours post-exercise) for $\mathrm{TAC}^{39}$. Thus, in an oxidative stress panel, each parameter has an ideal post-exercise sampling time-point, which varies from parameter to parameter. The present study all blood parameters in the oxidative stress panel were measured at the same time postexercise time-point, which was at $\sim 10$ minutes post-exercise, instead of the recommended 48 minutes to 96 minutes post-exercise for serum TBARS ${ }^{39}$. In order to measure serum levels of oxidative damage following an endurance run, multiple blood draws would also need to be performed. However, the cost associated with multiple blood draws for each 
participant at each of the three post-exercise blood sampling time points would be very expensive $^{28}$. In this study, every blood sample sent to Genova Diagnostics cost $\sim \$ 150$, thus for approximately 300 blood samples, the total analyses was $\$ 45,000$. In addition, it is unlikely that we would have been able to retain subjects if those subjects were asked to stay around after their race for an additional 48 to 96 minutes for multiple post-exercise blood draws, especially in a fasted state, hungry, and especially when all these subjects had to make it to work that morning. Despite this limitation, several studies have assessed oxidative damage within 10 minutes post-exercise and the preponderance of the data demonstrate that there should be a measurable increase in serum lipid peroxides post-exercise (Figure 1). As a whole, we did not see an increase in TBARS caused by allout exercise lasting $\sim 20$ minutes (Table 10, Figure 19), but again, as discussed earlier, $\sim 50 \%$ of the subjects were responders to oxidative damage caused by exercise and experienced a measureable acute increase in oxidative stress, and $\sim 50 \%$ were not responders to oxidative damage caused by exercise as assessed by serum TBARS.

Fourth, the validity of serum TBARS in detecting lipid peroxidation has been criticized for a lack of specificity. Serum TBARS is a direct marker of oxidative damage to polyunsaturated fatty acids within cell membranes, otherwise known as lipid peroxidation. But, the levels of serum TBARS are very general and do not precisely pinpoint where the oxidative damage is occurring in the body. However, many human studies have continued use serum lipid peroxides as a marker of oxidative damage (Figure 1), and this study is no different. Nonetheless, serum lipid peroxides does reflect oxidative damage of the heart and liver at rest and immediately post-exercise, as demonstrated in rats ${ }^{4}$. Glutathione levels in the blood also reflect muscle and heart 
glutathione levels at rest and immediately post-exercise ${ }^{4}$, so we believe that our findings are specific to those tissues.

Fifth, there were a many forms that the subjects had to fill out diligently and consistently for $\sim 88$ days, which can be considered another limitation. Subjects selfreported training diary, quality of life questionnaires, food diary recalls, signs-andsymptoms forms were a burden to the subjects. Thus, their diligence, compliance and honesty in filling out these forms could be a limitation and thus we are unsure of the accuracy of their reporting.

Sixth, there may have been compliance issues with the required ingestion of one pill every day for 90 days. Nonetheless, both groups forgot to similarly ingest only $3 \%$ of their allotted amount during the supplementation period. This indicates good compliance.

Seventh, the weather was an issue for a few subjects during the final session. Seven subjects experienced unseasonably hot and humid conditions (Temperature $=$ $71^{\circ} \mathrm{F}$, Humidity $=71 \%$, Dew point $=61^{\circ} \mathrm{F}$ ). According to the following source which adjusts for temperature and dew point ${ }^{79}$, the final times were adjusted down by $2 \%$ for only those seven subjects in that final session only.

The color of the pills could be a final limitation of the study. The inside contents of the placebo pills and the Protandim ${ }^{\circledR}$ pills was visibly different from one another. If the subjects got together and compared their pills with each other by opening the capsules of the individual pills, they may have been able to determine whether they were in the Protandim ${ }^{\circledR}$ group or the placebo group. However, this is just conjecture, and we have no idea how many subjects were that keen or that curious as to the contents of the pills. No 
subject discussed with us that they compared pills with fellow runners, so we are just speculating that this may have been a limitation.

\section{Conclusions}

In conclusion, this study demonstrated these findings:

1. Regular supplementation of Protandim ${ }^{\circledR}$ (675 mg/day for 88 days) did not reduce oxidative damage at rest in healthy athletes as assessed by serum lipid peroxides.

2. Regular supplementation of Protandim ${ }^{\circledR}$ in runners did not reduce the increase in oxidative damage post-race compared to pre-race as assessed by lipid peroxides (TBARS) in runners who were responders to oxidative stress of 5-km running.

3. Regular supplementation of Protandim ${ }^{\circledR}$ did not improve $5-\mathrm{km}$ time trial performance.

4. Regular supplementation of Protandim ${ }^{\circledR}$ did not improve, nor worsen, quality of life in runners.

\section{Future Research Directions}

Athletes are always seeking new ways to improve their athletic performance and the best method may require improving their daily nutrition and removing foods and drinks causing increased oxidative stress ${ }^{59}$. A healthy diet can play a protective role in reducing oxidative stress caused by exercise ${ }^{59}$. However, the adequate intakes of antioxidant micronutrients for athletes is unknown because of a lack of research ${ }^{59}$. Future research should focus on the amount and type of antioxidant supplementation athletes require to reduce oxidative stress and improve their performance ${ }^{59}$. 


\section{REFERENCES}

1. Matsuo M, Kaneko T. Chapter 1. The Chemistry of Reactive Oxygen Species and Related Free Radicals. In: Radak Z, ed. Free Radicals in Exercise and Aging. Champaign, IL: Human Kinetics; 2000, 1-33.

2. Slattery, K. M., Dascombe, B., Wallace, L. K. Bentley, D. J., \& Coutts, A. J. (2014). Effect of N-acetylcysteine on cycling performance after intensified training. Med Sci Sports Exerc., 46(6), 1114-1123. doi: 10.1249/MSS.0000000000000222

3. Ji LL, Hollander J. Chapter 2. Antioxidant Defense: Effects of Aging and Exercise. In: Radak Z, ed. Free Radicals in Exercise and Aging. Champaign, IL: Human Kinetics; 2000, 35-72.

4. Veskoukis, A. S., Nikolaidis, M. G., Kyparos, A., \& Kouretas, D. (2009). Blood reflects tissue oxidative stress depending on biomarker and tissue studied. Free Radical Biology \& Medicine, 47(10), 1371-1374. doi: 10.1016/j.freeradbiomed.2009.07.014

5. Arent, S. M. Pellegrino, J. K., Williams, C. A., DiFabio, D. A., \& Greenwood, J. C. (2010). Nutritional supplementation, performance, and oxidative stress in college soccer players. Journal of Strength and Conditioning Research, 24(4), 1117-1124. doi: 10.1519/JSC.0b013e3181cb70b8.

6. Margonis, K., Fatouros, I.G., Jamurtas, A. Z., Nikolaidis, M. G., Douroudos, I., Chatzinikolaou, A., Mitrakou, A., Mastorakos, G., Papassotiriou, I., Taxildaris, K., \& Kouretas, D. (2007). Oxidative stress biomarkers responses to physical overtraining: 
Implications for diagnosis. Free Radical Biology \& Medicine, 43(6), 901-910. doi:10.1016/j.freeradbiomed.2007.05.022

7. Chandwaney, R., Leichtweis, S., Leeuwenburgh, C., \& Ji, L. L. (1998). Oxidative stress and mitochondrial function in skeletal muscle: effects of aging and exercise training. Age, 2l(3), 109-117. doi: 10.1007/s11357-998-0017-5.

8. Revan, S., Balci, S. S., Pepe, H., Kurtoglu, F., Erol, A.E., \& Akkus, H. (2010). Short duration exhaustive running exercise does not modify lipid hydroperoxide, glutathione peroxides and catalase. Journal of Sports Medicine and Physical Fitness, $50(2), 235-240$.

9. Atalay, M., Lappalainen, J., \& Sen, C. K. (2006). Dietary antioxidants for the athlete. Current Sports Medicine Reports, 5, 182-186.

10. Ristow, M., Zarse, K., Oberbach, A., Kloting, N., Birringer, M., Kiehntopf, M., Stumvoll, M., Kahn, C. R., \& Bluher, M. (2009). Antioxidants prevent health-promoting effects of physical exercise in humans. Procedings of the National Acadamy of Sciences USA, 106(21), 8665-8670. doi: 10.1073/pnas.0903485106

11. Gomez-Cabrera, M. C., Domenech, E., Romagnoli, M., Arduini, A., Borras, C., Pallardo, F, V., Sastre, J., \& Vina, J. (2008). Oral administration of vitamin C decreases muscle mitochondrial biogenesis and hampers training-induced adaptations in endurance performance. The American Journal of Clinical Nutrition, 87(1), 142-149. doi:

10.1249/MSS.0b013e318203afa3.

12. Vina, J., Gomez-Cabrera, M. C., Lloret, A., Marquez, R., Minana, J. B., Pallardo, F. V., \& Sastre, J. (2000). Free radicals in exhaustive physical exercise: mechanism of 
production, and protection by antioxidants. International Union of Biochemistry and Molecular Biology Life, 50(4-5), 271-277.

13. Finaud, J., Scislowski, V., Lac, G., Durand, D., Vidalin, H., Robert, A., \& Filaire, E. (2006). Antioxidant status and oxidative stress in professional rugby players: evolution throughout a season. International Journal of Sports Medicine, 27(2), 87-93.

14. Slattery, K. M., Dascombe, B., Wallace, L. K. Bentley, D. J., \& Coutts, A. J. (2014). Effect of $\mathrm{N}$-acetylcysteine on cycling performance after intensified training. Medicine and Science in Sports and Exercise, 46(6), 1114-1123. doi:

10.1249/MSS.0000000000000222

15. Poljsak, B. (2011). Strategies for reducing or preventing the generation of oxidative stress. Oxidative Medicine and Cellular Longevity, 1-15. doi:

$10.1155 / 2011 / 194586$.

16. Nelson, S. K., Bose, S. K., Grunwald, G. K., Myhill, P., \& McCord, \& J. M. (2006). The induction of human superoxide dismutase and catalase in vivo: a fundamentally new approach to antioxidant therapy. Free Radical Biology \& Medicine, 40(2), 341-347.

17. Skevington, S. M., Lotfy, M., \& O'Connell, K. A., (2004). The World Health Organization's WHOQOL-BREF quality of life assessment: psychometric properties and results of the international field trial. A report from the WHOQOL group. Quality of Life Research, 13(2), 299-310.

18. Kreider, R. B., Wilborn, C. D., Taylor, L., Campbell, B., Almada, A. L., Collins, R., Cooke, M., Earnest, C. P., Greenwood, M., Kalman, D. S., Kerksick, C. M., Kleiner, 
S. M., Leutholtz, B., Lopez, H., Lowery, L. M., Mendel, R., Smith, A., Spano, M., Wildman, R., Willoughby, D. S., Ziegenfuss, T. Z., \& Antonio, J. (2010). ISSN exercise \& sport nutrition review: research and recommendations. Journal of the International Society of Sports Nutrition, 7(1), 5. doi: 10.1186/1550-2783-7-7.

19. Mullins, A. L., van Rosendal, S. P., Briskey, D. R., Fassett, R. G., Wilson, G. R., \& Coombes, J. S. (2013). Variability in oxidative stress biomarkers following a maximal exercise test. Biomarkers, 18(5), 446-454. doi: 10.3109/1354750X.2013.810668.

20. Burnham, E. L., McCord, J. M., Bose, S., Brown, L. A., House, R., Moss, M., \& Gaydos, J. (2012). Protandim ${ }^{\circledR}$ does not influence alveolar epithelial permeability or intrapulmonary oxidative stress in human subjects with alcohol use disorders. American Journal of Physiology. Lung Cellular and Molecular Physiology, 302(7), 688-699. doi: 10.1152/ajplung.00297.2011

21. Joddar, B., Reen, R. K., Firstenberg, M. S., Varadharaj, S., McCord, J. M., Zweier, J. L., \& Gooch, K. J. (2011). Protandim ${ }^{\circledR}$ attenuates intimal hyperplasia in human saphenous veins cultured ex vivo via a catalase-dependent pathway. Free Radical Biology \& Medicine,50(6), 700-709. doi: 10.1016/j.freeradbiomed.2010.12.008

22. Qureshi, M. M., McClure, W. C., Arevalo, N. L., Rabon, R. E., Mohr, B., Bose, S. K., McCord, J. M., \& Tseng, B. S. (2010). The Dietary Supplement Protandim ${ }^{\circledR}$ Decreases Plasma Osteopontin and Improves Markers of Oxidative Stress in Muscular Dystrophy Mdx Mice. Journal of Dietary Supplements, 7(2), 159-178.

doi: $10.3109 / 19390211.2010 .482041$

23. Liu, J., Gu, X., Robbins, D., Li, G., Shi, R., McCord, J. M., \& Zhao, Y. (2009). Protandim ${ }^{\circledR}$, a fundamentally new antioxidant approach in chemoprevention using mouse 
two-stage skin carcinogenesis as a model. PLoS One, 4(4), e5284. doi:

10.1371/journal.pone.0005284

24. Velmurugan, K., Alam, J., McCord, J. M., \& Pugazhenthi, S. (2009). Synergistic induction of heme oxygenase- 1 by the components of the antioxidant supplement Protandim ${ }^{\circledR}$. Free Radical Biology \& Medicine, 46(3), 430-440. doi:

10.1016/j.freeradbiomed.2008.10.050

25. Kyparos, A., Vrabas, I. S., Nikolaidis, M. G., Riganas, C. S., \& Kouretas, D. (2009). Increased oxidative stress blood markers in well-trained rowers following two thousand-meter rowing ergometer race. The Journal of Strength and Conditioning Research, 23(5), 1418-1426. doi: 10.1519/JSC.0b013e3181a3cb97.

26. Carmeli, E., Lavian, G., \& Reznick, A. Z. Chapter 3. The Role of Antioxidant Nutrition in Exercise and Aging. In: Radak Z, ed. Free Radicals in Exercise and Aging. Champaign, IL: Human Kinetics; 2000, 73-115.

27. (2009). Oxidative Stress Analysis 2.0. Genova Diagnostics. Retrieved from: http://www.gdx.net/core/interpretive-guides/Oxidative-Stress-Interp-Guide.pdf

28. Kyparos, A., Riganas, C., Nikolaidis, M. G., Sampanis, M., Koskolou, M. D., Grivas, G. V., Kouretas, D., \& Vrabas, I. S. (2012). The effect of exercise-induced hypoxemia on blood redox status in well-trained rowers. European Journal of Applied Physiology, 112(6), 2073-2083. doi: 10.1007/s00421-011-2175-x.

29. (2012). Oxidative Stress Analysis 2.0. Genova diagnostics. Retrieved from: http://www.gdx.net/core/one-page-test-descriptions/Oxidative-Stress2-Test Description.pdf 
30. Andrade, F. H. Chapter 4. Reactive Oxygen Species and Skeletal Muscle

Function. In: Radak Z, ed. Free Radicals in Exercise and Aging. Champaign, IL: Human Kinetics; 2000, 117-148.

31. Commoner, B., Townsend, J., \& Pake, G. E. (1954). Free radicals in biological materials. Nature, 174(4432), 689-691.

32. Koren, A., Schara, M., \& Sentjurc, M. (1980). EPR measurements of free radicals during tetanic contractions of frog skeletal muscle. Periodicum Biologorum, 82, 399401.

33. Davies, K. J., Quintanilha, A. T., Brooks, G. A., Packer, L. (1982). Free radicals and tissue damage produced by exercise. Biochemical and Biophysical Research Communications, 107(4), 1198-1205.

34. Pepe, H., Balci, S.S., Revan, S., Akalin, P. P., \& Kurtoğlu, K. (2009). Comparison of oxidative stress and antioxidant capacity before and after running exercises in both sexes. Gender Medicine, 6(4), 587-595. doi: 10.1016/j.genm.2009.10.001.

35. Ogonovszky, H., Sasvari, M., Dosek, A., Berkes, I., Kaneko, T., Tahara, S., Nakamoto, H., Goto, S., \& Radak, Z. (2005). The effects of moderate, strenuous, and overtraining on oxidative stress markers and DNA repair in rat liver. Canadian Journal of Applied Physiology, 30(2), 186-195.

36. Gomez-Cabrera, M. C., Domenech, E., \& Vina, J. (2008). Moderate exercise is an antioxidant: upregulation of antioxidant genes by training. Free Radical Biology \& Medicine, 44(2), 126-131. doi: 10.1016/j.freeradbiomed.2007.02.001.

37. Chen, H. J. \& Chiu, W. L. (2005). Association between cigarette smoking and urinary excretion of 1,N2-ethenoguanine measured by isotope dilution liquid 
chromatography-electrospray ionization/tandem mass spectrometry. Chemical Research in Toxicology, 18(10), 1593-1599.

38. Kabasakalis, A, Kyparos, A., Tsalis, G., Loupos, D., Pavlidou, A., \& Kouretas, D. (2011). Blood oxidative stress markers after ultramarathon swimming. Journal of Strength and Conditioning Research, 25(3), 805-811. doi:

10.1519/JSC.0b013e3181d0b109.

39. Michailidis, Y., Jamurtas, A. Z., Nikolaidis, M. G., Fatouros, I. G., Koutedakis, Y., Papassotiriou, I., \& Kouretas, D. (2007). Sampling time is crucial for measurement of aerobic exercise-induced oxidative stress. Medicine and Science in Sports and Exercise, 39(7), 1107-1113. doi: 10.1249/01.mss.0b013e318053e7ba

40. Fisher, G., Schwartz, D. D., Quindry, J., Barberio, M. D., Foster, E. B., Jones, K. W., \& Pascoe, D. D. (2011). Lymphocyte enzymatic antioxidant responses to oxidative stress following high-intensity interval exercise. Journal of Applied Physiology, 110(3), 730-737. doi: 10.1152/japplphysiol.00575.2010.

41. Rokitzki, L., Logemann, E., Sagredos, A. N., Murphy, M., Wetzel-Roth, W., \& Keul, L. (1994). Lipid peroxidation and antioxidative vitamins under extreme endurance stress. Acta Physiologica Scandinavica, 151(2), 149-158.

42. Margaritis, I., Tessier, F., Richard, M. J., \& Marconnet, P. (1997). No evidence of oxidative stress after a triathlon race in highly trained competitors. International Journal of Sports Medicine, 18(3), 186-190.

43. Vezzoli, A., Pugliese, L., Marzorati, M., Serpiello, F. R., La Torre, A., \& Porcelli, S. (2014). Time-course changes of oxidative stress response to high-intensity 
discontinuous training versus moderate-intensity continuous training in masters runners. PLoS One, 9(1), doi: 10.1371/journal.pone.0087506

44. Alessio, H. M., Goldfarb, A. H., \& Cao, G. (1997). Exercise-induced oxidative stress before and after vitamin C supplementation. International Journal of Sport Nutrition, 7(1), 1-9.

45. Vider, J., Lehtmaa, J., Kullisaar, T., Vihalemm, T., Zilmer, K., Kairane, C., Landor, A., Karu, T., \& Zilmer, M. (2001). Acute immune response in respect to exercise-induced oxidative stress. Pathophysiology, 7, 263-270.

46. Revan, S. (2011). Effects of acute high-intensity aerobic and anaerobic exercise on oxidative damage to lipids, proteins and DNA in untrained subjects. African Journal of Pharmacy and Pharmacology, 5(10), 1321-1326. doi: 10.5897/AJPP11.456

47. Maughan, R. J., Donnelly, A. E., Gleeson, M., Whiting, P. H., Walker, K. A., \& Clough, P. J. (1989). Delayed-onset muscle damage and lipid peroxidation in man after a downhill run. Muscle \& Nerve, 12(4), 332-336.

48. Diaz, K. M., Feairheller, D. L., Sturgeon, K. M., Williamson, S. T., \& Brown, M. D. (2011). Oxidative stress response to short duration bout of submaximal aerobic exercise in healthy young adults. International Journal of Exercise Science, 4(4), 247256. PMCID: PMC3856905

49. Fatouros, I. G., Jamurtas, A. Z., Villiotou, V., Pouliopoulou, S., Fotinakis, P., Taxildaris, K., \& Deliconstantinos, G. (2004). Oxidative stress responses in older men during endurance training and detraining. Medicine and Science in Sports and Exercise, 36(12), 2065-2072. 
50. Duthie, G. G., Robertson, J. D., Maughan, R. J., Morrice, P. C. (1990). Blood antioxidant status and erythrocyte lipid peroxidation following distance running. Archives of Biochemistry and Biophysics, 282(1), 78-83.

51. Feairheller, D. L., Diaz, K. M., Sturgeon, K. M., Williamson, S. T., \& Brown, M. D. (2011). Racial differences in the time-course oxidative stress responses to acute exercise. Journal of Exercise Physiology Online, 14(1), 49-59. PMID: 21691463

52. Bogdanis, G. C., Stavrinou, P., Fatouros, I. G., Philippou, A., Chatzinikolaou, A., Draganidis, D., Ermidis, G., \& Maridaki, M. (2013). Short-term high-intensity interval exercise training attenuates oxidative stress responses and improves antioxidant status in healthy humans. Food Chemical Toxicology, 61, 171-177. doi:10.1016/j.fct.2013.05.046 53. Inayama, T., Kumagai, Y., Sakana, M., Saito, M., \& Matsuda, M. (1996). Plasma protein-bound sulfhydryl group oxidation in humans following a full marathon race. Life Sciences, 59(7), 573-578.

54. Marzatico, F., Pansarasa, O., Bertorelli, L., Somenzini, L., \& Della Valle, G. (1997). Blood free radical antioxidant enzymes and lipid peroxides following longdistance and lactacidemic performances in highly trained aerobic and sprint athletes. $J$ Sports Medicine and Physical Fitness, 37(4), 235-239.

55. Miyazaki, H., Oh-ishi, S., Ookawara, T., Kizaki, T., Toshinai, K., Ha, S., Haga, S., Ji, L. L., \& Ohno, H. (2001). Strenuous endurance training in humans reduces oxidative stress following exhausting exercise. European Journal of Applied Physiology, 84(1-2), 1-6. 
56. Bloomer, R. J., Goldfarb, A. H., Wideman, L., McKenzie, M. J., \& Consitt, L. A. (2005). Effects of acute aerobic and anaerobic exercise on blood markers of oxidative stress. Journal of Strength and Conditioning Research, 19(2), 276-285.

57. Leonardo- Mendonca, R. C., Concepcion-Huertas, M., Guerra-Hernandez, E., Zabala, M., Escames, G., Acuna-Castroviejo, D. (2014). Redox status and antioxidant response in professional cyclists during training. European Journal of Sport Science, 14(8), 830-838. doi: 10.1080/17461391.2014.915345

58. Elosua, R., Molina, L., Fito, M., Arquer, A., Sanchez-Quesada, J. L., Covas, M. I., Ordonez-Llanos, J., Marrugat, J. (2003). Response of oxidative stress biomarkers to a 16-week aerobic physical activity program, and to acute physical activity, in healthy young men and women. Atherosclerosis, 167(2), 327-334.

59. Margaritis, I., \& Rousseau, A. S. (2008). Does physical exercise modify antioxidant requirements?. Nutrition Research Reviews, 21, 3-12.

60. Jacob, R. A., Aiello, G. M., Stephensen, C. B., Blumberg, J. B., Milbury, P. E., Wallock, L. M., \& Ames, B. N. (2003). Moderate antioxidant supplementation has no effect on biomarkers of oxidant damage in healthy men with low fruit and vegetable intakes. The Journal of Nutrition, 133(3), 740-743.

61. Van den Berg, R., van Vilet, T., Broekmans, W. M., Cnubben, N. H., Vaes, W. H., Roza, L., Haenen, G. R., Bast, A., \& van den Berg, H. (2001). A vegetable/fruit concentrate with high antioxidant capacity has no effect on biomarkers of antioxidant statud in male smokers. The Journal of Nutrition, 131(6), 1712-1722. 
62. Moller, P., Vogel, U., Pedersen, A., Dragsted, L. O., Sandstrom, B., \& Loft, S. (2003). No effect of 600 grams fruit and vegetables per day on oxidative DNA damage and repair in healthy nonsmokers. Cancer Epidemiology, Biomarkers \& Prevention, 12(10), 1016-1022.

63. Kanter, M. (1998). Free radicals, exercise and antioxidant supplementation. Proceedings of the Nutritiona Society, 57(1), 9-13.

64. Chandra, R. K., \& McBean, L. D. (1994). Zinc and immunity. Nutrition, 10(1), 79-80.

65. Sharman, I. M., Down, M. G., \& Sen, R. N. (1971). The effects of vitamin E and training on physiological function and athletic performance in adolescent swimmers. The British Journal of Nutrition, 26(2), 265-276.

66. Ali, S. S., Xiong, C., Lucero, J., Behrens, M. M., Dugan, L. L., \& Quick, K. L. (2006). Gender differences in free radical homeostasis during aging: shorter-lived female C57BL6 mice have increased oxidative stress. Aging Cell, 5(6), 565-574.

67. Chen, B., Lu, Y., Chen, Y., \& Cheng, J. (2015). The role of Nrf2 in oxidative stress-induced endothelial injuries. Journal of Endocrinology, 225(3), R83-R99. pii: JOE$14-0662$.

68. Schafer, M., \& Werner, S. (2015). Nrf2-A regulator of keratinoctye redox signaling. Free Radical Biology \& Medicine. doi.org/10.1016/j.freeradbiomed.2015.04.018

69. Physical Activity Readiness Questinniare (PAR-Q): http://www.csep.ca/cmfiles/publications/parq/par-q.pdf. Canadian Society for Exercise Physiology; 2002. 
70. Jeukendrup, A. E, \& Currell, K. (2005). Should time trial performance be predicted from three serial time-to-exhaustion tests? Medicine and Science in Sports and Exercise, 37(10):1820; author reply 1821.

71. Nikolaidis, M. G, Paschalis, V., Giakas, G., Fatouros, I. G., Koutedakis, Y., Kouretas, D., \& Jamurtas, A. Z. (2007). Decreased blood oxidative stress after repeated muscle-damaging exercise. Medicine and Science in Sports and Exercise, 39(7), 10801089. doi: $10.1249 / \mathrm{mss} .0 \mathrm{~b} 013 \mathrm{e} 31804 \mathrm{ca} 10 \mathrm{c}$

72. Nikolaidis, M. G., Jamurtas, A. Z., Paschalis ,V., Fatouros, I. G., Koutedakis, Y., \& Kouretas, D. (2008). The effect of muscle-damaging exercise on blood and skeletal muscle oxidative stress: magnitude and time-course considerations. Sports Medicine, 38(7), 579-606.

73. Scalzo, R., Davis, J., Beals, J., Biela, L., Giordano, G., Paris, H. Miller, B., Hamilton, K., Bell, C. (2014). Oxidative stress is decreased with short-term Protandim ${ }^{\circledR}$ use when piperine is substituted for ashwagandha [abstract]. FASEB Journal, 28: LB399. 74. Tan, X. L, Spivack, S.D (2009). Dietary chemoprevention strategies for induction of phase II xenobiotic-metabolizing enzymes in lung carcinogenesis: a review. Lung Cancer 65: 129-137. doi: 10.1016/j.lungcan.2009.01.002

75. Bland, J. M., Altman, D. G. (1996) Measurement error. British Medical Journal. 312(7047), 1654.

76. Hopkins, W. G. (2000). Measures of reliability in sports medicine and science. Sports Medicine 30(1), 1-15.

77. Bergner, M. (1989). Quality of life, health status, and clinical research. Medical Care, 27(3 Suppl), S148-S156 
78. Age Grading. http://www.usatf.org/statistics/calculators/agegrading/. USATF; 2015.

79. Temperature and dew point for pace adjustments.

http://maximumperformancerunning.blogspot.com/2013/07/temperature-dew-point.html. Maximum Performance Running; 2013. 
Table 1. Blood parameters measured by Genova Diagnostics ${ }^{29}$ :

\begin{tabular}{|c|c|c|}
\hline Parameter & Method of analysis & Reference range \\
\hline \multicolumn{3}{|l|}{ Reserve } \\
\hline Glutathione (GSH) & Colorimetric assay & $\geq 669 \mu \mathrm{mol} / \mathrm{L}$ \\
\hline Total Antioxidant Capacity & Enzymatic reaction & $\geq 0.54 \mathrm{mmol} / \mathrm{L}$ \\
\hline (TAC) & assay & \\
\hline Cysteine (Cys-SH) & Colorimetric assay & 0.61 to $1.16 \mathrm{mg} / \mathrm{dL}$ \\
\hline Sulfate & Turbidimetric assay & 3.0 to $5.9 \mathrm{mg} / \mathrm{dL}$ \\
\hline Cysteine to Sulfate ratio & - & 0.12 to 0.32 \\
\hline Cystine (Cys-S-S-Cys) & Colorimetric assay & 1.60 to $3.22 \mathrm{mg} / \mathrm{dL}$ \\
\hline Cysteine/Cystine Ratio & - & 0.23 to 0.53 \\
\hline \multicolumn{3}{|l|}{ Protective Enzymes } \\
\hline Glutathione Peroxidase (GPX) & $\begin{array}{c}\text { Enzymatic reaction } \\
\text { assay }\end{array}$ & 20 to $38 \mathrm{U} / \mathrm{g} \mathrm{Hb}$ \\
\hline Superoxide Dismutase (SOD) & Colorimetric assay & 5275 to $1662 \mathrm{U} / \mathrm{g} \mathrm{Hb}$ \\
\hline \multicolumn{3}{|l|}{ Damage } \\
\hline Lipid Peroxides & $\begin{array}{c}\text { Thiobarbituric acid- } \\
\text { reacting substances } \\
\text { (TBARS) assay }\end{array}$ & $<10 \mu \mathrm{mol} / \mathrm{L}$ \\
\hline
\end{tabular}


Table 2. Baseline anthropometric characteristics, baseline 5-km time-trial results, and baseline fasting blood glucose results

\begin{tabular}{|c|c|c|c|c|}
\hline Variables & $\begin{array}{l}\text { Protantim } \\
(n=19)\end{array}$ & $\begin{array}{c}\text { Placebo } \\
(n=19)\end{array}$ & $\begin{array}{c}p- \\
\text { value }\end{array}$ & $\begin{array}{c}\text { Combined } \\
\text { Mean } \\
(n=38) \\
\end{array}$ \\
\hline Age (yrs) & $\begin{array}{c}34(6) \\
{[23 \text { to } 44]}\end{array}$ & $\begin{array}{c}35(8) \\
{[20 \text { to } 46]}\end{array}$ & 0.56 & $\begin{array}{c}34(7) \\
{[20 \text { to } 46]}\end{array}$ \\
\hline Weight (kg) & $\begin{array}{c}68.1(11.4) \\
{[42.6 \text { to } 88.6]}\end{array}$ & $\begin{array}{c}64.6(11.1) \\
{[47.5 \text { to } 88.5]}\end{array}$ & 0.34 & $\begin{array}{c}66.4(11.2) \\
{[42.6 \text { to } 88.6]}\end{array}$ \\
\hline Height (cm) & $\begin{array}{c}174(10) \\
{[155 \text { to } 191]}\end{array}$ & $\begin{array}{c}171(11) \\
{[155 \text { to } 188]}\end{array}$ & 0.30 & $\begin{array}{c}172(11) \\
{[155 \text { to } 191]}\end{array}$ \\
\hline $\mathrm{BMI}\left(\mathrm{kg} / \mathrm{m}^{2}\right)$ & $\begin{array}{c}22.3(2.1) \\
{[17.7 \text { to } 26.3]}\end{array}$ & $\begin{array}{c}22.1(2.7) \\
{[18.6 \text { to } 27.6]}\end{array}$ & 0.82 & $\begin{array}{c}22.2(2.4) \\
{[17.7 \text { to } 27.6]}\end{array}$ \\
\hline 5-km time ( $\mathrm{sec})$ & $\begin{array}{c}1225(136) \\
{[1047 \text { to } 1450]}\end{array}$ & $\begin{array}{c}1210(121) \\
{[1029 \text { to } 1469]}\end{array}$ & 0.72 & $\begin{array}{c}1217(128) \\
{[1029 \text { to } 1469]}\end{array}$ \\
\hline 5-km time (min) & $\begin{array}{c}20.4(2.3) \\
{[17.5 \text { to } 24.2]}\end{array}$ & $\begin{array}{c}20.2(2.0) \\
{[17.2 \text { to } 24.5]}\end{array}$ & 0.72 & $\begin{array}{c}20.3(2.1) \\
{[17.2 \text { to } 24.5]}\end{array}$ \\
\hline $\begin{array}{l}\% \text { of world record } \\
\text { for age and gender }\end{array}$ & $\begin{array}{c}68 \%(4 \%) \\
{[61 \% \text { to } 76 \%]}\end{array}$ & $\begin{array}{c}69 \%(6 \%) \\
{[60 \% \text { to } 81 \%]}\end{array}$ & 0.34 & $\begin{array}{c}69 \%(5 \%) \\
{[60 \% \text { to } 81 \%]}\end{array}$ \\
\hline $\begin{array}{l}\text { Fasting blood } \\
\text { glucose }(\mathrm{mg} / \mathrm{dL})\end{array}$ & $\begin{array}{c}90(5) \\
{[81 \text { to } 97]}\end{array}$ & $\begin{array}{c}89(9) \\
{[73 \text { to } 104]}\end{array}$ & 0.73 & $\begin{array}{c}90(7) \\
{[73 \text { to } 104]}\end{array}$ \\
\hline \multicolumn{5}{|c|}{$\begin{array}{l}\text { Mean (SD), [range], } 22 \text { subjects ( } 58 \% \text { of the sample) was classified as Local Class, } 15 \\
\text { subjects ( } 40 \% \text { of the sample) was classified as Regional Class, one subject ( } 3 \% \text { of the } \\
\text { sample) was classified as National Class. Baseline } 5-\mathrm{km} \text { time trial performance was taken } \\
\text { as the best result between two baseline } 5-\mathrm{km} \text { time trials held one week apart. Baseline } \\
\text { fasting blood glucose values was the average fasting blood glucose values for both } \\
\text { baseline sessions held one week apart. All variables were normally distributed (Shapiro- } \\
\text { Wilk test } p>0.05 \text { for all). }\end{array}$} \\
\hline
\end{tabular}


Table 3. Baseline blood results.

\begin{tabular}{|c|c|c|c|c|c|}
\hline Variables & $\begin{array}{l}\text { Protandim }^{\circledR} \\
\quad(n=19)\end{array}$ & $\begin{array}{c}\text { Placebo } \\
(n=19)\end{array}$ & $\begin{array}{c}p- \\
\text { value }\end{array}$ & $\begin{array}{c}\text { Combined } \\
\text { Mean } \\
(\mathbf{n}=\mathbf{3 8})\end{array}$ & $\begin{array}{l}\text { Reference } \\
\text { Range }\end{array}$ \\
\hline \multicolumn{6}{|l|}{ Reserve } \\
\hline $\begin{array}{l}\text { Glutathione (GSH) } \\
(\mu \mathrm{mol} / \mathrm{L}) \geq 669\end{array}$ & $\begin{array}{c}1051(148) \\
{[785 \text { to } 1412]}\end{array}$ & $\begin{array}{c}1016(189) \\
{[740 \text { to } 1370]}\end{array}$ & 0.54 & $\begin{array}{c}1033(169) \\
{[740 \text { to } 1412]}\end{array}$ & $\geq 669$ \\
\hline $\begin{array}{l}\text { Total Antioxidant } \\
\text { Capacity (TAC) } \\
\text { (mmol/L) }\end{array}$ & $\begin{array}{c}0.86(0.07) \\
{[0.73 \text { to } 1.05]}\end{array}$ & $\begin{array}{c}0.85(0.06) \\
{[0.52 \text { to } 0.79]}\end{array}$ & 0.98 & $\begin{array}{c}0.86(0.06) \\
{[0.73 \text { to } 1.05]}\end{array}$ & $\geq 0.54$ \\
\hline Cysteine (mg/dL) & $\begin{array}{c}0.67(0.13) \\
{[0.40 \text { to } 0.87]}\end{array}$ & $\begin{array}{c}0.63(0.07) \\
{[0.52 \text { to } 0.79]}\end{array}$ & 0.29 & $\begin{array}{c}0.65(0.11) \\
{[0.40 \text { to } 0.87]}\end{array}$ & $0.46-1.20$ \\
\hline Cystine (mg/dL) & $\begin{array}{c}2.1(0.4) \\
{[1.4 \text { to } 3.0]}\end{array}$ & $\begin{array}{c}2.2(0.3) \\
{[1.6 \text { to } 3.0]}\end{array}$ & 0.14 & $\begin{array}{c}2.1(0.4) \\
{[1.4 \text { to } 3.0]}\end{array}$ & $1.6-3.2$ \\
\hline $\begin{array}{l}\text { Cysteine to Cystine } \\
\text { ratio }\end{array}$ & $\begin{array}{c}0.34(0.11) \\
{[0.18 \text { to } 0.59]}\end{array}$ & $\begin{array}{c}0.29(0.07) \\
{[0.21 \text { to } 0.48]}\end{array}$ & 0.14 & $\begin{array}{c}0.32(0.09) \\
{[0.18 \text { to } 0.59]}\end{array}$ & $0.17-0.50$ \\
\hline Sulphate (mg/dl) & $\begin{array}{c}3.8(0.4) \\
{[2.9 \text { to } 4.7]}\end{array}$ & $\begin{array}{c}3.9(0.9) \\
{[2.7 \text { to } 5.9]}\end{array}$ & 0.60 & $\begin{array}{c}3.9(0.7) \\
{[2.7 \text { to } 5.9]}\end{array}$ & $3.0-5.9$ \\
\hline $\begin{array}{l}\text { Cysteine to Sulphate } \\
\text { ratio }\end{array}$ & $\begin{array}{c}0.18(0.05) \\
{[0.09 \text { to } 0.27]}\end{array}$ & $\begin{array}{c}0.17(0.04) \\
{[0.09 \text { to } 0.25]}\end{array}$ & 0.51 & $\begin{array}{c}0.18(0.04) \\
{[0.09 \text { to } 0.27]}\end{array}$ & $0.12-0.32$ \\
\hline $\begin{array}{l}\text { Protective enzymes } \\
\text { Superoxide } \\
\text { dismutase (SOD, } \\
\mathrm{U} / \mathrm{g} \mathrm{Hb} \times 1000)\end{array}$ & $\begin{array}{c}11.4(3.1) \\
{[6.0 \text { to } 17.9]}\end{array}$ & $\begin{array}{c}11.7(3.7) \\
{[4.0 \text { to } 18.5]}\end{array}$ & 0.79 & $\begin{array}{c}11.5(3.4) \\
{[4.0 \text { to } 18.5]}\end{array}$ & $5.3-16.7$ \\
\hline $\begin{array}{l}\text { Glutathione } \\
\text { Peroxidase (GPX, } \\
\text { U/g Hb) }\end{array}$ & $\begin{array}{c}28.1(4.6) \\
{[22.1 \text { to } 36.6]}\end{array}$ & $\begin{array}{c}28.4(7.4) \\
{[18.7 \text { to } 43.2]}\end{array}$ & 0.87 & $\begin{array}{c}28.2(6.1) \\
{[18.7 \text { to } 43.2]}\end{array}$ & $20-38$ \\
\hline $\begin{array}{l}\text { Damage } \\
\text { Lipid Peroxides } \\
\text { (TBARs, } \mu \mathrm{mol} / \mathrm{L} \text { ) }\end{array}$ & $\begin{array}{c}8.2(2.0) \\
{[5.1 \text { to } 11.6]}\end{array}$ & $\begin{array}{c}7.9(1.9) \\
{[4.8 \text { to } 10.8]}\end{array}$ & 0.67 & $\begin{array}{c}8.0(1.9) \\
{[4.8 \text { to } 11.6]}\end{array}$ & $\leq 10$ \\
\hline
\end{tabular}

Mean (SD), [range], baseline blood parameters in a fasted state was determined to be the mean of two baseline sessions held one week apart. All variables were normally distributed except for the cysteine to cystine ratio and GSH. For GSH, one extreme outlier was removed. A non-parametric Mann Whitney $t$-test was use to compare groups for the cysteine to cystine ratio. 
Table 4. The week to week coefficient of variation in the blood variables. All blood variables were measured by Genova Diagnostics $(n=38)$.

\begin{tabular}{|c|c|c|c|}
\hline Blood Profile components & $\begin{array}{l}\text { Week-to-week } \\
\text { coefficient of } \\
\text { variation }(\%) \\
\text { (at rest, fasted) }\end{array}$ & $\begin{array}{c}\text { Correlation } \\
\text { between session } \\
1 \text { at baseline } \\
\text { versus session } 2 \\
\text { at baseline (r) }\end{array}$ & $\begin{array}{l}\text { Percent of shared } \\
\text { variance between } \\
\text { both baseline } \\
\text { sessions } \\
\left(r^{2} \times 100\right)\end{array}$ \\
\hline $\begin{array}{l}\text { RESERVE } \\
\text { Glutathione (GSH) }(\mu \mathrm{mol} / \mathrm{L})\end{array}$ & $16 \%$ & $\begin{array}{c}0.52^{*} \\
{[0.24 \text { to } 0.72]}\end{array}$ & $\begin{array}{c}27 \% \\
{[6 \% \text { to } 52 \%]}\end{array}$ \\
\hline $\begin{array}{l}\text { Total Antioxidant Capacity } \\
\text { (TAC) } \\
(\mathrm{mmol} / \mathrm{L})\end{array}$ & $7 \%$ & $\begin{array}{c}0.45^{*} \\
{[0.15 \text { to } 0.67]}\end{array}$ & $\begin{array}{c}20 \% \\
{[2 \% \text { to } 45 \%]}\end{array}$ \\
\hline Cysteine (mg/dL) & $19 \%$ & $\begin{array}{c}0.24 \\
{[-0.08 \text { to } 0.52]}\end{array}$ & $\begin{array}{c}6 \% \\
{[1 \% \text { to } 27 \%]}\end{array}$ \\
\hline Cystine (mg/dL) & $13 \%$ & $\begin{array}{c}0.62^{*} \\
{[0.37 \text { to } 0.78]}\end{array}$ & $\begin{array}{c}38 \% \\
{[14 \% \text { to } 61 \%]}\end{array}$ \\
\hline Cysteine to Cystine ratio & $27 \%$ & $\begin{array}{c}0.41^{*} \\
{[0.11 \text { to } 0.65]}\end{array}$ & $\begin{array}{c}17 \% \\
{[1 \% \text { to } 42 \%]}\end{array}$ \\
\hline Sulphate (mg/dL) & $19 \%$ & $\begin{array}{c}0.40^{*} \\
{[0.10 \text { to } 0.64]}\end{array}$ & $\begin{array}{c}16 \% \\
{[1 \% \text { to } 41 \%]}\end{array}$ \\
\hline Cysteine to Sulphate ratio & $24 \%$ & $\begin{array}{c}0.37^{*} \\
{[0.06 \text { to } 0.62]}\end{array}$ & $\begin{array}{c}14 \% \\
{[0 \% \text { to } 37 \%]}\end{array}$ \\
\hline $\begin{array}{l}\text { PROTECTIVE ENZYMES } \\
\text { Superoxide Dismutase (SOD) } \\
\text { (U/g Hb) }\end{array}$ & $24 \%$ & $\begin{array}{c}0.52^{*} \\
{[0.24 \text { to } 0.72]}\end{array}$ & $\begin{array}{c}27 \% \\
{[6 \% \text { to } 52 \%]}\end{array}$ \\
\hline $\begin{array}{l}\text { Glutathione Peroxidase (GPX) } \\
\text { (U/g Hb) }\end{array}$ & $15 \%$ & $\begin{array}{c}0.80^{*} \\
{[0.64 \text { to } 0.89]}\end{array}$ & $\begin{array}{c}64 \% \\
{[41 \% \text { to } 79 \%]}\end{array}$ \\
\hline $\begin{array}{l}\text { DAMAGE } \\
\text { Lipid peroxides (TBARS, } \\
\mu \mathrm{mol} / \mathrm{L})\end{array}$ & $26 \%$ & $\begin{array}{c}0.37^{*} \\
{[0.06 \text { to } 0.62]}\end{array}$ & $\begin{array}{c}14 \% \\
{[0 \% \text { to } 38 \%]}\end{array}$ \\
\hline $\begin{array}{l}\text { OTHER } \\
\text { Fasting Blood Glucose (mg/dL) }\end{array}$ & $5 \%$ & $\begin{array}{c}0.64 * \\
{[0.40 \text { to } 0.80]}\end{array}$ & $\begin{array}{c}41 \% \\
{[16 \% \text { to } 64 \%]}\end{array}$ \\
\hline
\end{tabular}

Brackets signify the $95 \%$ confidence interval. * The correlation between baseline week 1 and baseline week 2 is statistically significant $p<0.05$ 
Table 5. Genova Diagnostic's intra and inter-assay coefficient of variation for most parameters in the oxidative stress panel.

\begin{tabular}{|c|c|c|}
\hline Blood Profile components & $\begin{array}{l}\text { Acceptable coefficient of } \\
\text { variation for replicates } \\
\text { from the same sample; } \\
\text { assayed at a different } \\
\text { time point }\end{array}$ & $\begin{array}{c}\text { Coefficient of } \\
\text { variation }(\%) \text { of } \\
\text { current controls }\end{array}$ \\
\hline $\begin{array}{l}\text { Reserve } \\
\text { Glutathione (GSH) }(\mu \mathrm{mol} / \mathrm{L})\end{array}$ & $25 \%$ & $18 \%$ \\
\hline $\begin{array}{l}\text { Total Antioxidant Capacity (TAC) } \\
(\mathrm{mmol} / \mathrm{L})\end{array}$ & $25 \%$ & $9 \%$ \\
\hline Cysteine (mg/dL) & $25 \%$ & $16 \%$ \\
\hline Cystine (mg/dL) & $25 \%$ & $16 \%$ \\
\hline Sulphate (mg/dL) & $25 \%$ & $18 \%$ \\
\hline \multicolumn{3}{|l|}{ Protective enzymes } \\
\hline $\begin{array}{l}\text { Superoxide Dismutase (SOD) } \\
\text { (U/g Hb) }\end{array}$ & $30 \%$ & $27 \%$ \\
\hline $\begin{array}{l}\text { Glutathione Peroxidase (GPX) } \\
\text { (U/g Hb) }\end{array}$ & $25 \%$ & $15 \%$ \\
\hline \multicolumn{3}{|l|}{ Damage } \\
\hline Lipid peroxides (TBARS, $\mu \mathrm{mol} / \mathrm{L}$ ) & $30 \%$ & $16 \%$ \\
\hline
\end{tabular}


Table 6. The aerobic training index between groups. This is the total amount of physical activity in minutes over a two week period multiplied by the average rating of perceived exertion value.

\begin{tabular}{|c|c|c|c|}
\hline Variables & $\begin{array}{c}\text { Baseline (pre- } \\
\text { supplementation) }\end{array}$ & $\begin{array}{c}88 \text { days post- } \\
\text { supplementation }\end{array}$ & $\begin{array}{c}\text { Mean } \\
\text { Difference } \\
(\mathrm{n}=38)\end{array}$ \\
\hline $\begin{array}{l}\text { Protandim }^{\circledR} \\
n=15\end{array}$ & $\begin{array}{c}6457(4497) \\
{[4901]}\end{array}$ & $\begin{array}{c}5753(5340) \\
{[4474]}\end{array}$ & $-704(2836)$ \\
\hline $\begin{array}{c}\text { Placebo } \\
n=19\end{array}$ & $\begin{array}{c}7982(5992) \\
{[6235]}\end{array}$ & $\begin{array}{c}9184(5302) \\
{[8864]}\end{array}$ & $+1202(3891)$ \\
\hline
\end{tabular}

Mean (SD), [median], Median values are also reported due to non-normal distribution.

For the baseline value, the total amount of physical activity in minutes over the previous two week period prior to the issue of the supplement was multiplied by the average rating of perceived exertion value for those two weeks. $(6=$ no exertion to $20=$ maximal exertion). For the post-test period, the total amount of physical activity in minutes over the previous two week period prior to the 88 days post-supplementation period was multiplied by the average the average rating of perceived exertion value for those two weeks. The changes in the aerobic training index was not different between groups $(t=-$ $1.63, p=0.11)$ 
Table 7. Environmental conditions for all three 5-km time trials held at the University of Louisville outdoor track.

\begin{tabular}{|c|c|c|c|c|c|c|}
\hline & \multicolumn{2}{|c|}{$\begin{array}{c}\text { First baseline 5-km } \\
\text { time trial }\end{array}$} & \multicolumn{2}{|c|}{$\begin{array}{c}\text { Second baseline 5-km } \\
\text { time trial }\end{array}$} & \multicolumn{2}{|c|}{$\begin{array}{l}\text { Final 5-km time trial } \\
\text { ( 100 days after the } \\
\text { first time trial) }\end{array}$} \\
\hline & Protandim & Placebo & Protandim ${ }^{\circledR}$ & Placebo & Protandim & Placebo \\
\hline $\begin{array}{l}\text { Temp. } \\
\left({ }^{\circ} \mathbf{F}\right)\end{array}$ & $35(5)^{\circ}$ & $34(6)^{\circ}$ & $36(3)^{\circ}$ & $37(2)^{\circ}$ & $49(14)^{\circ}$ & $50(15)^{\circ}$ \\
\hline $\begin{array}{l}\text { Dew } \\
\text { Point } \\
\left({ }^{\circ} \text { F }\right)\end{array}$ & $28(8)^{\circ}$ & $26(9)^{\circ}$ & $28(4)^{\circ}$ & $30(5)^{\circ}$ & $39(15)^{\circ}$ & $39(15)^{\circ}$ \\
\hline $\begin{array}{l}\text { Humidit } \\
\text { y (\%) }\end{array}$ & $79(11) \%$ & $77(12) \%$ & $73(11) \%$ & $\begin{array}{l}76(13) \\
\%\end{array}$ & $71(19) \%$ & $70(18) \%$ \\
\hline $\begin{array}{l}\text { groups wit } \\
\text { to condens } \\
\text { Above this } \\
\text { close to th } \\
\text { point is we }\end{array}$ & $\begin{array}{l}\text { here was n } \\
\text { each sessi } \\
\text { at of the ai } \\
\text { nperature } t\end{array}$ & $\begin{array}{l}\text { tatisticall } \\
\text { The Dev } \\
\text { he temper } \\
\text { moisture } \\
\text { ture, then }\end{array}$ & $\begin{array}{l}\text { significant } d \\
\text { Point is the } \\
\text { ture at whic } \\
\text { vill stay in th } \\
\text { he relative h }\end{array}$ & $\begin{array}{l}\text { erences } i \\
\text { iperature } \\
\text { ir becom } \\
\text { ir. If the }\end{array}$ & $\begin{array}{l}\text { ny parame } \\
\text { which wat } \\
\text { completely } \\
\text { w-point ter }\end{array}$ & $\begin{array}{l}\text { between } \\
\text { vapor start } \\
\text { turated). } \\
\text { erature is } \\
\text { the dew }\end{array}$ \\
\hline
\end{tabular}


Table 8. Summary probabilities for all blood parameters at rest using a 2 x 4 repeated measures ANOVA.

\begin{tabular}{|c|c|c|c|}
\hline $\begin{array}{l}\text { Repeated measures ANOVA } \\
\text { results }\end{array}$ & $\begin{array}{l}\text { Main } \\
\text { effect of } \\
\text { group }\end{array}$ & $\begin{array}{l}\text { Main effect of } \\
\text { Time }\end{array}$ & $\begin{array}{r}\text { Group } x \\
\text { Time } \\
\text { interaction } \\
\text { effect }\end{array}$ \\
\hline \multicolumn{4}{|l|}{ RESERVE } \\
\hline Glutathione (GSH) $(\mu \mathrm{mol} / \mathrm{L})$ & 0.51 & $\begin{array}{c}<0.001^{*} \\
\left(\text { Partial } \eta^{2}=0.26\right)\end{array}$ & 0.27 \\
\hline $\begin{array}{l}\text { Total Antioxidant Capacity } \\
\text { (TAC) }(\mathrm{mmol} / \mathrm{L})\end{array}$ & 0.68 & $\begin{array}{c}<0.001^{*} \\
\left(\text { Partial } \eta^{2}=0.31\right)\end{array}$ & 0.85 \\
\hline Cysteine (mg/dL) & 0.60 & $\begin{array}{c}0.055 \\
\left(\text { Partial } \eta^{2}=0.07\right)\end{array}$ & 0.21 \\
\hline Cystine (mg/dL) & 0.52 & $\begin{array}{c}0.038^{*} \\
\left(\text { Partial } \eta^{2}=0.08\right)\end{array}$ & 0.23 \\
\hline Cysteine to Cystine ratio & 0.30 & $\begin{array}{c}0.14 \\
\left(\text { Partial } \eta^{2}=0.05\right)\end{array}$ & 0.35 \\
\hline Sulphate (mg/dL) & 0.66 & $\begin{array}{c}0.001 * \\
\left(\text { Partial } \eta^{2}=0.15\right)\end{array}$ & 0.84 \\
\hline Cysteine to Sulphate ratio & 0.69 & $\begin{array}{c}0.002 * \\
\left(\text { Partial } \eta^{2}=0.13\right)\end{array}$ & 0.48 \\
\hline $\begin{array}{l}\text { PROTECTIVE ENZYMES } \\
\text { Superoxide Dismutase (SOD) } \\
\text { (U/g Hb) }\end{array}$ & 0.81 & $\begin{array}{c}<0.001^{*} \\
\left(\text { Partial } \eta^{2}=0.40\right)\end{array}$ & 0.55 \\
\hline $\begin{array}{l}\text { Glutathione Peroxidase } \\
\text { (GPX) }\end{array}$ & 0.66 & $\begin{array}{c}<0.001^{*} \\
\left(\text { Partial } \eta^{2}=0.23\right)\end{array}$ & 0.851 \\
\hline $\begin{array}{l}(\mathrm{U} / \mathrm{g} \mathrm{Hb}) \\
\text { DAMAGE } \\
\text { Lipid Peroxides (TBARS, } \\
\mu \mathrm{mol} / \mathrm{L})\end{array}$ & 0.74 & $\begin{array}{c}0.31 \\
\left(\text { Partial } \eta^{2}=0.035\right)\end{array}$ & 0.38 \\
\hline $\begin{array}{l}\text { OTHER } \\
\text { Fasting Blood Glucose } \\
(\mathrm{mg} / \mathrm{dL})\end{array}$ & 0.67 & $\begin{array}{c}0.01 \\
\left(\text { Partial } \eta^{2}=0.15\right)\end{array}$ & 0.26 \\
\hline
\end{tabular}


Table 9. The number of individuals in each group that ate the same food 24 hrs prior to the blood draw for each of the five blood draw days.

\section{Not at all $(<40 \%)$ or Mostly $(61$ to $85 \%)$ \\ Somewhat (40 to $60 \%$ ) or Completely (86 \\ to $100 \%$ )}

\section{Protandim ${ }^{\circledR}$ Group $(\mathbf{n}=18)$}

\section{5}

13

\section{Placebo Group $(n=19)$}

14

5

Not at all $(<40 \%)$ or Somewhat (40 to $60 \%$ ) category represent the combined number of individuals in each group who ate less than $60 \%$ of the same food and drink prior to each session. Mostly (61 to $85 \%$ ) or Completely ( $86 \%$ to $100 \%$ ) category represent the combined number of individuals in each group who ate $>61 \%$ of the same food and drink prior to each session. Fisher's exact test, $p<0.01$ between groups. 
Table 10. Pre and post exercise blood values from both baseline sessions and at 88 days post-supplementation. Both groups were combined due to lack of a between group effect.

\begin{tabular}{|c|c|c|c|c|}
\hline & $\begin{array}{l}\text { Pre- } \\
\text { exercise }\end{array}$ & $\begin{array}{c}\text { 10-minutes } \\
\text { post exercise }\end{array}$ & change & $p$ value \\
\hline \multicolumn{5}{|l|}{ Damage } \\
\hline \multicolumn{5}{|l|}{ Lipid Peroxides (TBARs, $\mu \mathrm{mol} / \mathrm{L}$ ) } \\
\hline Baseline week 1 & $8.7(3.4)$ & $9.4(2.4)$ & $+0.6(3.1)$ & 0.21 \\
\hline Baseline week 2 & 7.4 (2.2)\# & $7.5(2.1)$ & $+0.1(1.7)$ & 0.78 \\
\hline Average of both baseline weeks & $8.1(1.9)$ & $8.4(2.4)$ & $+0.4(1.8)$ & 0.22 \\
\hline 88 days post-supplementation & $7.6(3.2)$ & $7.1(2.5)$ & $-0.5(3.6)$ & 0.47 \\
\hline \multicolumn{5}{|l|}{ Protective Enzymes } \\
\hline \multicolumn{5}{|l|}{$\begin{array}{l}\text { Superoxide dismutase } \\
\text { (SOD, U/g Hb x 1000) }\end{array}$} \\
\hline Baseline week 1 & $11.8(3.3)$ & $12.2(3.4)$ & $+0.3(1.5)$ & 0.17 \\
\hline Baseline week 2 & $11.2(4.4)$ & $11.1(4.3)$ & $-0.1(1.7)$ & 0.66 \\
\hline Average of both baseline weeks & $11.5(3.4)$ & $11.6(3.3)$ & $+0.1(1.1)$ & 0.55 \\
\hline 88 days post-supplementation & $19.3(7.1)$ & $19.9(7.0)$ & $+0.5(3.1)$ & 0.35 \\
\hline \multicolumn{5}{|l|}{ Glutathione Peroxidase (GPX, U/g } \\
\hline Baseline week 1 & $29.5(8.1)$ & $29.3(7.7)$ & $-0.2(2.6)$ & 0.63 \\
\hline Baseline week 2 & 26.9 (4.6)\# & $27.0(4.6)$ & $+0.1(1.9)$ & 0.68 \\
\hline Average of both baseline weeks & $28.2(6.1)$ & $28.2(5.9)$ & $0.0(1.6)$ & 0.88 \\
\hline 88 days post-supplementation & $31.3(6.4)$ & $31.4(5.9)$ & $+0.1(3.1)$ & 0.89 \\
\hline \multicolumn{5}{|l|}{ Other } \\
\hline \multicolumn{5}{|l|}{ Glucose levels (fasted) (mg/dL) } \\
\hline Baseline week 1 & $92(7)$ & $165(33)$ & $+72(31)$ & $<0.01$ \\
\hline Baseline week 2 & $90(7)$ & $158(36)$ & $+68(37)$ & $<0.01$ \\
\hline Average of both baseline weeks & $91(7)$ & $161(31)$ & $+70(29)$ & $<0.01$ \\
\hline 88 days post-supplementation & $91(8)$ & $163(44)$ & $+72(41)$ & $<0.01$ \\
\hline \multicolumn{5}{|l|}{ Reserve } \\
\hline \multicolumn{5}{|l|}{ Glutathione $(\mathrm{GSH})(\mu \mathrm{mol} / \mathrm{L})$} \\
\hline Baseline week 1 & $1087(252)$ & $1076(223)$ & $-11(131)$ & 0.61 \\
\hline Baseline week 2 & 1013(196)\# & $998(206)$ & $-15(200)$ & 0.64 \\
\hline Average of both baseline weeks & $1033(169)$ & $1023(165)$ & $-11(84)$ & 0.45 \\
\hline 88 days post-supplementation & $999(235)$ & $1042(186)$ & $+43(229)$ & 0.27 \\
\hline \multicolumn{5}{|c|}{$\begin{array}{l}\text { Mean (SD). Both Protandim }{ }^{\circledR} \text { and placebo groups were combined due to the fact that there were } \\
\text { no differences between them. Probability values compares post-exercise with pre-exercise within } \\
\text { each session. } \mathrm{n}=38 \text { for both baseline sessions, } \mathrm{n}=35 \text { at } 88 \text { days post-supplementation period. \# } \\
p<0.05 \text { compared to baseline week } 1 \text {.\# Baseline week } 2 \text { pre-exercise is significantly different } \\
\text { compared to Baseline week } 1 \text { pre-exercise }(p<0.05) \text {. }\end{array}$} \\
\hline
\end{tabular}


Table 11. Pre and post exercise blood values at both baseline sessions and at 88 days postsupplementation. Both groups were combined due to lack of a between group effect.

\begin{tabular}{|c|c|c|c|c|}
\hline & $\begin{array}{l}\text { Pre- } \\
\text { exercise }\end{array}$ & $\begin{array}{c}\text { 10-min post } \\
\text { exercise }\end{array}$ & change & $p$-value \\
\hline \multicolumn{5}{|l|}{ Reserve } \\
\hline \multicolumn{5}{|l|}{$\begin{array}{l}\text { Total Antioxidant Capacity (TAC) } \\
(\mathrm{mmol} / \mathrm{L})\end{array}$} \\
\hline Baseline week 1 & $0.86(0.06)$ & $0.96(0.08)$ & $+0.11(0.07)$ & $<0.01$ \\
\hline Baseline week 2 & $0.87(0.08)$ & $0.98(0.09)$ & $+0.11(0.07)$ & $<0.01$ \\
\hline Average of both baseline weeks & $0.86(0.06)$ & $0.97(0.07)$ & $+0.11(0.05)$ & $<0.01$ \\
\hline 88 days post-supplementation & $0.80(0.06)$ & $0.91(0.08)$ & $+0.11(0.04)$ & $<0.01$ \\
\hline \multicolumn{5}{|l|}{ Cysteine (mg/dL) } \\
\hline Baseline week 1 & $0.62(0.14)$ & $0.65(0.13)$ & $+0.02(0.11)$ & 0.18 \\
\hline Baseline week 2 & $0.68(0.14) \#$ & $0.72(0.17)$ & $+0.05(0.18)$ & 0.13 \\
\hline Average of both baseline weeks & $0.65(0.11)$ & $0.69(0.12)$ & $+0.03(0.11)$ & 0.06 \\
\hline 88 days post-supplementation & $0.59(0.13)$ & $0.64(0.16)$ & $+0.04(0.12)$ & 0.04 \\
\hline \multicolumn{5}{|l|}{ Cystine (mg/dL) } \\
\hline Baseline week 1 & $2.1(0.4)$ & $2.2(0.4)$ & $+0.1(0.4)$ & 0.15 \\
\hline Baseline week 2 & $2.2(0.5)$ & $2.2(0.4)$ & $+0.1(0.3)$ & 0.03 \\
\hline Average of both baseline weeks & $2.1(0.4)$ & $2.2(0.4)$ & $+0.1(0.3)$ & 0.02 \\
\hline 88 days post-supplementation & $2.1(0.3)$ & $2.2(0.5)$ & $0.0(0.4)$ & 0.63 \\
\hline \multicolumn{5}{|l|}{ Cysteine to Cystine ratio } \\
\hline Baseline week 1 & $0.31(0.10)$ & $0.31(0.10)$ & $0.0(0.08)$ & 0.98 \\
\hline Baseline week 2 & $0.33(0.12)$ & $0.33(0.14)$ & $0.0(0.12)$ & 0.85 \\
\hline Average of both baseline weeks & $0.32(0.10)$ & $0.32(0.10)$ & $0.0(0.08)$ & 0.81 \\
\hline 88 days post-supplementation & $0.29(0.09)$ & $0.39(0.56)$ & $0.10(0.56)$ & 0.28 \\
\hline \multicolumn{5}{|l|}{ Sulphate (mg/dL) } \\
\hline Baseline week 1 & $3.6(0.8)$ & $3.8(0.9)$ & $+0.2(0.7)$ & 0.08 \\
\hline Baseline week 2 & $4.1(0.8) \#$ & $4.6(1.3)$ & $+0.5(1.2)$ & 0.02 \\
\hline Average of both baseline weeks & $3.9(0.7)$ & $4.2(0.9)$ & $+0.3(0.8)$ & 0.01 \\
\hline 88 days post-supplementation & $3.8(0.7)$ & $4.1(0.8)$ & $+0.3(0.5)$ & $<0.01$ \\
\hline \multicolumn{5}{|l|}{ Cysteine to Sulphate ratio } \\
\hline Baseline week 1 & $0.18(0.06)$ & $0.18(0.06)$ & $0.0(0.04)$ & 0.69 \\
\hline Baseline week 2 & $0.17(0.05)$ & $0.17(0.06)$ & $0.0(0.05)$ & 0.72 \\
\hline Average of both baseline weeks & $0.18(0.04)$ & $0.17(0.05)$ & $0.0(0.04)$ & 0.67 \\
\hline 88 days post-supplementation & $0.16(0.04)$ & $0.16(0.04)$ & $0.0(0.04)$ & 0.96 \\
\hline
\end{tabular}


Table 12. The total number of participants and events of a given sign / symptom over the supplementation period of 88 days.

\begin{tabular}{|c|c|c|c|}
\hline Signs/ Symptoms & $\begin{array}{c}\text { Protandim }^{\circledR} \\
\quad(n=19)\end{array}$ & $\begin{array}{c}\text { Placebo } \\
(n=19)\end{array}$ & $\begin{array}{c}\text { Total number of } \\
\text { events from both } \\
\text { groups over } 88 \\
\text { days }\end{array}$ \\
\hline Stomach Ache & $5(18)$ & $2(2)$ & 20 \\
\hline Diarrhea & $5(10)$ & $2(12)$ & 22 \\
\hline Vomiting & $2(2)$ & (2) & 4 \\
\hline Headache & $6(40)$ & $3(12)$ & 52 \\
\hline Rash (Hands/Feet) & 0 & 0 & 0 \\
\hline Gas & $1(51)$ & $4(137)$ & 188 \\
\hline Drowsiness & $2(3)$ & $4(17)$ & 20 \\
\hline Constipation & $2(17)$ & $1(8)$ & 25 \\
\hline Nausea & $5(17)$ & $2(7)$ & 24 \\
\hline Dizziness & $5(33)$ & $2(5)$ & 38 \\
\hline Insomnia & $1(1)$ & $(0)$ & 1 \\
\hline Itching & $1(8)$ & 0 & 8 \\
\hline Joint Pain & $2(12)$ & $3(6)$ & 18 \\
\hline Low Blood Sugar & $2(18)$ & $(0)$ & 18 \\
\hline Low Blood Pressure & 0 & 0 & 0 \\
\hline $\begin{array}{l}\text { Head cold / } \\
\text { congestion }\end{array}$ & $1(1)$ & 0 & 1 \\
\hline Increased appetite & $(0)$ & (1) & 1 \\
\hline Total & (233) & $(220)$ & 453 \\
\hline
\end{tabular}


The numbers outside of parentheses represents the number of individuals who had the sign or symptom over the supplementation period. The numbers within the parentheses represent the number of events in each group compared to the summed total of both groups. 
Table 13. The stability of the responses for the WHOQOL-BREF Questionnaire over a one week baseline period $(n=38)$.

\begin{tabular}{|c|c|c|c|c|}
\hline & $\begin{array}{l}\text { Week-to- } \\
\text { week C.V \% } \\
\text { for the raw } \\
\text { scores }\end{array}$ & $\begin{array}{c}\text { Within } \\
\text { subject } S D \\
\left(\text { SD }_{w}\right) \text { for raw } \\
\text { scores }\end{array}$ & $\begin{array}{l}\text { Reproducibility } \\
\left(2.77 \times \mathrm{SD}_{w}\right) \text { of } \\
\text { the raw scores }\end{array}$ & $\begin{array}{c}\text { Smallest } \\
\text { measureable } \\
\text { change for } \\
\text { raw scores }\end{array}$ \\
\hline $\begin{array}{c}\text { Physical } \\
\text { Health } \\
\text { (Raw scores } \\
\text { can range } \\
\text { from } 7 \text { to 35) }\end{array}$ & $5.3 \%$ & 1.5 & 4.1 & 2.0 \\
\hline $\begin{array}{l}\text { Psychological } \\
\text { Health } \\
\text { (Raw scores } \\
\text { can range } \\
\text { from } 6 \text { to 30) }\end{array}$ & $7.2 \%$ & 1.7 & 4.6 & 2.3 \\
\hline $\begin{array}{c}\text { Social } \\
\text { Relationships } \\
\text { (Raw scores } \\
\text { can range } \\
\text { from } 3 \text { to 15) }\end{array}$ & $4.4 \%$ & 0.5 & 1.4 & 0.7 \\
\hline $\begin{array}{l}\text { Environment } \\
\text { (Raw scores } \\
\text { can range } \\
\text { from } 8 \text { to 40) }\end{array}$ & $4.0 \%$ & 1.4 & 3.7 & 1.9 \\
\hline
\end{tabular}

The within subject SD is considered the measurement error. 
Figure 1. A meta-analysis of the acute effect of intense exercise on oxidative damage as assessed lipid peroxides from serum blood samples. This represents an immediate postexercise change (within 10 minutes post exercise) in lipid peroxides compared to preexercise. Using a fixed effect model on 282 subjects from 22 studies, the effect size was $+0.8(95 \% \mathrm{CI}=0.6$ to $1.0, p<0.001)$. With a random effects model, the effect size was $+1.6(95 \% \mathrm{CI}=0.9$ to $2.3, p<0.001)$. There was a heterogeneity effect between studies $(\mathrm{Q}=278.4, \mathrm{Df}=21, p<0.001)^{5,8,25,38-56}$.

Vezzoli et al. (2014), Running Duthie et al. (1990), Running

Diaz et al. (2011), Running

Alessio et al. (1997), Running

Maughan et al. (1989), Running

Revan (2011), Running

Revan (2010), Running

Vider et al. (2001), Running

Arent et al. (2010), Running

Bogdanis et al. (2013), Running

Michailidis et al. (2007), Running

Feairheller et al. (2011), Running

Inayama et al. (1996), Running

Marzatico et al. (1997), Running

Rokitzki et al. (1994), Running

Fatouros et al. (2004), Running

Miyazaki et al. (2001), Bike

Fisher at al. (2011), Bike

Bloomer et al. (2005), Bike

Kyparos et al. (2009), Rowing

Kabasakalis et a. (2011), Swimming

Margaritis et al. (1997), Triathlon

Total (fixed effects)

Total (random effects)

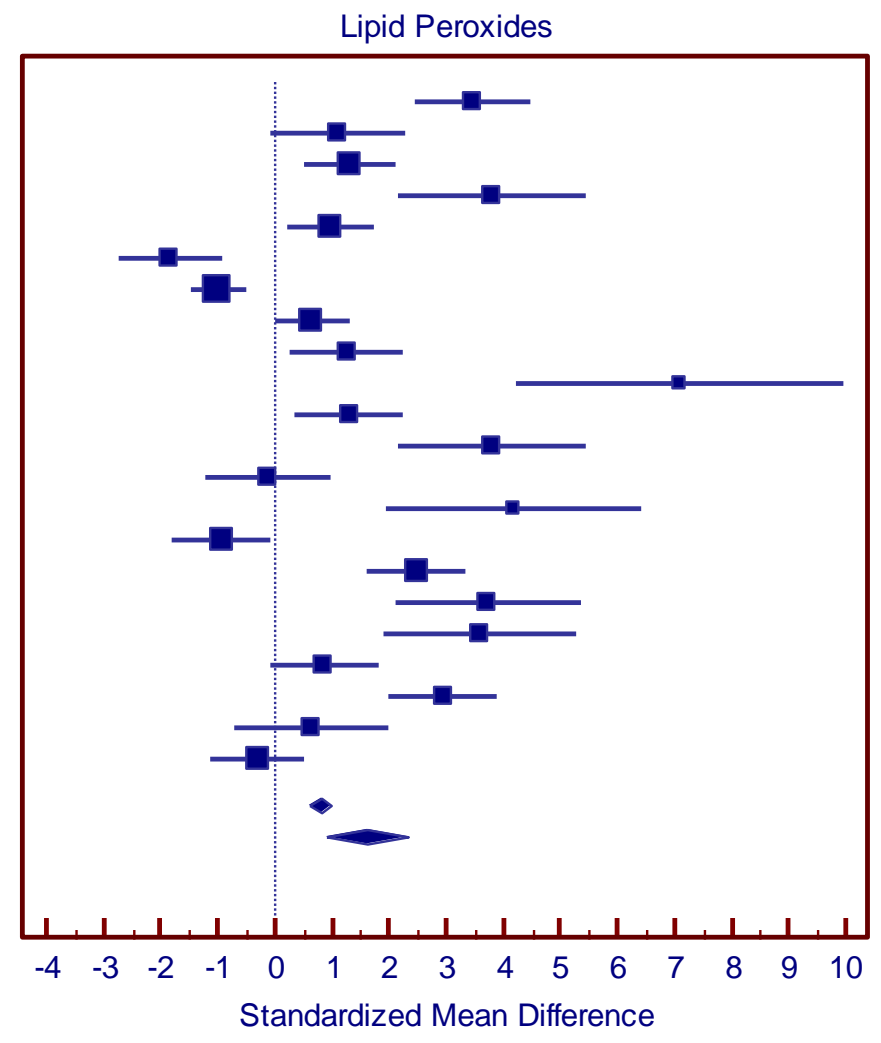


Figure 2. A meta-analysis of the acute effect of intense exercise on superoxide dismutase concentration from serum blood samples. This represents an immediate post-exercise change (within 10 minutes post exercise) in superoxide dismutase compared to preexercise. Using a fixed effect model on 85 subjects from 8 studies, the effect size was $+0.7(95 \% \mathrm{CI}=0.4$ to $1.0, p<0.001)$. With a random effects model, the effect size was $+1.2(95 \% \mathrm{CI}=0.2$ to $2.0, p=0.014)$. There was a heterogeneity effect between studies $(\mathrm{Q}=50.7, \mathrm{Df}=7, p<0.001)^{40,42,45,48,50,51,54,55}$.

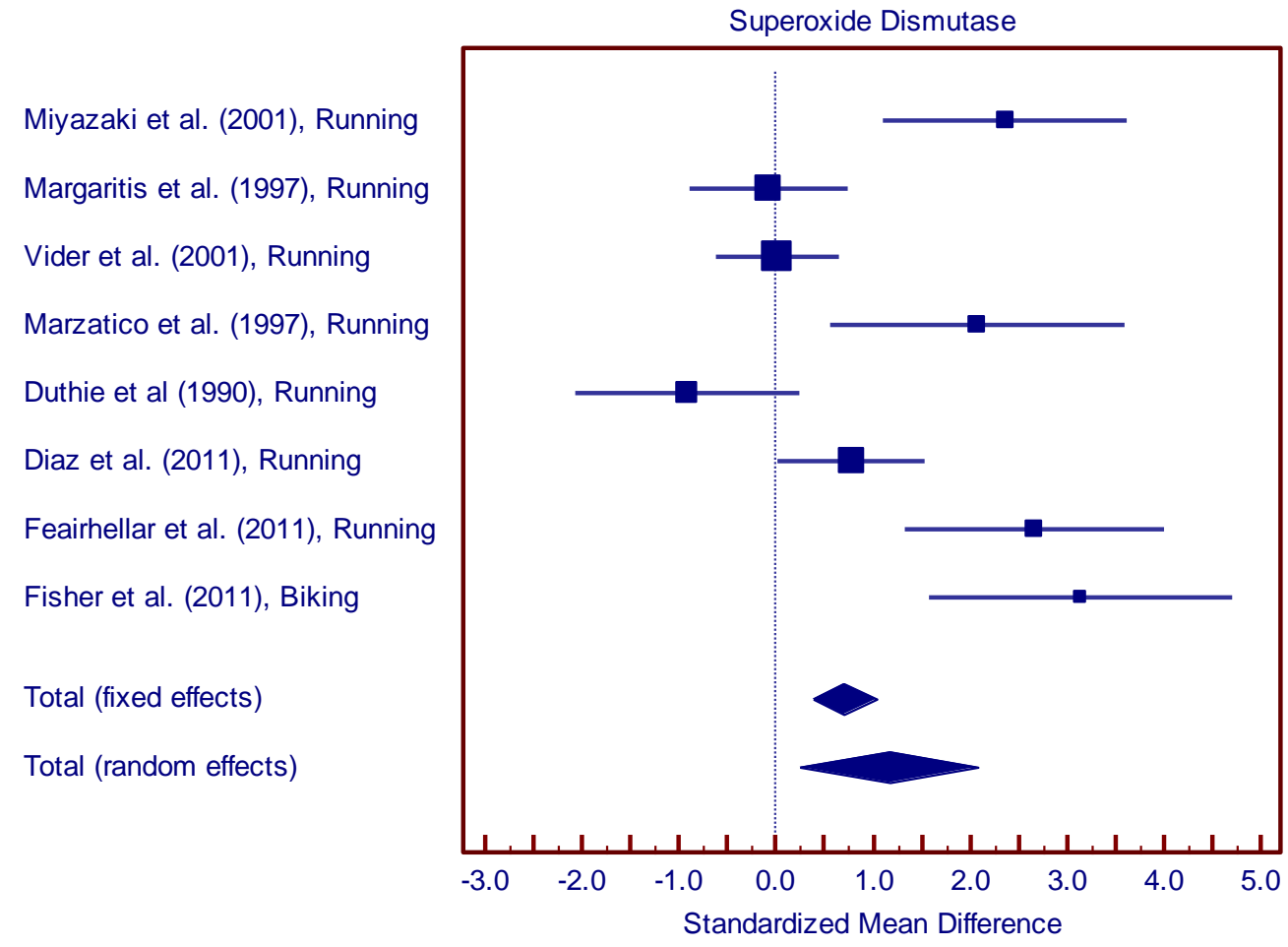


Figure 3. A meta-analysis of the acute effect of intense exercise on glutathione peroxidase concentration from serum blood samples. This represents an immediate postexercise change (within 10 minutes post exercise) in Glutathione Peroxidase compared to pre-exercise. Using a fixed effect model on 167 subjects from 11 studies, the effect size was $+0.5(95 \% \mathrm{CI}=0.3$ to $0.7, p<0.001)$. With a random effects model, the effect size was $+0.8(95 \% \mathrm{CI}=0.3$ to $1.3, p=0.004)$. There was a heterogeneity effect between studies $(\mathrm{Q}=54.6, \mathrm{Df}=10, p<0.001)^{8,19,40,42,45,49,50,52,54,55}$.

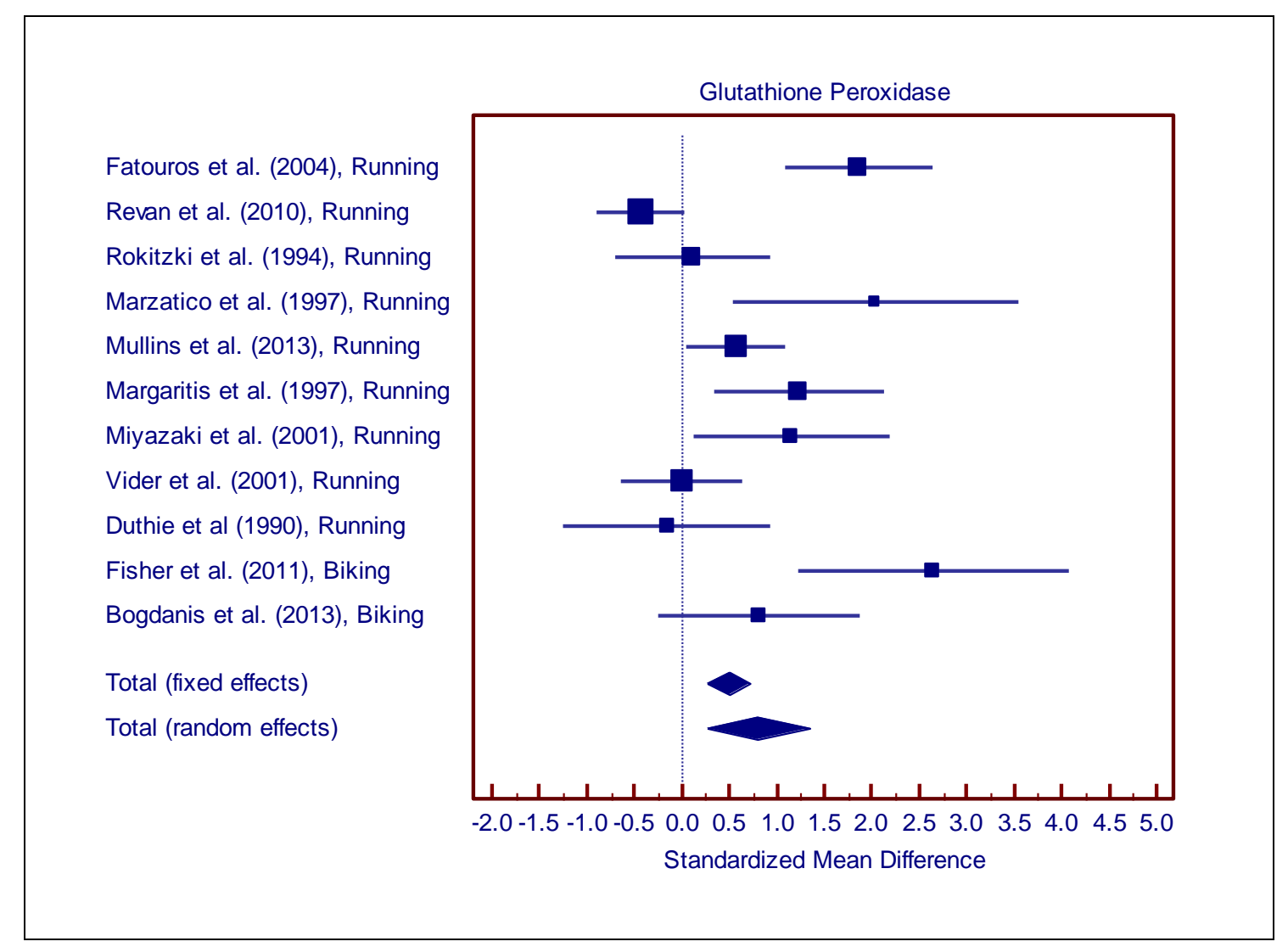


Figure 4. A meta-analysis of the acute effect of intense exercise on total antioxidant capacity from serum blood samples. This represents an immediate post-exercise change (within 10 minutes post exercise) in total antioxidant capacity compared to pre-exercise. Using a fixed effect model on 143 subjects from 9 studies, the effect size was $+0.5(95 \%$ $\mathrm{CI}=0.2$ to $0.7, p<0.001)$. With a random effects model, the effect size was $+1.2(95 \%$ $\mathrm{CI}=0.3$ to $2.0, p=0.007)$. There was a heterogeneity effect between studies $(\mathrm{Q}=81.3$, $\mathrm{Df}=8, p<0.001)^{13,19,25,28,38,39,45,48,49,52}$.

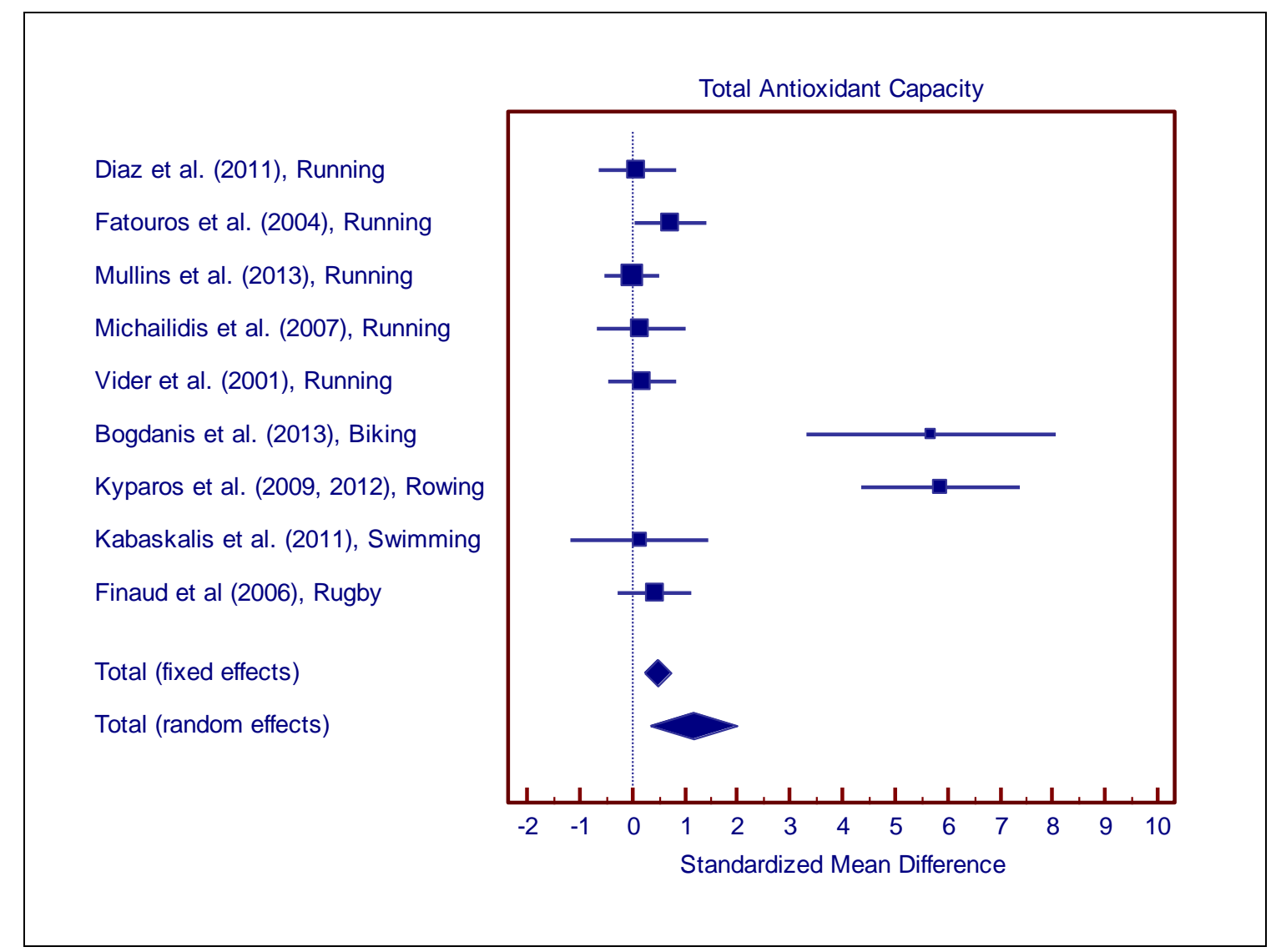

Data taken from Kyparos et al. (2009 and 2012) seemed to be the same data published in both articles. 
Figure 5. A meta-analysis of the effect of long term chronic training on oxidative damage as assessed lipid peroxides from serum blood samples. This represents serum values in a rested state after a period of long term training. Using a fixed effect model on 61 subjects from 5 studies, the effect size was $+0.2(95 \% \mathrm{CI}=-0.2$ to $+0.7, p=0.32)$. With a random effects model, the effect size was $+1.6(95 \% \mathrm{CI}=-1.4$ to $+4.5, p=0.30)$. Thus, no effect of long term training on serum lipid peroxides values. There was a heterogeneity effect between studies $(\mathrm{Q}=121.7 \text {, } \mathrm{Df}=4, p<0.001)^{43,49,52,55,57}$.

Vezzoli et al. (2014), Running

Fatouros et al. (2004), Running

Leonardo-Mendonça et al. (2014), Biking

Bogdanis et al. (2013), Biking

Miyazaki et al (2001), Biking

Total (fixed effects)

Total (random effects)

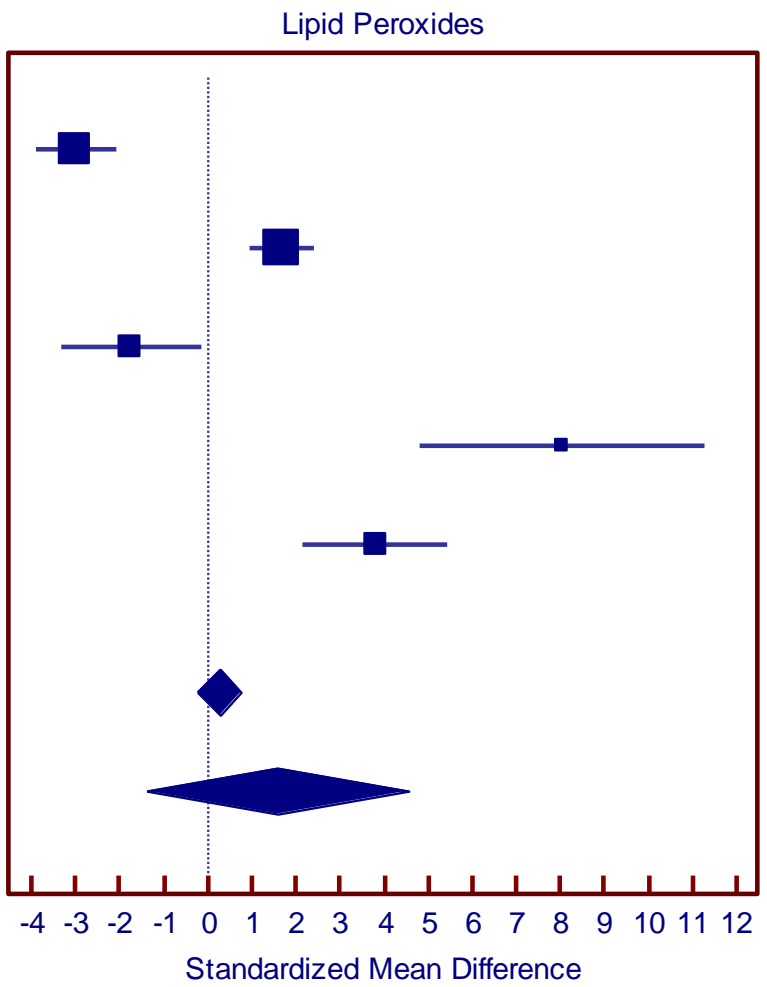


Figure 6. A meta-analysis of the effect of long term training on superoxide dismutase concentration from serum blood samples. This represents serum values in a rested state after a period of long term training. Using a fixed effect model on 26 subjects from 2 studies, the effect size was $+0.4(95 \% \mathrm{CI}=-0.1$ to $1.0, p=0.13)$. With a random effects model, the effect size was $+0.4(95 \% \mathrm{CI}=0.1$ to $1.0, p=0.13)$. There was no heterogeneity effect between studies $(\mathrm{Q}=0.30, \mathrm{Df}=1, p=0.58)$. There was no long term training effects of superoxide dismutase ${ }^{55,58}$.

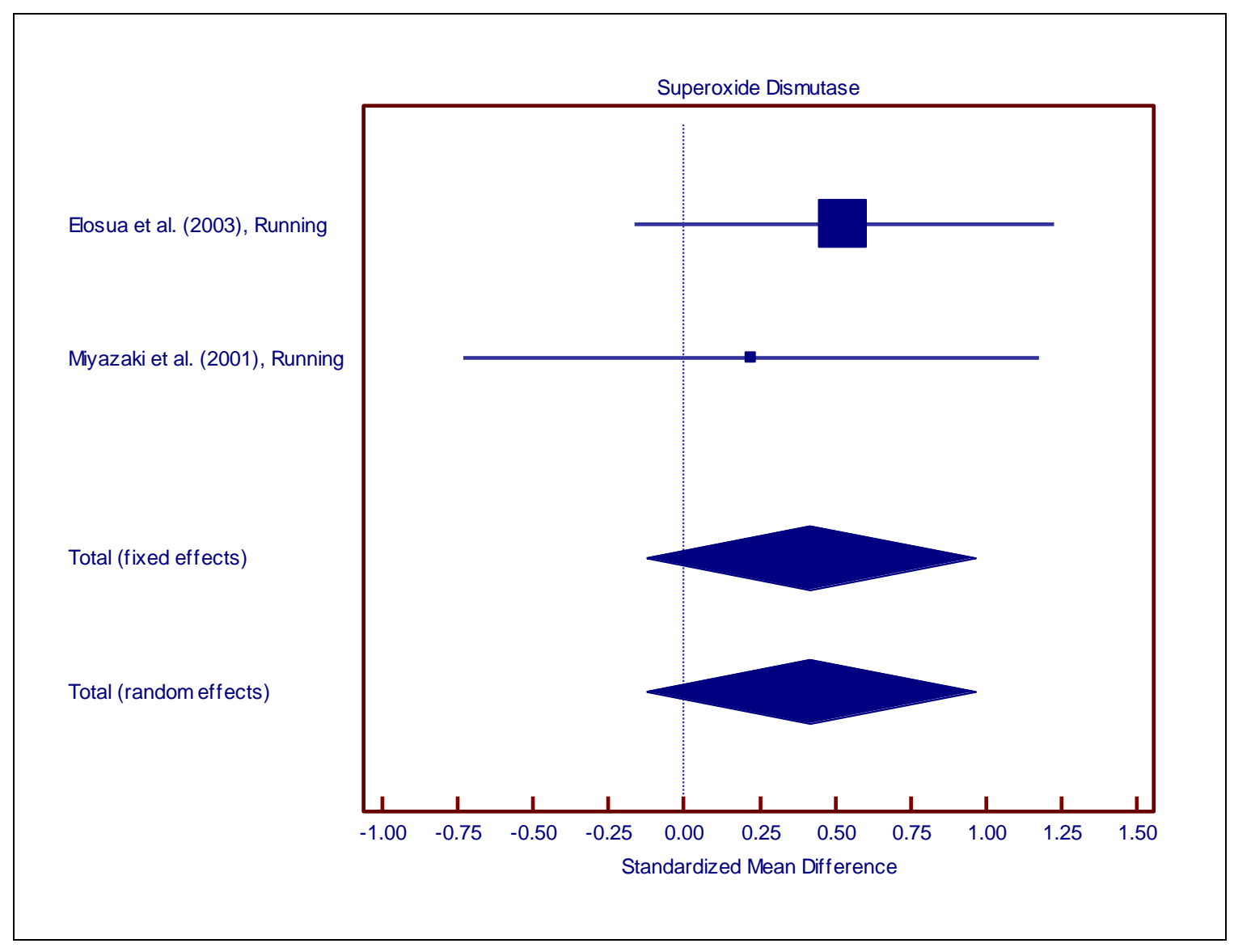


Figure 7. A meta-analysis of the effect of long term training on glutathione peroxidase concentration from serum blood samples. This represents serum values in a rested state after a period of long term training. Using a fixed effect model on 53 subjects from 4 studies, the effect size was $+1.0(95 \% \mathrm{CI}=0.5$ to $1.4, p<0.001)$. With a random effects model, the effect size was $+1.0(95 \% \mathrm{CI}=-0.7$ to $+2.6, p=0.27)$. There was heterogeneity effect between studies $(\mathrm{Q}=42.4$, $\mathrm{Df}=3, p<0.001)$. There was no long term effect of training on glutathione peroxidase concentration from the random effects

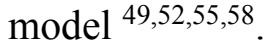

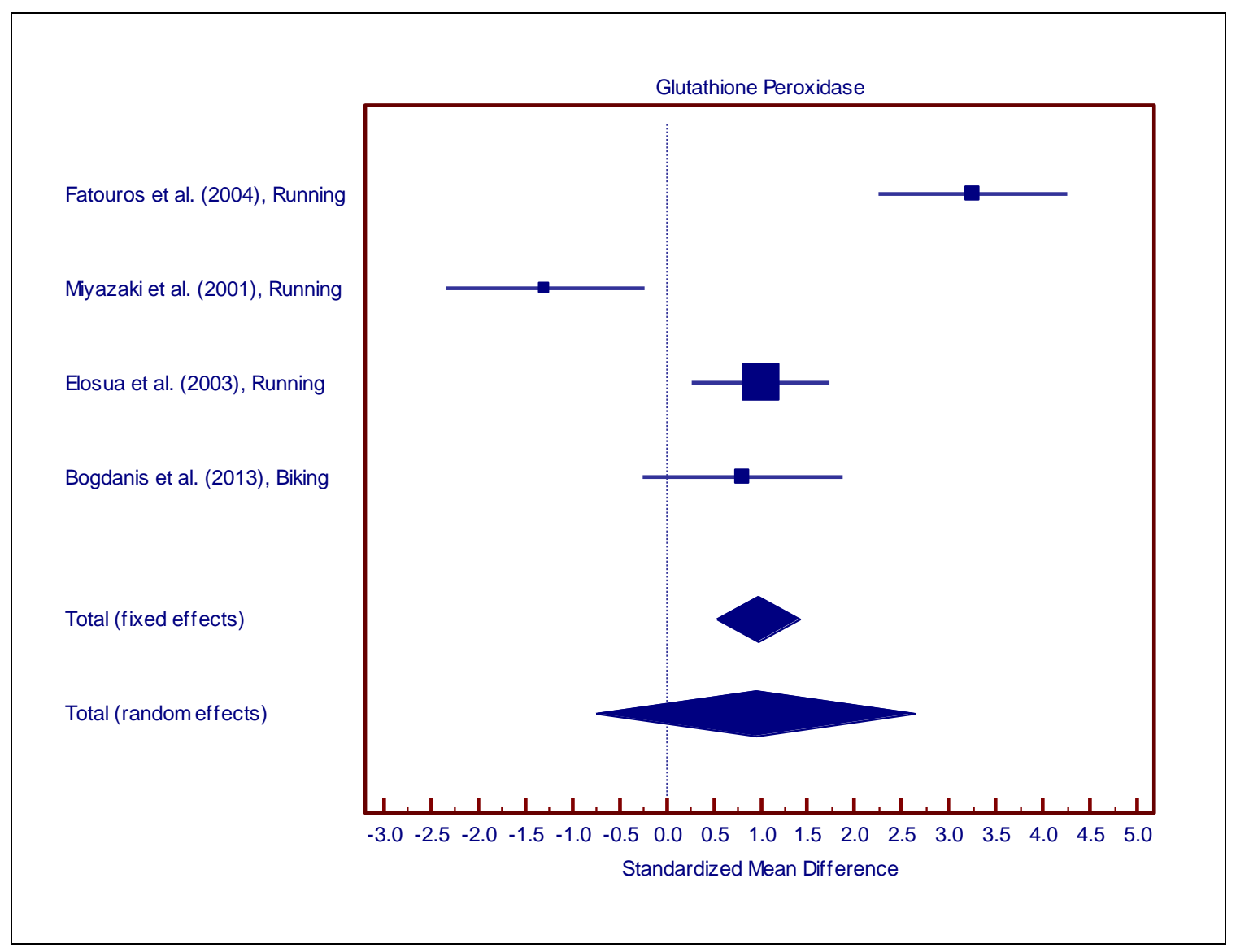


Figure 8. A meta-analysis of the effect of long term training on total antioxidant capacity from serum blood samples. This represents serum values in a rested state after a period of long term training. Using a fixed effect model on 42 subjects from 4 studies, the effect size was $+0.5(95 \% \mathrm{CI}=0.0$ to $0.9, p=0.065)$. With a random effects model, the effect size was $+0.9(95 \% \mathrm{CI}=-1.0$ to $+2.8, p=0.34)$. There was heterogeneity effect between studies $(\mathrm{Q}=38.7, \mathrm{Df}=3, p<0.001)$. There was no long term effect of training on total antioxidant capacity $43,49,52,57$.

Vezzoli et al. (2014), Running

Fatouros et al. (2004), Running

Bogdanis et al. (2013), Biking

Leonardo-Mendonça et al. (2014), Biking

Total (fixed effects)

Total (random effects)

Total Antioxidant Capacity

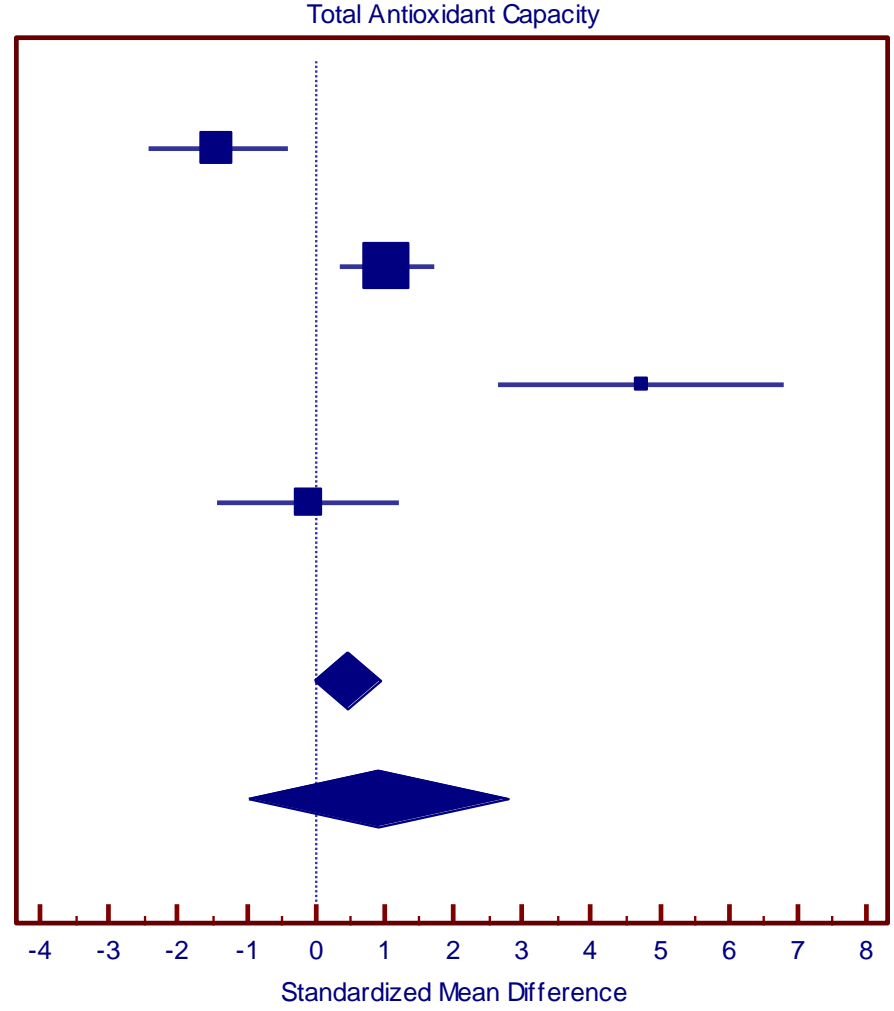


Figure 9. Normal subjects before supplementation with Protandim ${ }^{\circledR 16}$.

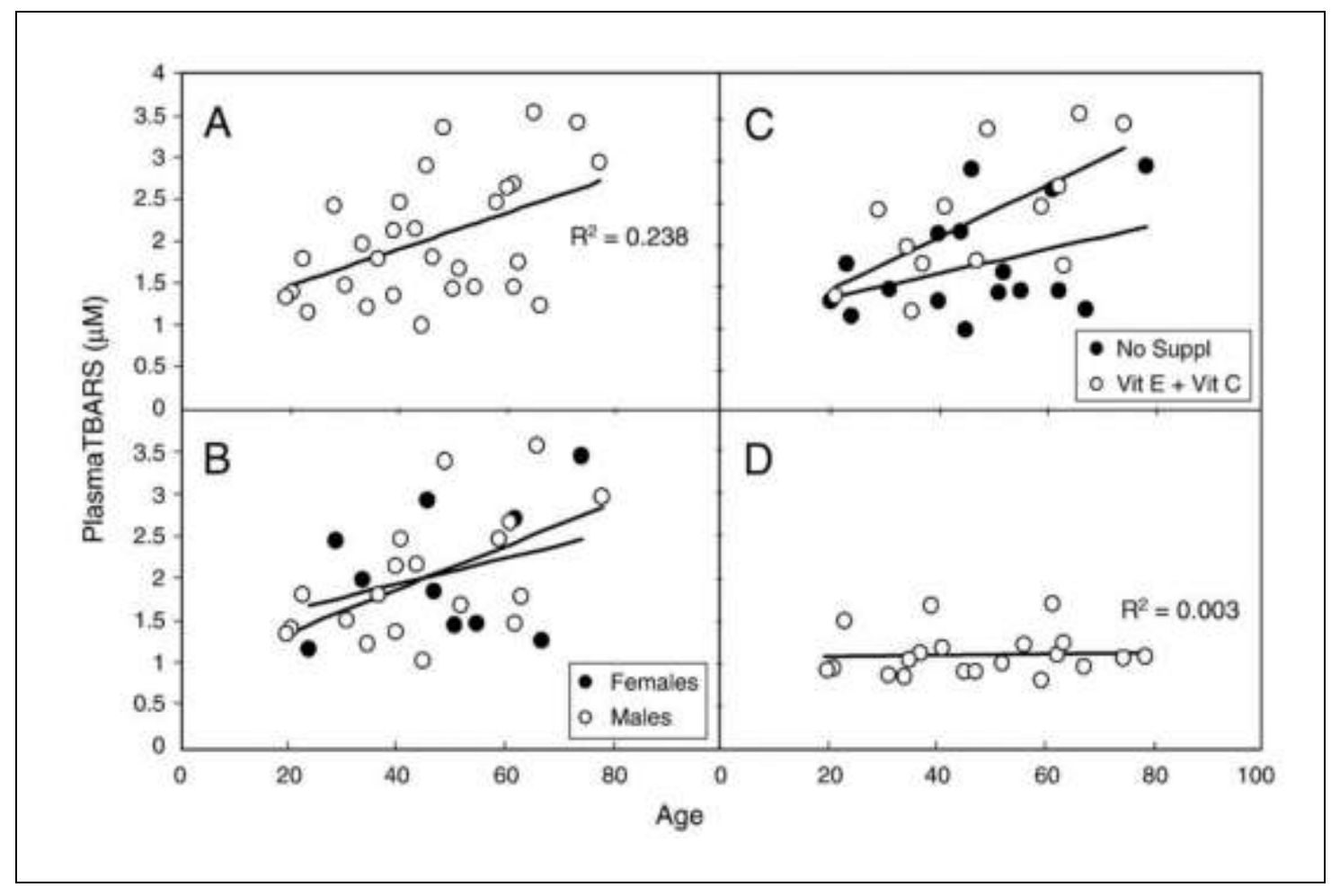


Figure 10. Group 1 subjects supplemented with Protandim ${ }^{\circledR}$ for 120 days showed a significant increase $(*)$ in erythrocyte superoxide dismutase (SOD) of $30 \%$ (SD 10\%) (n $=10, p<0.01)^{16}$.

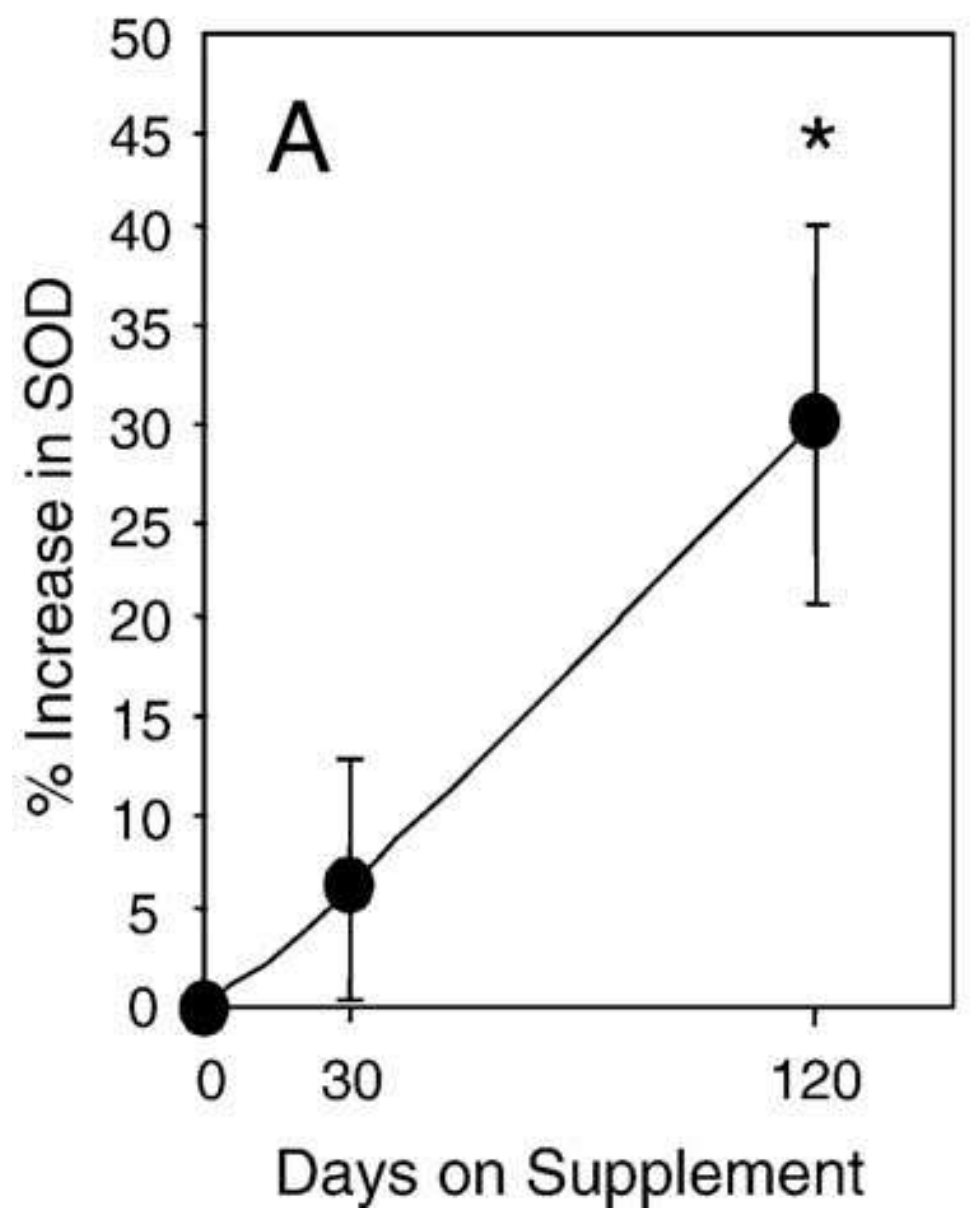


Figure 11. Group 2 subjects supplemented with Protandim ${ }^{\circledR}$ at $338 \mathrm{mg} /$ day for 30 day showed a substantial decline in TBARS at 5 and 12 days (squares, $n=4$ ). By 30 days, the levels of plasma TBARS dropped an average of $50 \%(p<0.03)$. The closed circle shows the average TBARS of the Group 1 (675 mg/day) subjects after 30 days, which is not significantly different ${ }^{16}$.

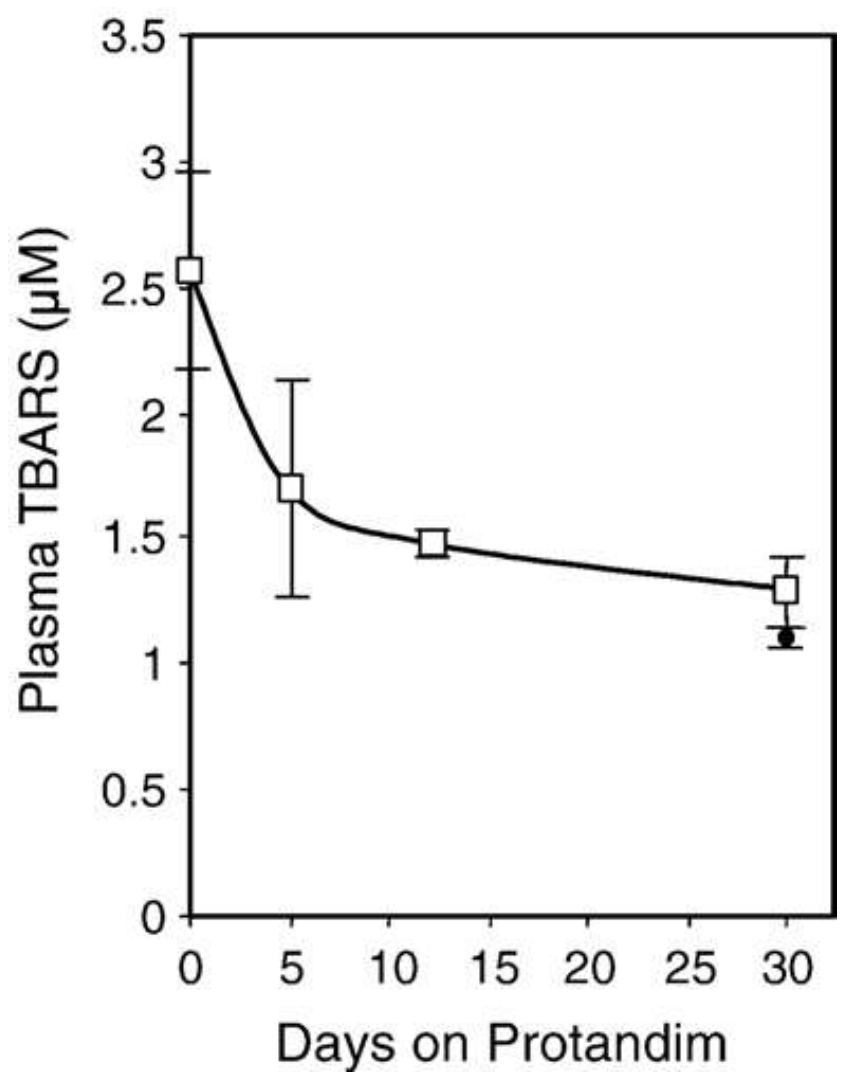


Figure 12. The $5-\mathrm{km}$ time trial performance times between the post-supplementation period and baseline (minutes). There was no significant differences between groups ( $p=$ $0.91)$, there was no significant differences between the two time-points $(p=0.19)$, and there was no interaction effect between group and time $(p=0.84)$

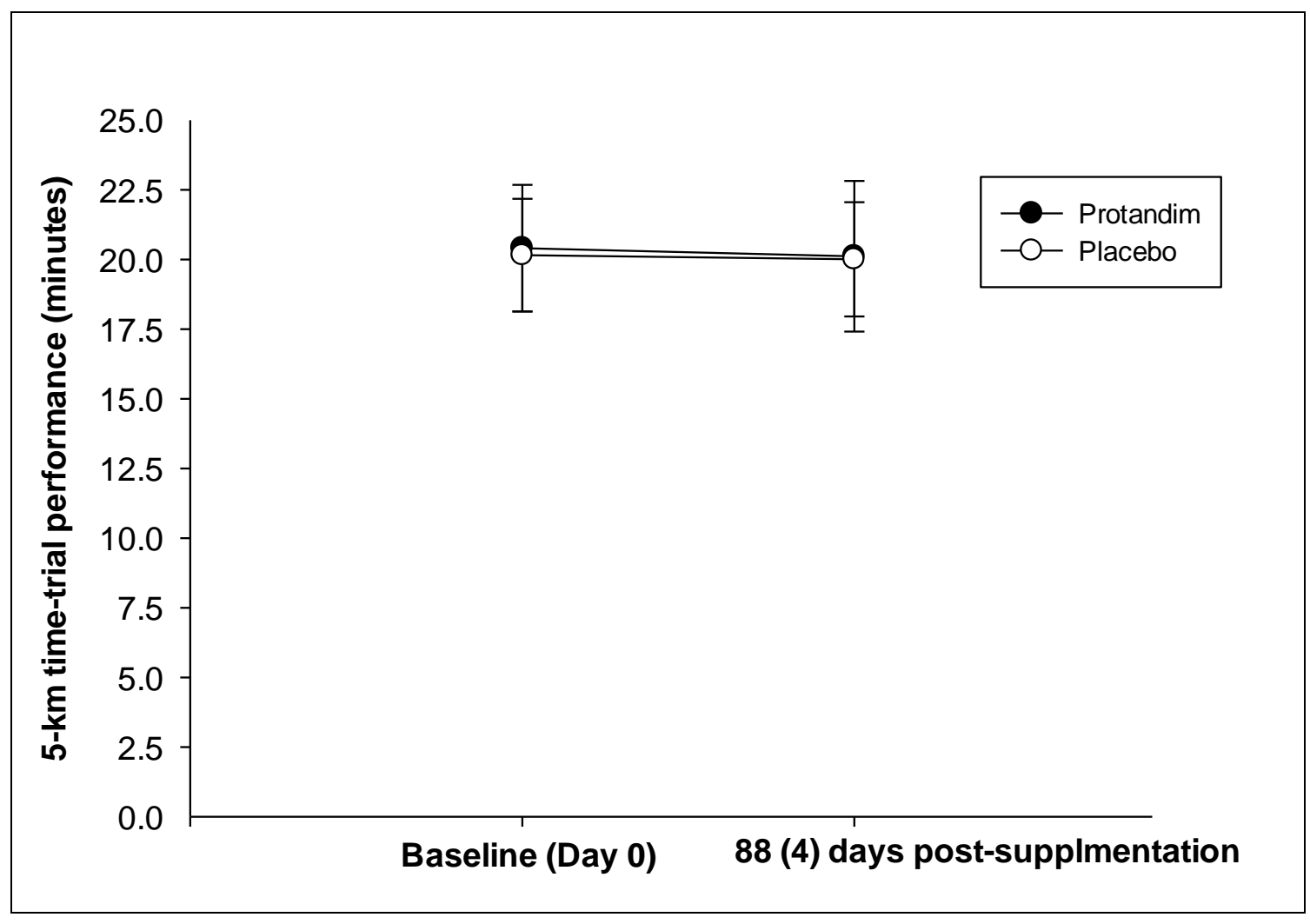


Figure 13. Box-and-whisker plots of the change in 5-km time trial performance (minutes) between post-supplementation period and baseline (post - pre). There was no significant differences between groups ( $p=0.84, \mathrm{n}=16$ in the Protandim ${ }^{\circledR}$ group, $\mathrm{n}=19$ in the placebo group). The $10^{\text {th }}, 25^{\text {th }}, 75^{\text {th }}$, and $90^{\text {th }}$ percentiles are vertical boxes with error bars. The middle horizontal line across each box represents the $50^{\text {th }}$ percentile. The solid circles represent the lowest and highest value in each group, usually the $5^{\text {th }}$ and $95^{\text {th }}$ percentiles for each group. One outlier was present in the Protandim ${ }^{\circledR}$ group $(+1.6$ minutes). An outlier is defined as larger than the upper quartiles plus 1.5 times the interquartile range)

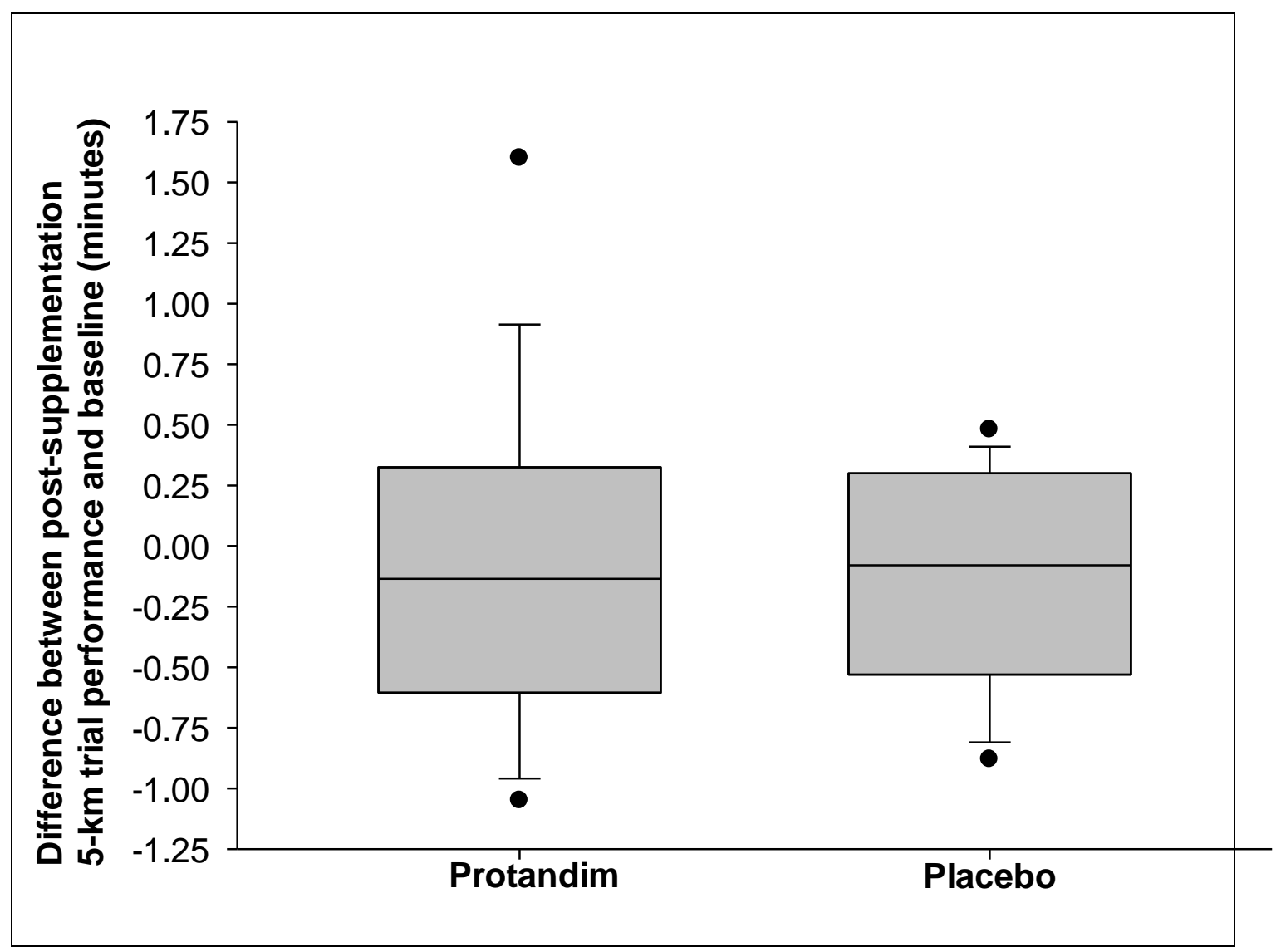


Figure 14. The long term effects of supplementation on various blood parameters (rest, fasted state). There was no difference between groups for either variable. $\left({ }^{*} p<0.05\right.$ compared to baseline). Mean values represented by circles, error bars represent SD.

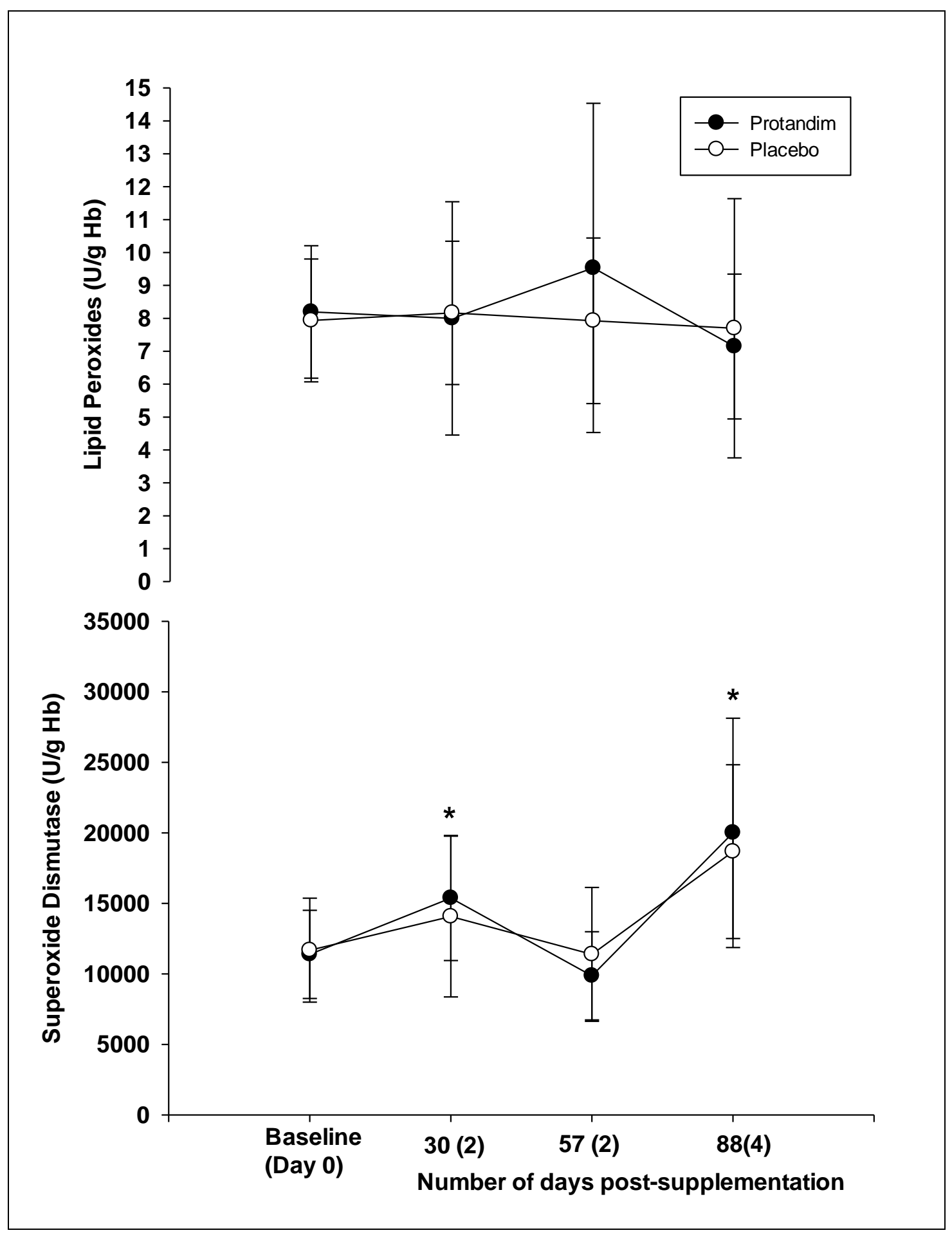


Figure 15. The long terms effects of supplementation on various blood parameters (rest, fasted state). There was no difference between groups for either variable. $(* p<0.05$ compared to baseline). Mean values represented by circles, error bars represent SD.

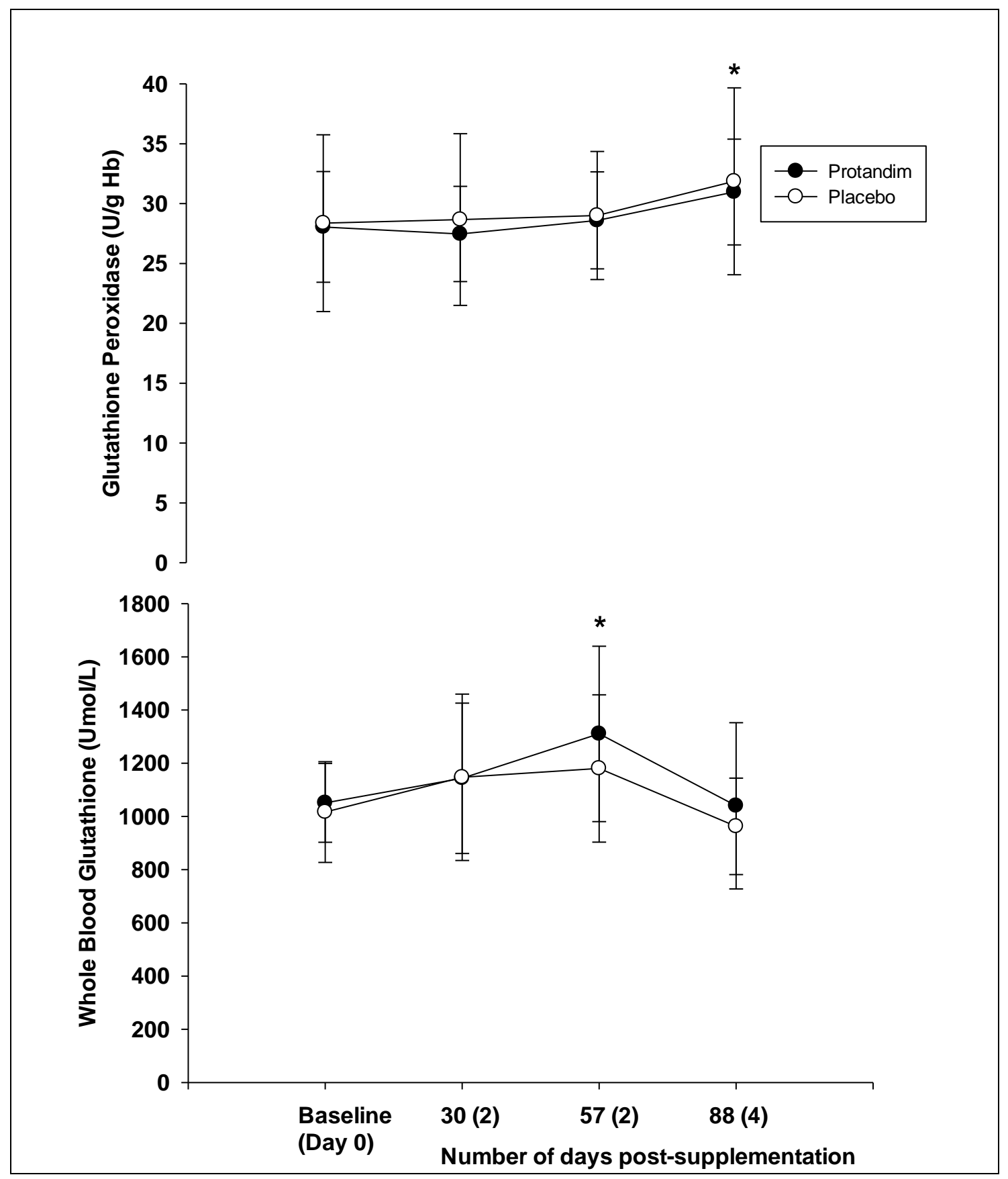


Figure 16. The long terms effects of supplementation on various blood parameters (rest, fasted state). There was no difference between groups for either variable. $\left({ }^{*} p<0.05\right.$ compared to baseline). Mean values represented by circles, error bars represent SD.

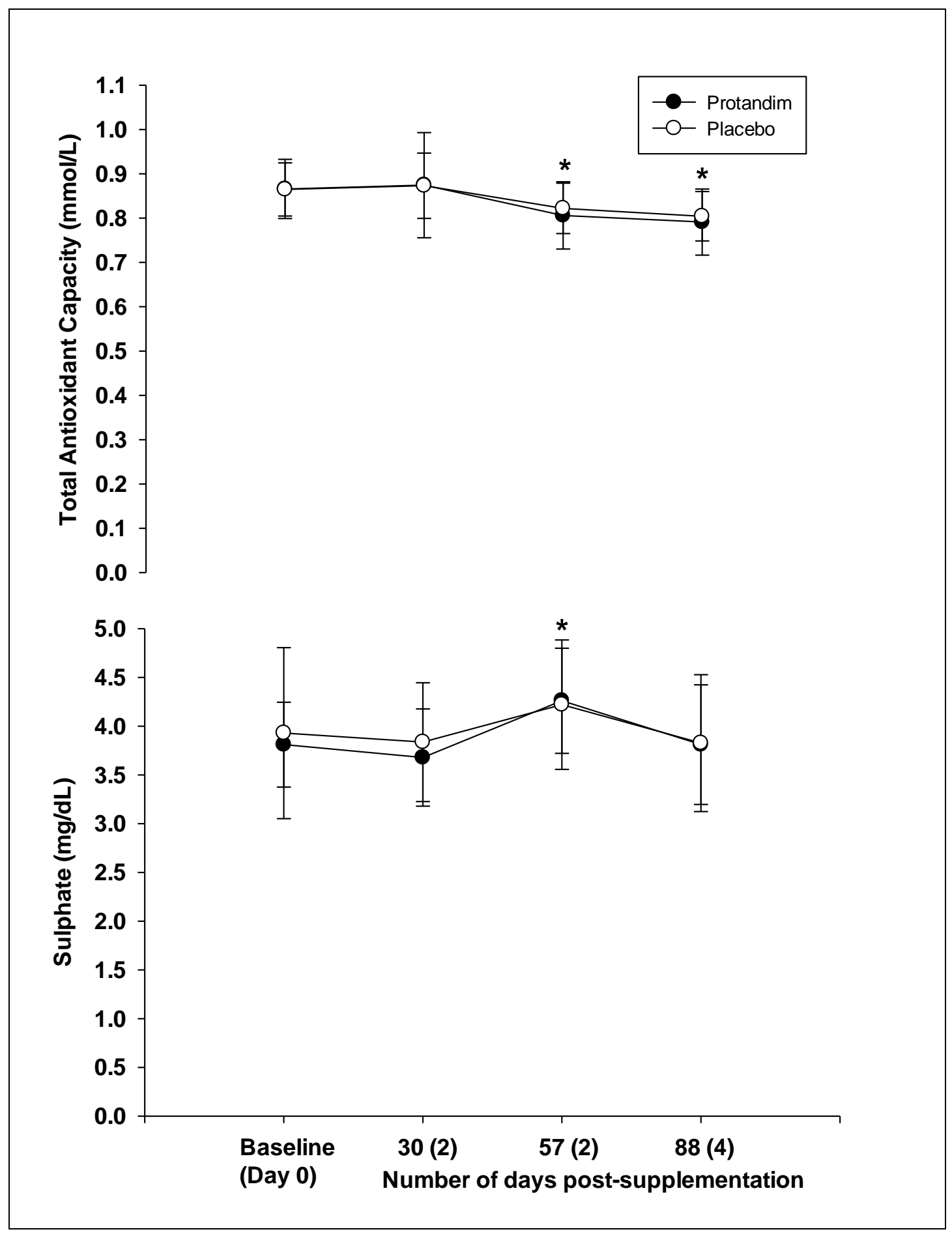


Figure 17. The long terms effects of supplementation on various blood parameters (rest, fasted state). There was no difference between groups for either variable, and there was no difference in these variables at any time point $(p>0.05)$. Mean values represented by circles, error bars represent SD.

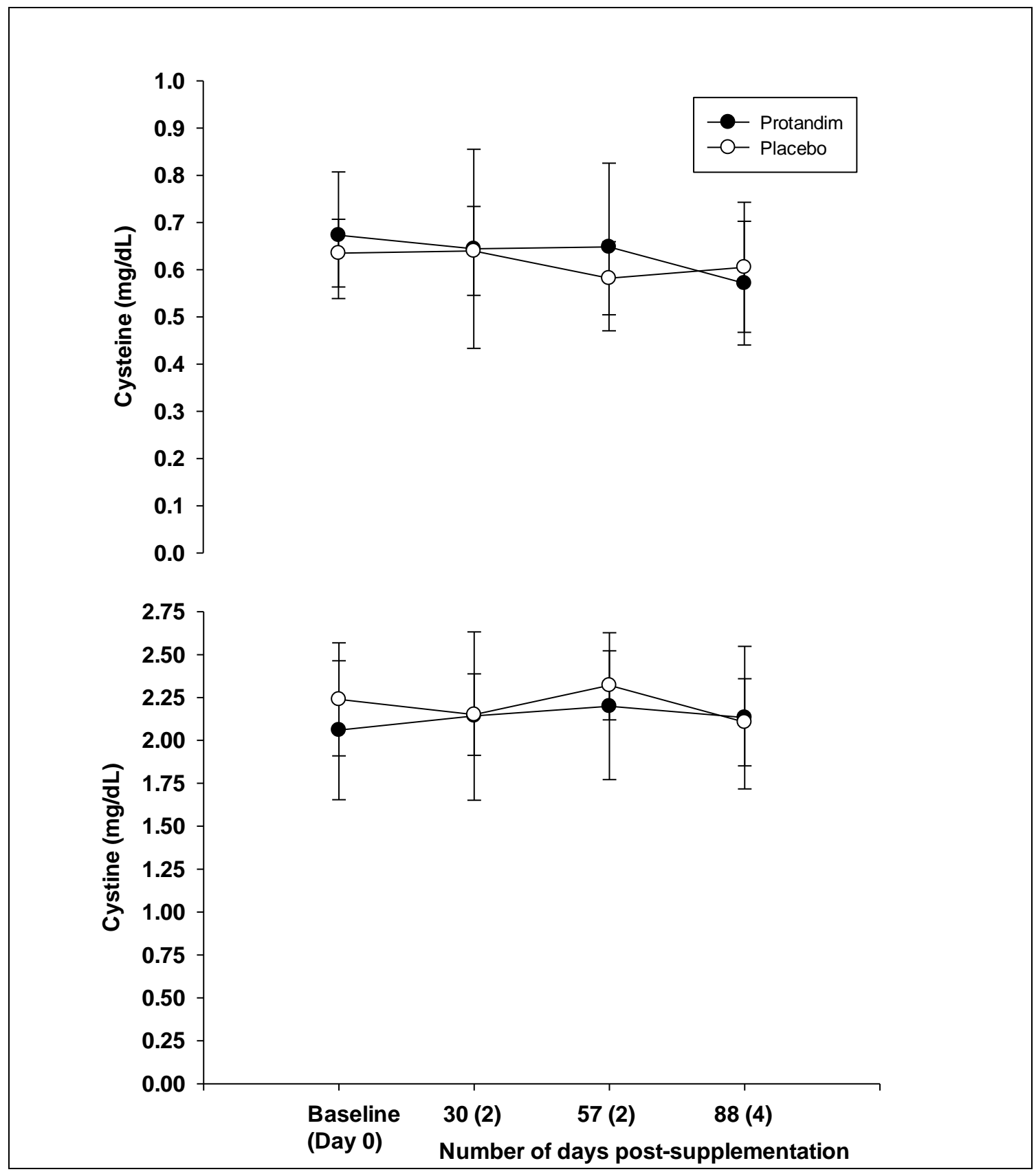


Figure 18. The long terms effects of supplementation on various blood parameters (rest, fasted state). There was no difference between groups for either variable. $\left({ }^{*} p<0.05\right.$ compared to baseline). Mean values represented by circles, error bars represent SD.

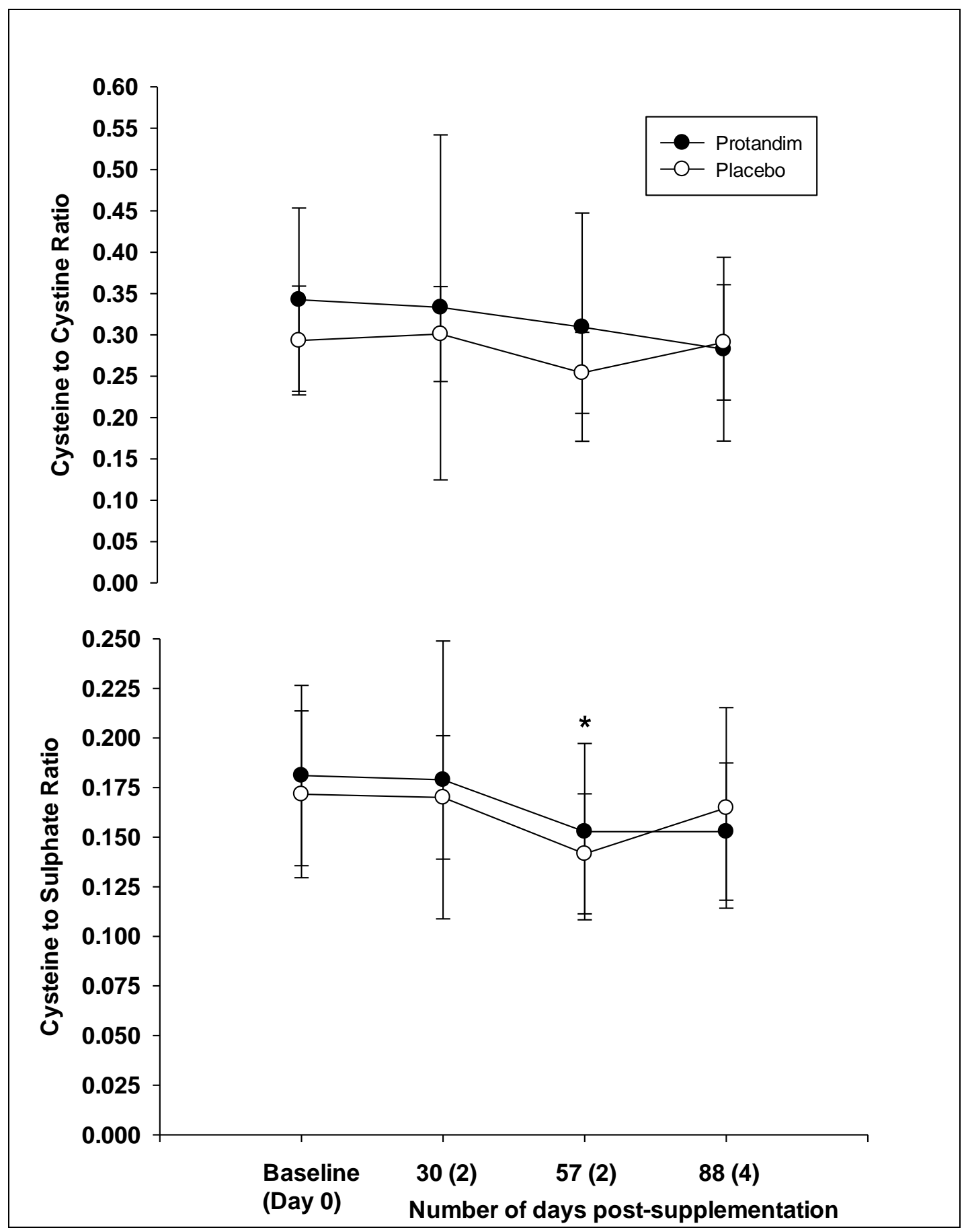


Figure 19. Acute changes in blood parameters of oxidative stress between rest and 10minutes post exercise at baseline and 88 days post-supplementation. There was no difference between groups nor was there any difference between baseline and post supplementation periods. Mean values represented by circles, error bars represent SD.
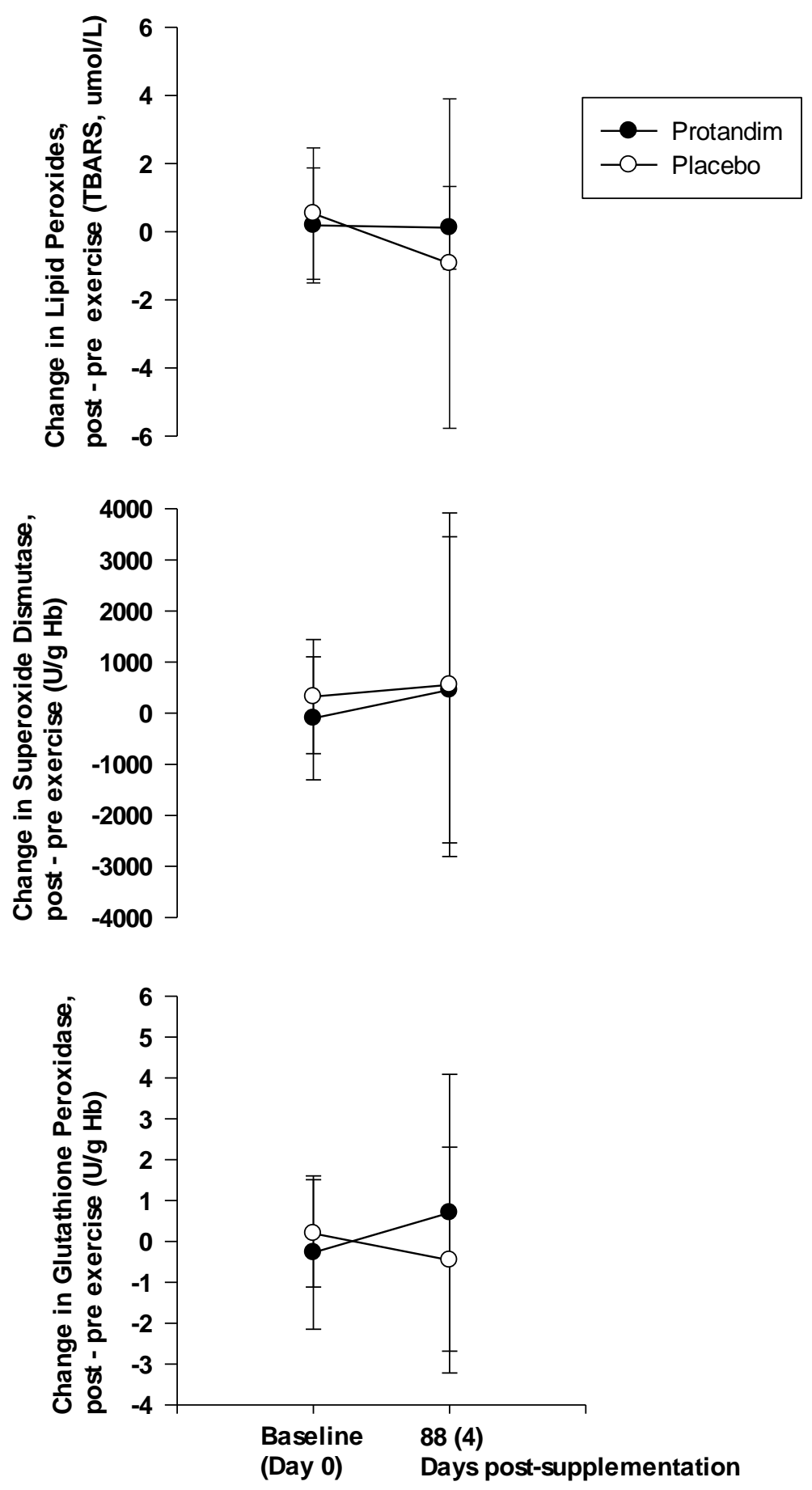
Figure 20. Acute changes in blood parameters of oxidative stress between rest and 10minutes post exercise at baseline and 88 days post-supplementation. There was no difference between groups nor was there any difference between baseline and post supplementation periods. Mean values represented by circles, error bars represent SD.

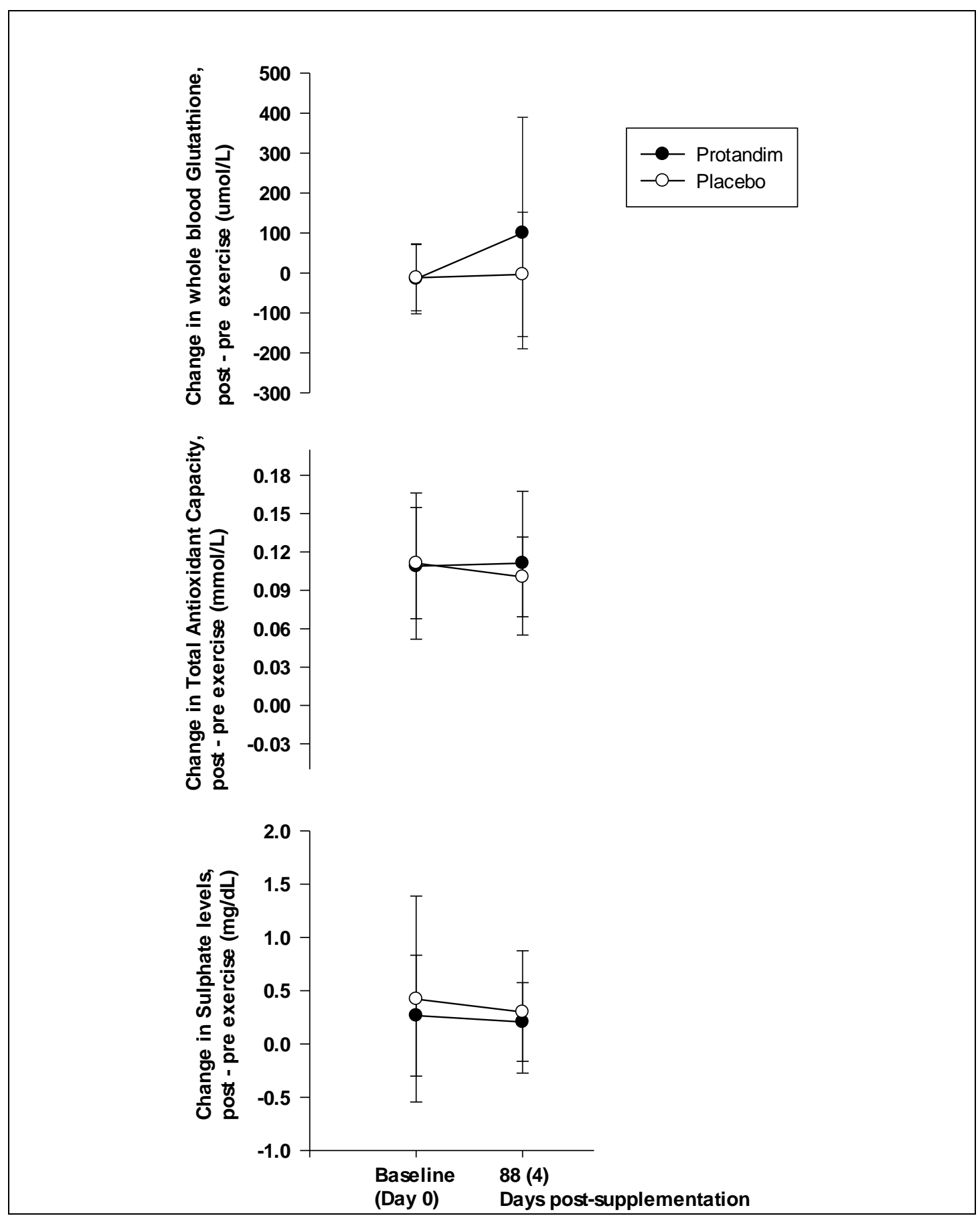


Figure 21. Acute changes in blood parameters of oxidative stress between rest and 10minutes post exercise at baseline and 88 days post-supplementation. There was no difference between groups nor was there any difference between baseline and post supplementation periods. Mean values represented by circles, error bars represent SD.
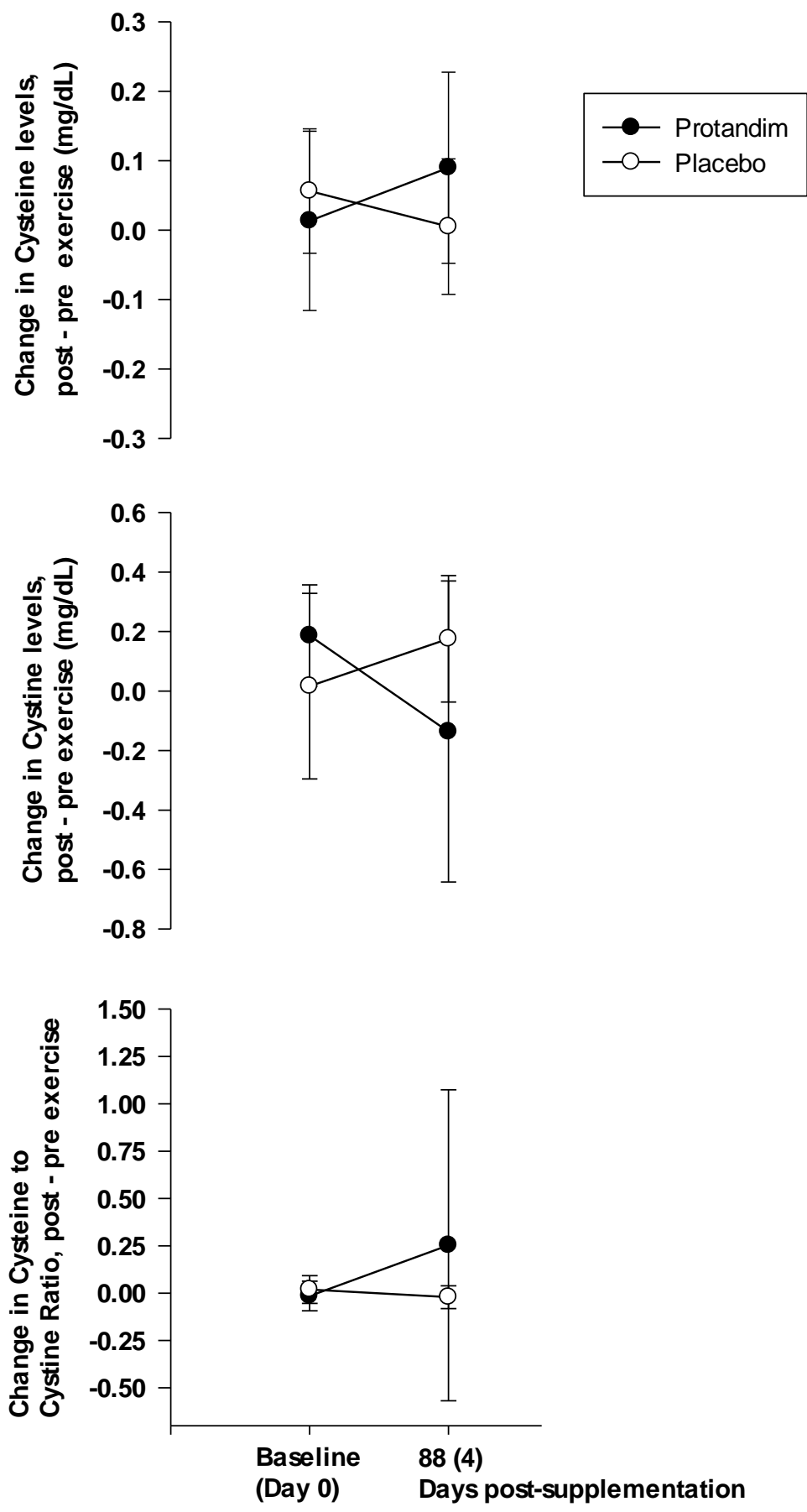
Figure 22. World Health Organization Quality of life (BREF) raw scores. Upper panel A, circles, represent Physical Health scores, triangles represent Social Relationship scores. Lower panel B, circles, represent Psychological Health scores, triangles represent Environment scores. $\left(\right.$ Black $=$ Protandim $^{\circledR}$, White $=$ Placebo $)$. Only at 88 days post-supplementation did the placebo group have higher "environment scores" compared to Protandim ${ }^{\circledR}(* p=0.047)$. Mean values represented by circles and triangles, error bars represent SD.

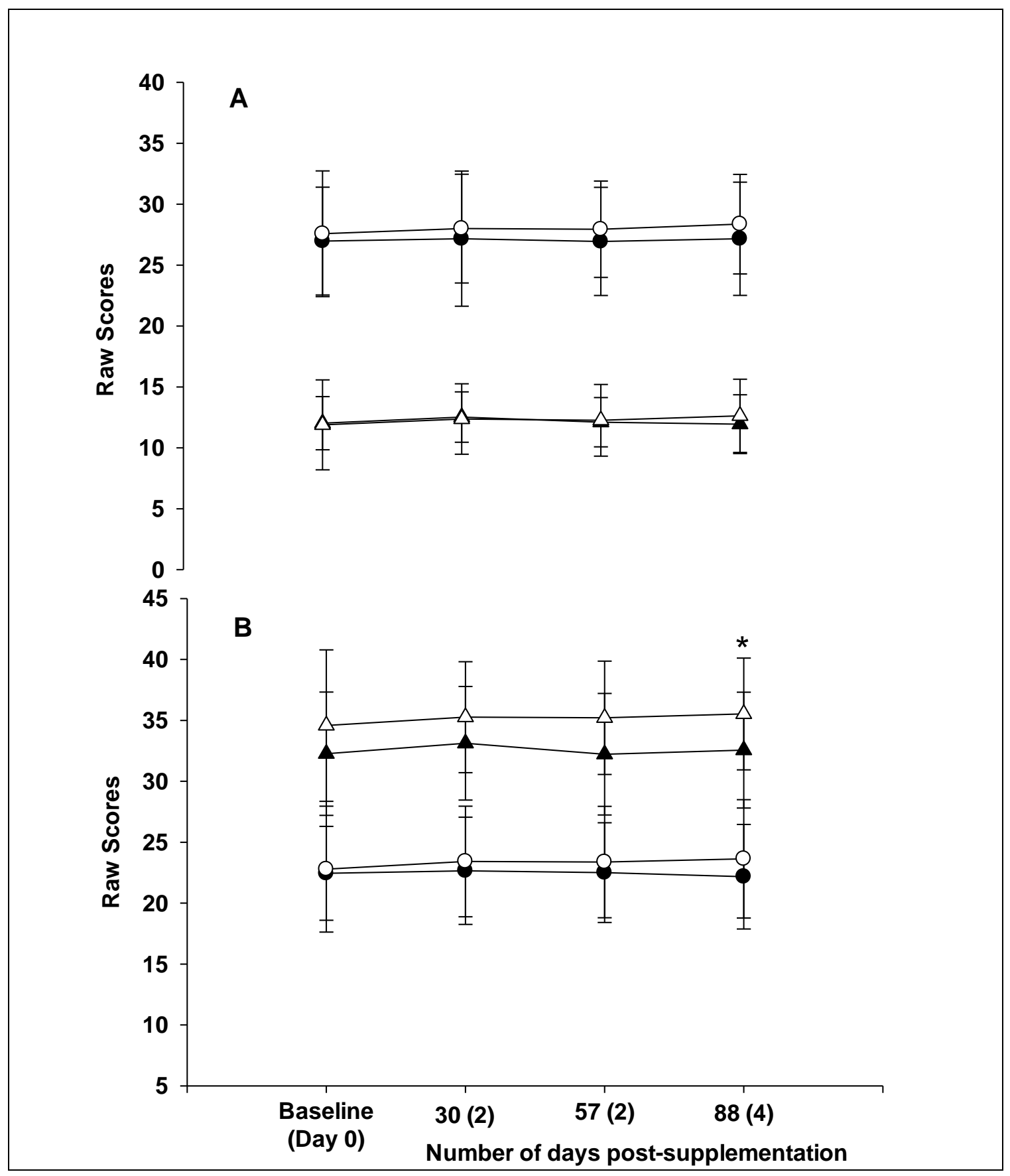


CURRICULUM VITAE

Seteena Leigh Ueberschlag

\section{Key Qualifications}

- Certified Kinesiologist with the OKA (Ontario Kinesiology Association)

- Ontario Certified Teacher (OCT\# 619894)

- Intermediate/ Senior teaching qualification

- Physical Education and Geography

- Professional Certification - Completed Special Education Part 1 - Ontario College of Teachers Certification

- Played varsity basketball for the Wilfrid Laurier Golden Hawks (2006- 2009)

- Owner and Head Trainer of 'KinX Functional Training' (20102012)

- OFSAA (Ontario Federation of School Athletic Associations) Coaching Certification, March 2011

- Certified Sports Nutritionist with the International Society of Sports Nutrition (CISSN)

- CPR and First Aid Certified (American Red Cross), 2015

- Currently working towards being a Certified Strength \& Conditioning Specialist (NSCA)

\section{Education}

Currently (January 2014 to August 2015)

University of Louisville, Louisville, Kentucky

M.S Exercise Physiology- Concentration in Strength and Conditioning Thesis: "The effect of Protandim supplementation on oxidative damage and athletic performance"

Sept. 2010 to April 2011

University of Western Ontario, London, Ontario, Canada.

Bachelor of Education

- Deans honor roll

Sept. 2006 to April 2010

Wilfrid Laurier University, Waterloo, Ontario, Canada.

Honors Bachelor of Arts Kinesiology and Physical Education

- Deans honor roll 
Sept. 2001 to June 2005

Preston High School, Cambridge, Ontario, Canada.

- Ontario Secondary School Diploma (Ontario Scholar)

\section{Health and Fitness Specific Training}

August to December 2014, \& January 2015 to April 2015

University of Louisville, Kentucky.

Course: Strength and Conditioning I \& II

Knowledge gained from this class includes:

- The skills and ability to conduct effective needs analyses, performance testing batteries, create effective, and sport-specific exercise/movement menus.

- The ability to design effective age, ability, sport and positionspecific training programs (macro, meso, micro) based on desired outcomes.

- The ability to teach/coach/program Olympic lifting progressions, and foundational strength movements

- The ability to teach/coach speed development skills (determine needed progressions/regressions), create effective bioenergetics programs (macro, meso, micro) based upon target outcomes, and the ability to lead/coach workouts with small and medium-sized groups

August 2014 to December 2014

University of Louisville, Kentucky.

Course: Applied Exercise Physiology \& Advanced Exercise

Physiology

Knowledge gained from this class includes:

- Knowledge of how the organ systems of the body work to help to maintain homeostasis during exercise by: biological control systems, exercise metabolism, and endocrine function.

- Performing and applying techniques for measurement of work, power and energy expenditure

- Knowledge of how performance can be enhanced by:

A. identifying factors involved in fatigue

B. using work test to evaluate performance

C. using training techniques

D. preparing for and adjusting to environmental influences

E. use and misuse of nutritional supplements

August 2014 to December 2014

University of Louisville, Kentucky.

Course: Laboratory Methods in Exercise Physiology

Knowledge gained from this class includes: 
- Pre-participation Screening \& Pre-participation Physical Exam

- How to perform hydrostatic weighing, skin fold measurements, and calculations involves to obtain body composition measures.

- Submaximal aerobic capacity testing

- Aerobic capacity testing \& calibration techniques

- Maximal aerobic capacity testing - protocol evaluation

- Electrocardiography \& stress testing

- Lactate threshold testing

- Anaerobic power \& capacity testing/agility

- Muscular strength \& endurance

- Mobility \& stability measures

January 2014 to April 2014

University of Louisville, Kentucky.

Course: Principles of Exercise Testing and Prescription

Knowledge gained from this class includes:

- Effects of exercise to prevent coronary heart disease and atherosclerosis. Specific effects of exercise on the established risk factors. Exercise as a rehabilitative measure in heart attack recovery. Exercise testing and prescription for special populations (other than cardiac).

January 2010 to April 2010

Wilfrid Laurier University, Waterloo, Ontario

Course: Advanced Fitness Assessment, Training and Exercise

Prescription

Knowledge gained from these courses includes:

- Knowledge about the legal and business aspects of personal training

- Conducted counseling (confidence and conviction intervention), where I gained tools for coaching weight management

- Designed plyometric training, complex training, strength training, balance $\&$ stability training, and speed training for athletes and non-athletes.

September 2009 to December 2009

Wilfrid Laurier University, Waterloo, Ontario

Course: Fitness Assessment and Exercise Prescription

\section{Health and Fitness Experience}

February 2013 to December 2013

The Athletic Club- Waterloo, Ontario, Canada

Position: Personal Trainer 
- Designed, implemented, and coached individuals through personalized fitness programs to meet their specific goals

- Responsible for consistently monitoring flexibility, strength, blood pressure, heart rate, muscular endurance, tracking total body measurements, body composition analysis, and a cardiovascular assessment.

March 2010 to September 2012

Owner and Head Trainer of 'KinX Functional Training' Personal

Training

- Designed and implemented group fitness classes outdoors for individuals of all ages and abilities

- Conducted fitness assessments and evaluations

- Prescribed personalized nutrition plans and fitness programs for in home and gym training

January 2010 to August 2012

Grand River Collegiate, Kitchener, Ontario

Women's and Men's High School Basketball Assistant Coach \& Strength and Conditioning Coach

- Prepared pre season strength and conditioning workouts for athletes

- Independently coached and implemented team strength and conditioning workouts

- Conducted team fitness assessments, testing and evaluation

- Provides safe, effective training methods for students varying from grade 9-12 and of different skill levels

- Created and implemented sport-specific training for basketball

September 2010 to December 2010

Preston High School, Cambridge, Ontario

Woman's Basketball, Assistant Coach

- Taught technical skills to athletes through demonstration and correction

- Attended to injuries of players

September 2009 to April 2011

Special Olympics Canada 
Basketball Coach

- Trained athletes with special needs and varying skill levels

- Adapted physical activities to meet the needs of each athlete

- Developed relationships with athletes

2007 to 2008

Top 60 Basketball Camp, Wilfrid Laurier University

2006 to 2008

Wilfrid Laurier Summer Sports Camp, Wilfrid Laurier University

2005 to 2007

Naismith Basketball Camp, Wilfrid Laurier University

- Supervised and coordinated a variety of activities for girls and boys of all ages and levels of athleticism.

- Provided guidance and reinforced instructions to boys and girls aged 7 to 17 .

- Encourage participation and the practice of safety in a variety of activities.

Related Experience (Physical Education Teacher)

October 2010

December 2012

March 2011
Preston High School, Cambridge, ON

- Physical Education Teacher

Grand River High School, Kitchener, ON

- Physical Education Teacher

Kitchener Waterloo Collegiate and Vocational School

- Geography and Physical Education Teacher

\section{Additional Certificates/Award}

- Bachelor of Education, University of Western Ontario, London, ON, Canada. - Deans honor roll

- Honors B.A in Physical Education and Kinesiology, Wilfrid Laurier University - Deans honor roll

- Teaching Promise Award, Preston High School, Cambridge, ON, Canada.

- Graduating Athlete of the Year, Preston High School

- Senior Athlete of the Year, Preston High School

- Senior Girls Basketball Most Valuable Player, Preston High School 